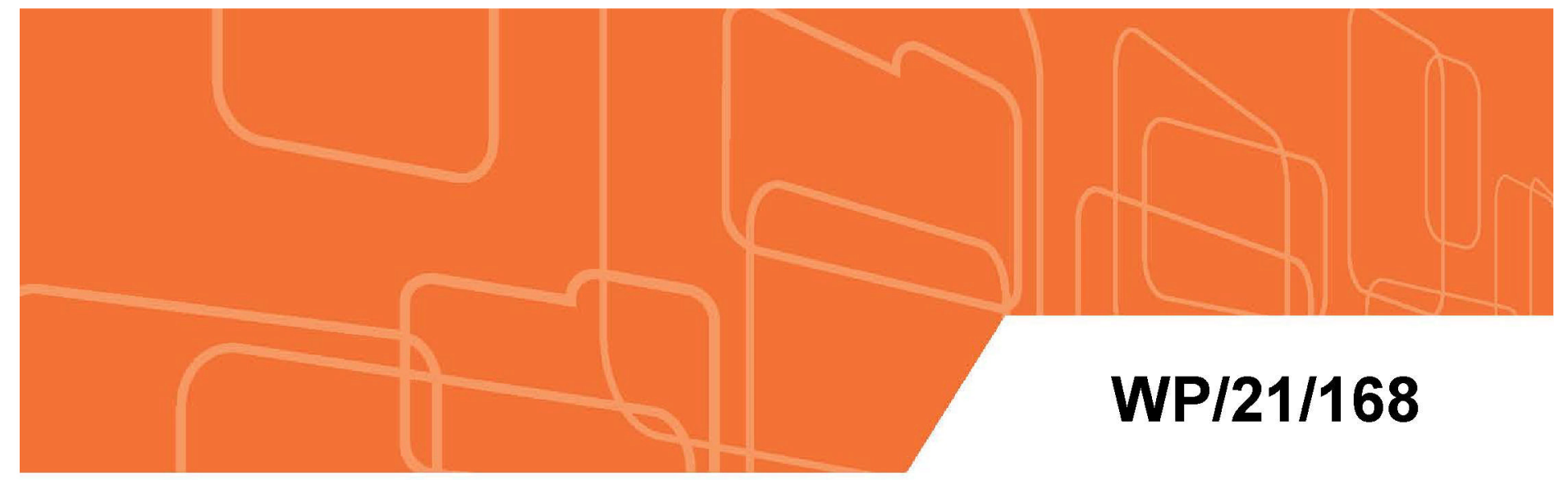

\title{
COVID-19 in Latin America: A High Toll on Lives and Livelihoods
}

by Bas B. Bakker and Carlos Goncalves

IMF Working Papers describe research in progress by the author(s) and are published to elicit comments and to encourage debate. The views expressed in IMF Working Papers are those of the author(s) and do not necessarily represent the views of the IMF, its Executive Board, or IMF management. 


\title{
IMF Working Paper
}

Western Hemisphere Department

COVID-19 in Latin America: A High Toll on Lives and Livelihoods

Prepared by Bas B. Bakker and Carlos Goncalves ${ }^{1}$

June 2021

\section{IMF Working Papers describe research in progress by the author(s) and are published to} elicit comments and to encourage debate. The views expressed in IMF Working Papers are those of the author(s) and do not necessarily represent the views of the IMF, its Executive Board, or IMF management.

\begin{abstract}
Latin America was hit hard by Covid-19, both in terms of lives and livelihoods. Early lockdowns in the second quarter of 2020 prevented an explosion of deaths at the time but did not stop the pandemic from later wreaking havoc in the region. This paper investigates the dynamics of pandemics in Latin America and how it differed from elsewhere. We probe the role of non-pharmaceutical interventions; the effectiveness (or lack of thereof) of lock-downs in Latin America; which structural factors contributed to the high death toll in Latin America; and the extent to which the epidemic harmed the economy. Finally, we briefly analyze the roots of the second-waves that started in the fourth quarter of 2020.
\end{abstract}

JEL Classification Numbers: I12, I15, I18

Keywords: Latin America, COVID19, Economic growth, Reproduction rates

Author's E-Mail Address: bbakker@imf.org; cgoncalves@,imf.org

\footnotetext{
${ }^{1}$ This paper is an extended and updated version of Chapter 2 of the IMF's October 2020 Regional Economic Outlook for Western Hemisphere "COVID-19 in Latin America and the Caribbean: A High Toll on Lives and Livelihoods" (Bakker et al., 2020). The paper has benefited from comments from Alejandro Werner, Francesca Caselli, Joshua Felman, Anna Ivanova, Leslie Lipschitz, Pedro Rodriguez, Frederik Toscani and the Argentinean authorities. All remaining errors are the sole responsibility of the authors.
} 


\section{Contents}

1 Introduction and Conclusions $\underline{4}$

2 Slow Burns, Forest Fires and Put-outs - the Dynamics of Covid-19 Epidemics $\underline{8}$

2.1 SEIR Model . . . . . . . . . . . . . . . . . . . 8

2.2 Reduced Form Equation . . . . . . . . . . . . . . . . . 13

3 The Dynamics of Covid-19 Epidemics: Some Empirics $\underline{17}$

3.1 Higher Stringency, Lower Mobility and Higher Temperatures are Associated with a Lower Growth Rate of New Deaths . . . . . . . . . . . . . . . . 17

3.2 Later Lockdowns Lead to Higher Deaths . . . . . . . . . . . . . . $\underline{20}$

3.3 Randomness . . . . . . . . . . . . . . . . . . . 22

3.4 Geographical Spread . . . . . . . . . . . . . . $\underline{22}$

4 Why did Lockdowns in Latin America not Stop the Pandemic?

4.1 Early Lockdowns Require a Sharper Reduction of $R_{0 t} \ldots \ldots \ldots$

4.2 Mobility Rebounded as Cases Increased . . . . . . . . . . . . . $\underline{27}$

4.3 Weak Institutional Capacity may Have Hampered the Effectiveness of Lockdowns ........................... 30

5 Second Waves $\underline{34}$

6 What Factors made Latin America Vulnerable? $\quad \underline{36}$

7 The Impact of Lockdowns and Fear on Economic Activity and Mobility $\underline{41}$

7.1 The Impact of Covid-19 on Economic Growth . . . . . . . . . . . . . . . $4 \underline{41}$

7.2 What Explains the Sharp Drop in Mobility in Latin America-Policies or

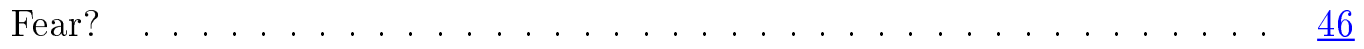

8 The Future of the Pandemic in Latin America $\underline{50}$

Bibliography $\quad \underline{53}$

A Data Issues $\quad \underline{55}$

B Covid in Individual Countries $\quad \underline{59}$

C Data Sources $\quad \underline{60}$ 


\section{Introduction and Conclusions}

Latin America has been hit hard by the Covid-19 pandemic. As of early June 2021, the death toll in the region is similar to that in Western Europe and the United States (Figure 1.1) - despite earlier and longer lockdowns, and a much younger population. ${ }^{1}$ Further, it is likely that the official death count is far below the real one, since testing has been low and excess-over-normal deaths in some countries have been far higher than Covid-related deaths (Annex A). ${ }^{2}$

At the same time, the pattern of the pandemic has been strikingly different. Western Europe saw sharp explosions in the Spring (Q2) of 2020, very modest infections during the Summer of 2020, and renewed explosions in late 2020 and early 2021. Latin America mostly avoided these explosions (which we here dub as "forest-fires") but also did not see periods of very modest infections (Figure 1.1 and 1.2). ${ }^{3}$ Instead, its daily death toll gradually increased ("slow-burn") and, in many countries, only peaked in the fall of 2020 or the first half of 2021.

Here we shed light on some important questions, such as why did the lockdowns not reduce the pandemic in the region as they did in Europe at the time? In addition, to what extent were formal - i.e., regulatory or legal measures - correlated with effective reductions in contact and mobility? What was the impact of the epidemic on the economy of Latin America? To what extent was the impact the result of stringency (i.e., government policies) and what role did "fear" (as proxied by daily deaths) play?

The paper addresses these questions using a reduced form of a SEIR (susceptibility, exposed, infectious, recovered) model. An epidemic explodes when the effective reproduction number $(R)$ is greater than 1 ; it is contained when $R$ is below 1 . The latter can best be achieved with efficacious vaccines, but until these were generally available there was great uncertainty and debate on how to proceed. For most countries the stated strategy was to bridge the time until vaccines became available through non-pharmaceutical measures-i.e., lockdowns and mask mandates. Limiting infections would prolong the period before herd immunity could be achieved, but it would also reduce deaths and prevent medical facilities being overwhelmed in the pre-vaccine period.

The data show that lockdowns and other non-pharmaceutical interventions helped. Higher stringency reduced mobility and slowed the spread of the pandemic. But, not surprisingly, the efficacy of early lockdowns was greater to the extent that the population susceptibility had already fallen. Moreover, we find that measures of government effectiveness exerted an independent, significant effect: lockdowns delivered better results in countries with higher measures of government effectiveness. Finally, the impact of higher stringency on mobility and thus on infections declined over time.

\footnotetext{
${ }^{1}$ With the exception of Uruguay.

${ }^{2}$ In early June 2021, just before this paper was published, Peru almost tripled its official death toll after a scientific review of medical records ordered by the government.

${ }^{3}$ For data on individual countries, see Annex B.
} 
But stringent measures also had costs. Our regression analysis suggests that both stringency and daily deaths affected economic activity, but the impact of the former was quantitatively more important. The sharp downturn in Latin America in the second quarter of 2020 was chiefly associated with tough and binding lockdowns; and the recovery in the second half with both an easing of formal measures and a reduced impact of stringency on mobility and activity.

Explanations based on only a few major policy-sensitive variables cannot tell the whole story, of course. Other variables-demographic, economic, and sociological characteristics - that are not amenable to policy influence in the relevant time intervals are important in explaining substantial differences between countries.

- Countries with older populations and/or higher levels of obesity fared significantly worse.

- The pandemic has been more difficult to contain in countries and municipalities with low income levels - not surprisingly, the imperative of earning living incomes makes it more difficult for lower-income workers to reduce their mobility.

- Areas with high population density - whether large cities like New York, or areas of significant poverty like the favelas of Rio-are disadvantaged.

- The medical services infrastructure is important: countries with more hospital beds saw a lower death toll.

- Temperature and the caprice of seasonality are important. Temperature has a negative influence on the spread and morbidity of the pandemic, hence differences when the northern hemisphere is moving into Spring and the southern hemisphere into Fall.

- BCG vaccines for infants (against tuberculosis) are common in some countries but not in those with a longer history of much lower incidences of tuberculosis. These vaccines appear to reduce somewhat both rates of Covid-19 infection and morbidity.

- Finally, new variants that are more contagious and/or more deadly are another seemingly capricious difference between countries (although, notably, they have been more characteristic of southern hemisphere countries).

The lessons from this close analysis of the data can be summarized as follows:

- There may be a fine line in when to lock down. Locking down too late will lead to an explosion of deaths. But locking down very early may not be sustainable and ultimately may not succeed in stopping the pandemic (with the notable exception of small islands).

- Lowering stringency and increasing mobility will help the economy, but if done too rapidly can lead to second waves. 
- The "safe" level of stringency and mobility depends on the share of the still susceptible population. The higher the total death toll (or the higher the share of the population that has been vaccinated), the more stringency can be reduced. Countries most at risk of an explosion in new deaths are not the ones where the total death toll is already very high, but those where the total death toll is still low and few have been vaccinated.

- The "safe" level of stringency and mobility also depends on the season. A high level of mobility during the summer months may be consistent with a low level of infections. But keeping the same mobility level when winter approaches may lead to a sharp increase in infections.

- Latin America avoided the second wave explosions in late 2020 and early 2021 that Europe and the United States saw because mobility had not picked up as much as in Europe, the share of the still susceptible population was lower and because it was summer in the Southern Hemisphere. But with winter approaching, and more virulent new variants, we are seeing new waves in many countries. Much more rapid vaccination will be key to stop the pandemic.

The broad conclusions of this section are substantiated by a careful analysis of the available data in the sections that follow. 
Figure 1.1. Covid: Global Overview

Total COVID-19 deaths

Per million

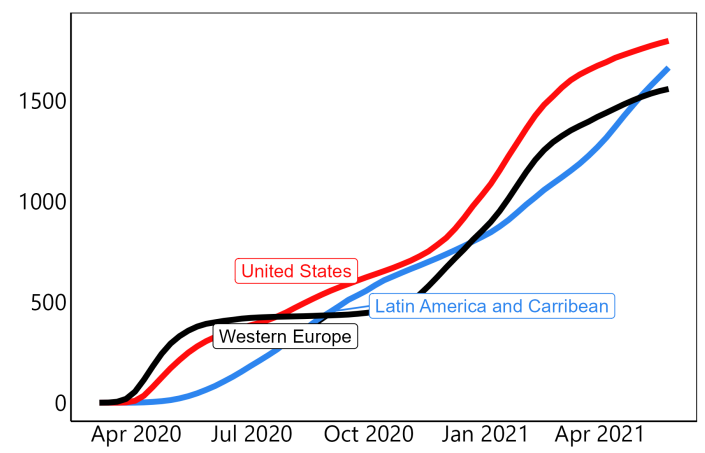

New COVID-19 deaths

Per million, 7-day moving average

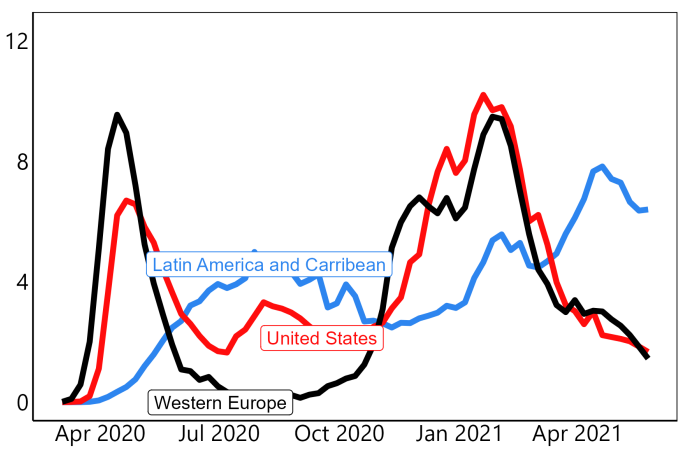

CESEE excluding CIS

Source: Google Covid-19 hub.

\section{Figure 1.2. Covid in Latin America}

Total COVID-19 deaths

Per million

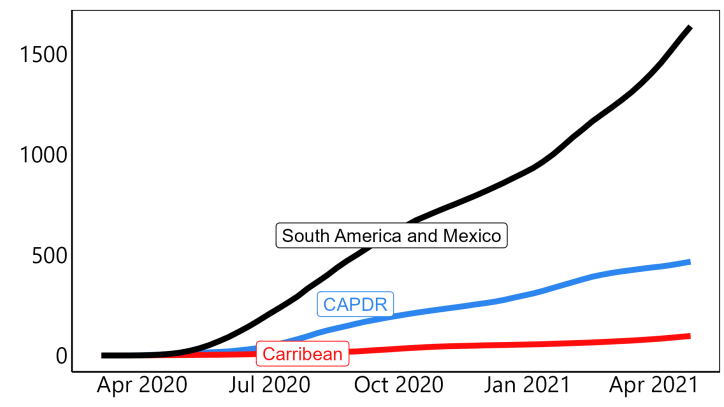

CAPDR $=$ Central America, Panama, Dominican Republic Source: John Hopkins.
Total COVID-19 cases

Per million

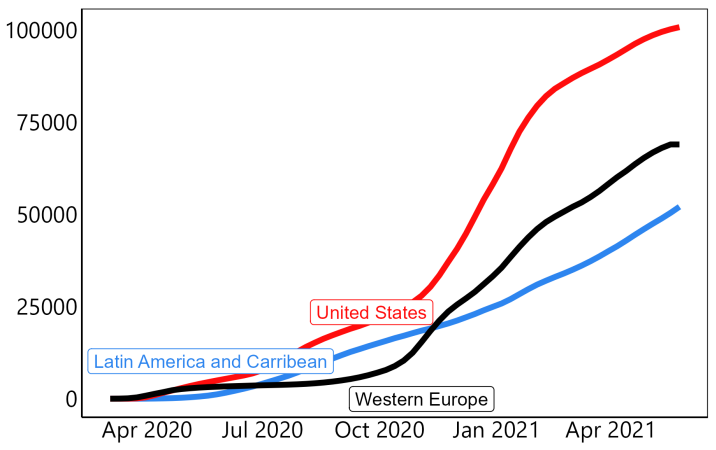

New COVID-19 cases

Per million, 7-day moving average

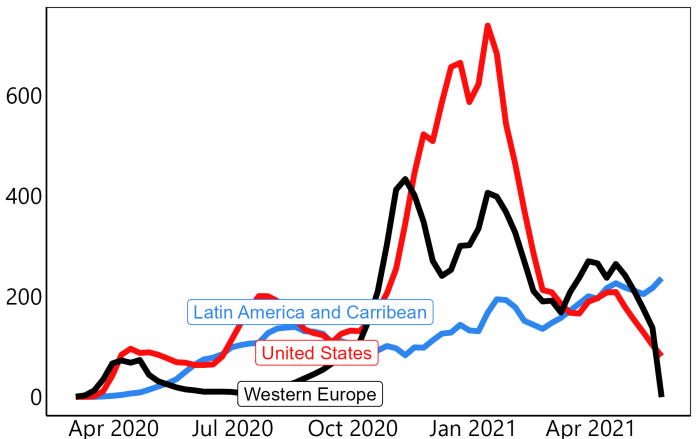

Daily COVID-19 deaths

Per million

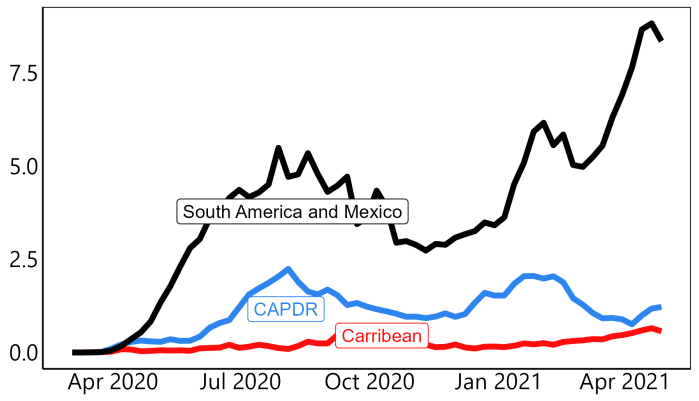




\section{Slow Burns, Forest Fires and Put-outs-the Dynamics of Covid-19 Epi- demics}

\subsection{SEIR Model}

At each moment of time, the population $(N)$ is divided into five mutually exclusive categories. ${ }^{4}$ These are susceptible (no immunity) $S$, exposed (infected but not yet infectious) $E$, infectious $I$, recovered $R$, and dead $D$. We use the following SEIR model: ${ }^{5}$

$$
\begin{gathered}
\frac{d S}{d t}=-I \lambda_{t} \pi_{t} \frac{S}{N} \\
\frac{d E}{d t}=\lambda_{t} \pi_{t} I \frac{S}{N}-\sigma E \\
\frac{d I}{d t}=\sigma E-\gamma I \\
\frac{d D}{d t}=\alpha \gamma I \\
\frac{d R}{d t}=\gamma(1-\alpha) I
\end{gathered}
$$

We start with a brief description of the workings of a SEIR model. Every day, an infectious person bumps into $\lambda_{t}$ persons. The probability that he will infect a person during a contact is $\frac{S}{N} \pi_{t}$, where $\frac{S}{N}$ the likelihood that the person will be susceptible and $\pi_{t}$ is the probability that a susceptible person will be infected. $\sigma$ is the rate at which people that have been exposed to the virus become infectious. Following Wang et al. (2020) and Atkeson (2020) it is set to $\sigma=\frac{1}{5.2}$ reflecting an estimated incubation period of the disease of 5.2 days. The parameter $\gamma$ is the rate at which infectious people either recover or die. Following Wang et al. (2020) and Atkeson (2020) we set $\gamma=\frac{1}{18}$ reflecting an estimated duration of illness of 18 days. The share of those that die is $\alpha$; the share that recovers $1-\alpha$. We assume $\alpha=0.01$.

\footnotetext{
${ }^{4}$ This section is based on Atkeson (2020).

${ }^{5}$ The model is similar to Atkeson (2020), with the difference that we distinguish between recovered and dead persons.
} 


\section{Dynamics}

As an infected person is infectious for $\frac{1}{\gamma}$ days, he will infect $\frac{\lambda_{t} \pi_{t}}{\gamma} \frac{S}{N}$ persons while infectious. This ratio is also known as $R_{t}$, the effective reproduction number:

$$
R_{t}=\frac{\lambda_{t} \pi_{t}}{\gamma} \frac{S}{N}
$$

If $R_{t}$ is greater than 1 , each infectious person will infect more than one other persons, which means that the number of currently infected people will continue to increase. If it is smaller than 1, the number of currently infected persons will decline, and the epidemic will die out. Defining $R_{0 t}$ as the expected number of secondary cases produced by a single (typical) infection in a completely susceptible population:

$$
R_{0 t}=\frac{\lambda_{t} \pi_{t}}{\gamma}
$$

we can further rewrite this as

$$
R_{t}=R_{0 t} \frac{S}{N}
$$

The effective reproduction rate $R_{t}$ depends both on $R_{0 t}$ and the share of the still susceptible population.

It should be noted that $R_{0 t}$ is not necessarily constant, as it depends on the number of contacts $\lambda_{t}$ and the transmission probability $\pi_{t}$. If the number of contacts an infectious person has falls (for example, because of a drop in mobility), or if the transmission probability declines (for example, because people start to wear masks and wash their hands frequently), $R_{0 t}$ will drop.

\section{The Epidemic in the Absence of Sanitary measures and Behavior Changes}

In the absence of any sanitary measures and behavior changes (i.e., with unchanged $R_{0 t}$ ), the number of currently infected persons will continue to explode until the share of the susceptible population has dropped below $\frac{1}{R_{0 t}}$. At that stage, each infected person will infect less than one other person, and the disease will start to die out.

$$
\frac{S}{N}<\frac{1}{R_{0 t}} \rightarrow R_{t}<1
$$

The lower $R_{0 t}$, the higher the level of $\frac{S}{N}$ at which $R_{t}$ falls below 1 . For example, if $R_{0 t}=3$, $R_{t}$ will fall below 1 if the share of the still susceptible population is less than one third (i.e., two thirds of the population has been infected), while if $R_{0 t}$ is $1.25, R_{t}$ falls below one if the share of the still suceptible population is less than 80 percent (i.e., 20 percent of the population has been infected). 


\section{The Impact of Lockdowns: Theory}

Lockdowns and other sanitary measures reduce $R_{0 t}$ by reducing the number of contacts and the transmission probability. We will distinguish between fully effective lockdowns and partially effective lockdowns, and between early and late lockdowns:

- A fully effective lockdown is a lockdown which reduces $R_{0 t}$ to below 1 and manages to keep it there. A partially effective lockdown is a lockdown which reduces $R_{0 t}$ but to a level above 1

- An early lockdown is a lockdown that occurs when few people have been infected (i.e, the share of the still suceptible population is high), while a late lockdown is a lockdown that occurs when many people have already been infected.

The dynamics of an epidemic after a lockdown will depend on both the timing and effectiveness of the lockdown (Figure 2.1):

- An early and effective lockdown will resemble a "put-out". The disease soon disappears.

- An early and partially effective lockdown will resemble a "slow-burn." The number of infected persons will continue to rise after the lockdown (albeit at a slower rate) until the share of the still susceptible population has fallen enough. For example, with an early lockdown that reduces $R_{0 t}$ to 1.25 , the number of currently infected people will continue to rise until the the share of the still susceptible population has fallen to 80 percent.

- A late and effective lockdown will resemble a "forest-fire"- similar to the no-intervention scenario, but peaking at a lower level.

- A late and partially effective lockdown will also resemble a "forest-fire", but peak at a higher level than in the late and effective scenario.

It should be noted that while an early, partially effective lockdown will not stop a pandemic, a late, partially effective lockdown may. To see this note that whether a lockdown reduces $R_{t}$ to below 1 depends not only on by how much $R_{0 t}$ falls, but also on the share of the still susceptible population. For example, reducing $R_{0 t}$ to 1.25 will not stop an epidemic when 10 percent of the population has been infected, but will do so when 30 percent has been infected.

It should be noted that in an SEIR model there is an inverse U relationship between the total number of deaths and new deaths (Figure 2.2). The number of daily deaths increases until total deaths has reached a certain threshold; thereafter it declines. The growth rate of new deaths declines steadily as the total number of deaths rises (Figure 2.3).

The patterns in Figure 2.1 and 2.2 can be observed in practice. New York City in the Spring of 2020 (which locked down very late) had a severe forest fire and looked almost like 
the no-intervention pattern (Figure 2.4). Spain in the Spring of 2020 also had a forest fire (Figure 2.5). Argentina, by contrast, had a slowburn - daily deaths only peaked in October (Figure 2.6). ${ }^{6}$

Figure 2.1. Modeling Lockdown Types Using the SEIR Model
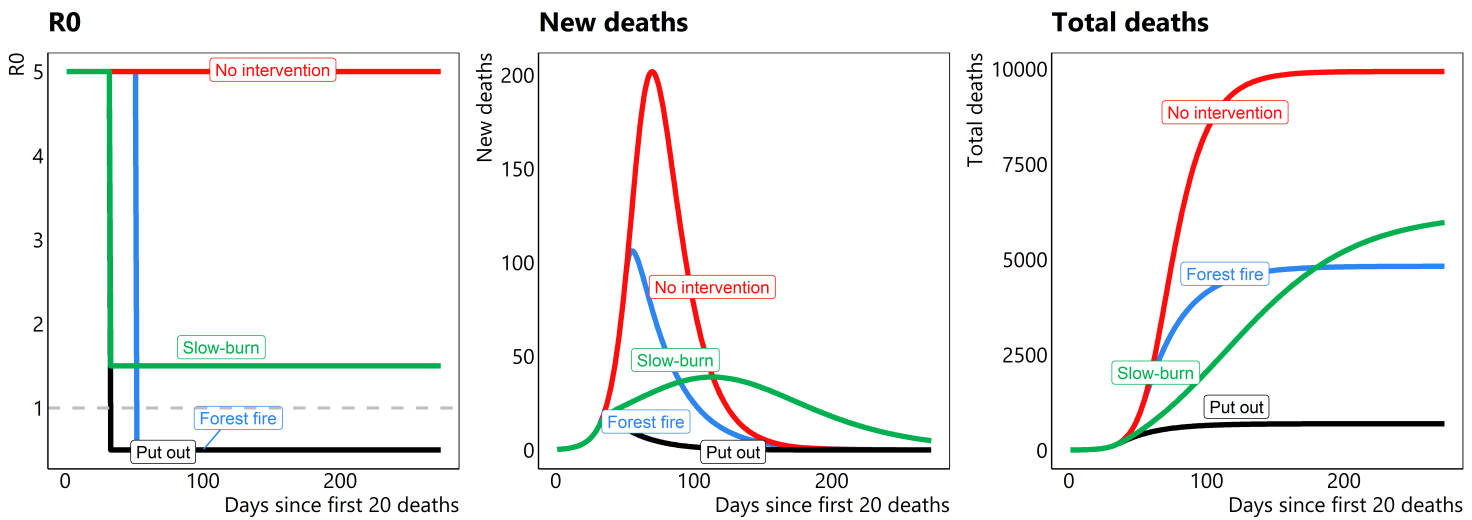

Source: Simulations

Figure 2.2. Total Deaths versus New Deaths

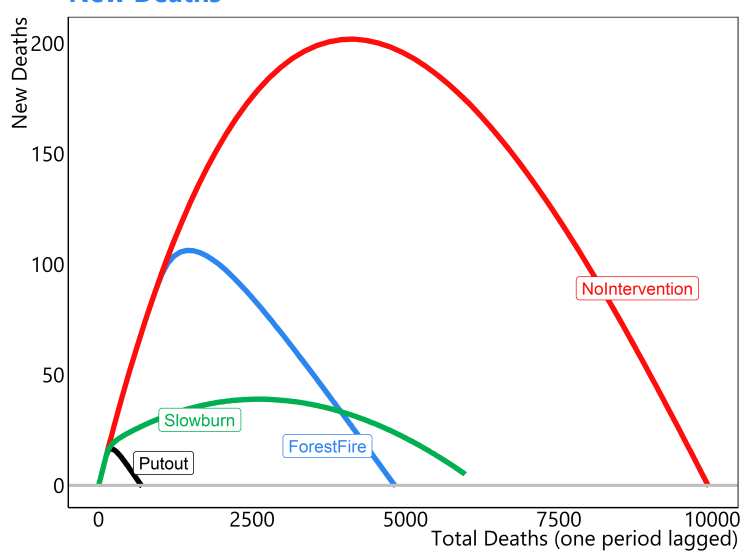

Figure 2.3: Total Deaths versus Growth Rate of New Deaths

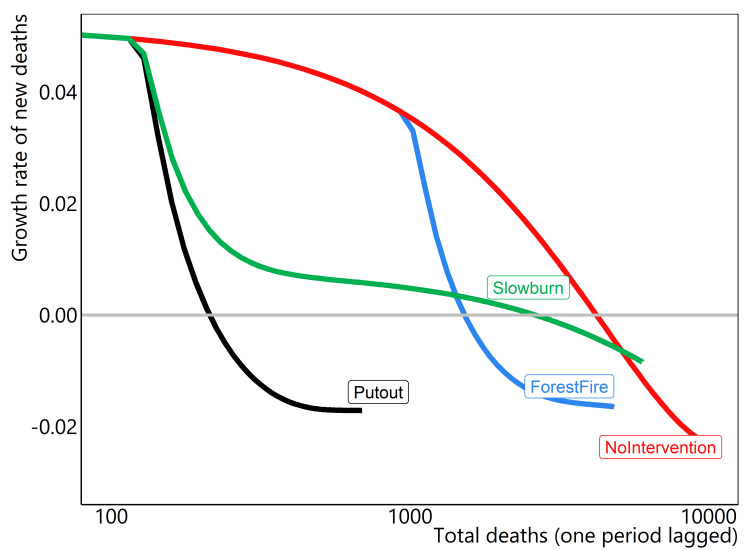

${ }^{6}$ Note the different y-axes in Figures 2.4, 2.5 and 2.6. 
Figure 2.4. New York City: Covid-19 Outbreak in Spring 2020

Daily deaths

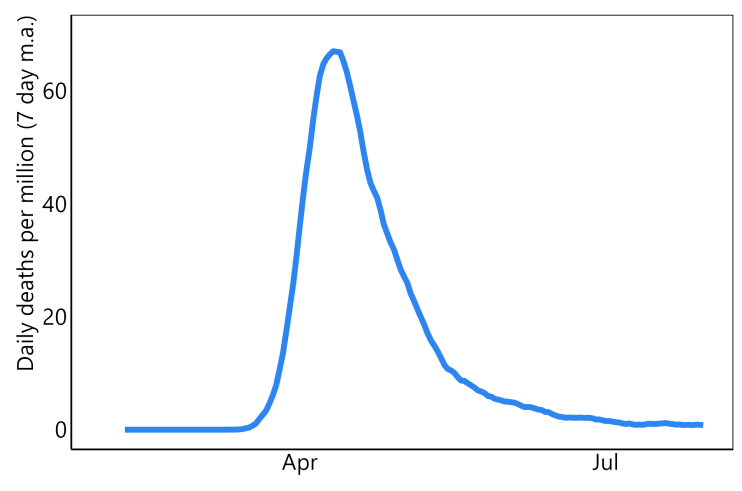

Source: Google Covid-19 hub
Total deaths versus daily deaths

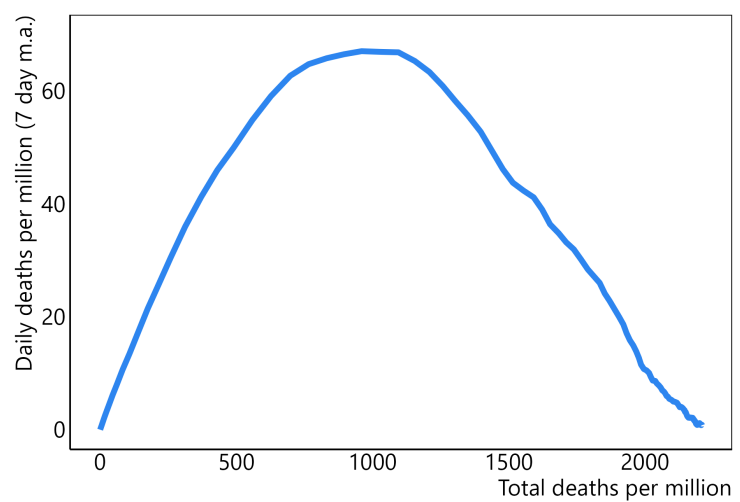

Figure 2.5. Spain: Covid-19 Outbreak in Spring 2020

Daily deaths

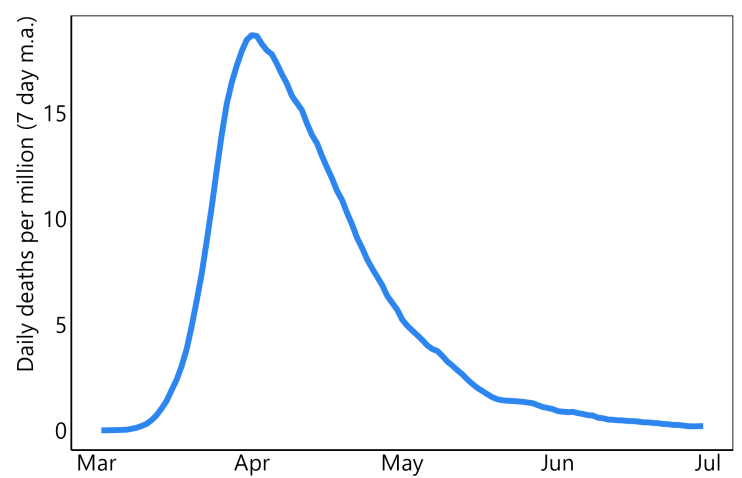

Source: Google Covid-19 hub

Figure 2.6. Argentina: Covid-19

Daily deaths

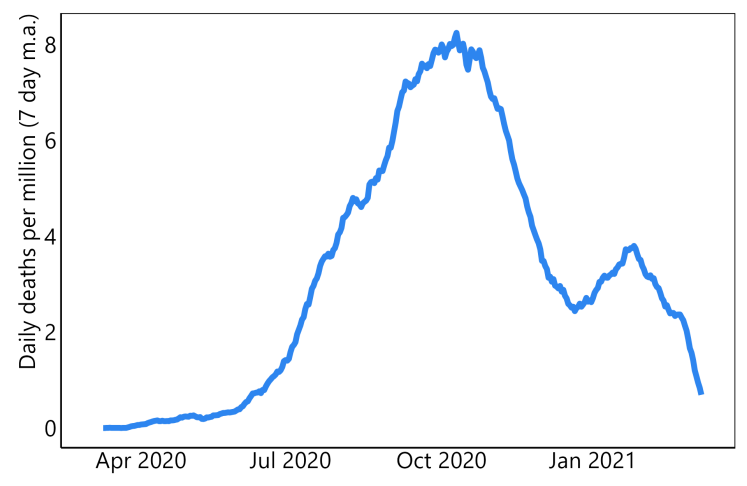

Source: Google Covid-19 hub
Total deaths vs daily deaths

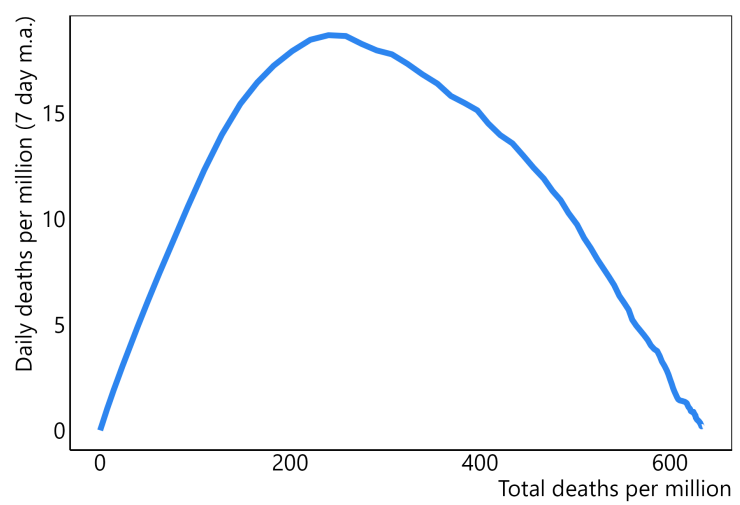

Total deaths vs daily deaths

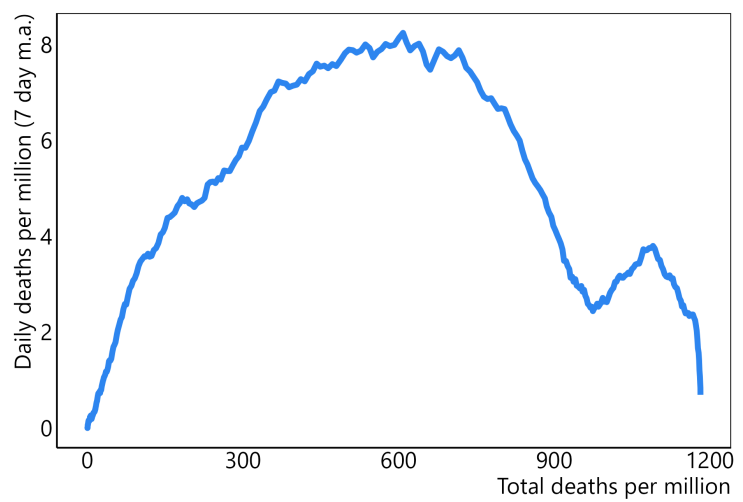




\subsection{Reduced Form Equation}

The key variable in a pandemic is the effective reproduction rate $R_{t}$. If it is above 1 , the epidemic will continue to explode, and when it is below 1 , the epidemic will start to die out. Recall from equation (8) (which we repeat here for convenience) that the effective reproduction rate $R_{t}$ depends both on $R_{0 t}$ (the expected number of secondary cases produced by a single (typical) infection in a completely susceptible population) and the share of the still susceptible population.

$$
R_{t}=R_{0 t} \frac{S}{N}
$$

According to equation (6), which we repeat here for convenience, $R_{0 t}$ depends on the number of persons an infected person meets each day $(\lambda)$, the probability that an infected person will infect a non-infected person during a contact $\left(\pi_{t}\right)$, and the number of days an infected person is infectious $\left(\frac{1}{\gamma}\right)$.

$$
R_{0 t}=\frac{\lambda_{t} \pi_{t}}{\gamma}
$$

The number of persons an infected person meets and the probability that an infected person will infect a non-infected person are not constant. They depend on behavior (which in turn is influenced by government policies) ${ }^{7}$ and on the temperature, which may have a bearing on the ease at which the disease spreads. To measure the stringency of government policies we will use the Oxford Stringency index (Hale et al. (2021). ${ }^{8}$ We assume therefore that $R_{t}$ is a function of the susceptible population, the stringency index $\left(s_{t}\right)$ and the temperature $\left(t_{t}\right)$ :

$$
R_{t}=f\left(\frac{S_{t}}{N_{t}}, s_{t}, t_{t}\right)
$$

The impact of policies on behavior may change over time, as lockdowns become less effective, or people lose their fear. We will therefore also use an alternative specification in which we use Google's mobility index (Google (2021)) as a proxy for the number of persons

\footnotetext{
${ }^{7}$ Government policies influence behavior. Stay-at-home requirements curtail the number of persons an infected person meets, while mask requirements reduce the probability that an infected person will infect a non-infected person during a meeting.

${ }^{8}$ The Oxford Stringency Index is calculated from ordinal scores on 7 indicators: school closings, workplace closings, canceling of public events, closing of public transport, public info campaigns, restrictions on internal movement and international travel controls. Each indicator is rescaled to a maximum of 100; and the average of all indicators then yields the stringency index. A required closing of schools, targeted closings of workplaces, required cancelling of all public events, and a ban on international travel from high-risk regions would raise the index by 52 points.
} 
an infected person meets each day. ${ }^{910}$ The alternative specification is therefore:

$$
R_{0 t}=f\left(\frac{S_{t}}{N_{t}}, m_{t}, t_{t}\right)
$$

where $m_{t}$ is mobility.

As the effective reproduction rate is not directly observable, we will instead use a proxy, the growth rate of new deaths. ${ }^{11}$ If the growth rate is positive, the epidemic will continue to explode, while if it is negative the epidemic will die out. The growth rate of new deaths can be written as:

$$
g_{t}^{n d}=\frac{n d_{t}}{n d_{t-1}}-1 \approx \Delta \log n d_{t}=\Delta \log \Delta d_{t}
$$

Replacing the effective reproduction rate by the growth rate of new deaths, and acknowledging that there is a lag between infections and deaths, we can rewrite equation (12) as: ${ }^{12}$

$$
\Delta \log \Delta d_{t}=f\left(\frac{S_{t-1}}{N_{t-1}}, s_{t-1}, t_{t-1}\right)
$$

We assume that the share of the still susceptible population can be proxied by the total death toll. The higher the number of people that have died, the lower the share of the still susceptible population.

$$
\frac{S_{t}}{N_{t}}=g\left(\frac{d_{t}}{N_{t}}\right)
$$

Combining (15) and (16) we get:

$$
\Delta \log \Delta d_{t}=h\left(\frac{d_{t-1}}{N_{t-1}}, s_{t-1}, t_{t-1}\right)
$$

The alternative specification with mobility is:

$$
\Delta \log \Delta d_{t}=h\left(\frac{d_{t-1}}{N_{t-1}}, m_{t-1}, t_{t-1}\right)
$$

\footnotetext{
${ }^{9}$ Google's mobility measures are based on aggregated, anonymized sets of data from mobile device users who have turned on the location history setting - for example, because they are using Google Maps. Since the behavior regarding turning on location history may be different across countries, mobility measures may not be strictly comparable accross countries.

${ }^{10}$ As we will show in section 7.2 , mobility depends on both stringency and the daily number of deaths. Quantitatively, stringency seems more important, although its impact on mobility declines over time.

${ }^{11}$ In theory, the growth rate of new cases would be a better indicator, but in practice the number of cases is likely to have been underestimated severely, particularly in the Spring of 2020 (see Annex A).

${ }^{12}$ We use $t-1$ as a shortcut for lag.
} 


\section{Specification}

We will use the following specification for equation (17):

$$
\Delta \log \Delta d_{t}=\alpha-\beta \log \left(\frac{d_{t-1}}{N_{t-1}}\right)-\gamma s_{t-1}-\delta t_{t-1}
$$

While is this a simple equation, the dynamics of the equation are very similar to that of the SEIR model. For example, we can simulate the effects of an early versus late lockdown, and the effects of a more versus less stringenent lockdown (Figure 2.7). With no intervention an explosion of new deaths ensues, followed by a rapid decline. The earlier intervention takes place, the lower the peak number of daily deaths and the total number of deaths. Moreover, for a given start date of stringency, the higher the stringency the lower peak deaths and total deaths (Figure 2.8).

The alternative specification with mobility is:

$$
\Delta \log \Delta d_{t}=\alpha-\beta \log \left(\frac{d_{t-1}}{N_{t-1}}\right)-\gamma m_{t-1}-\delta t_{t-1}
$$


Figure 2.7. Later Stringency leads to More Deaths

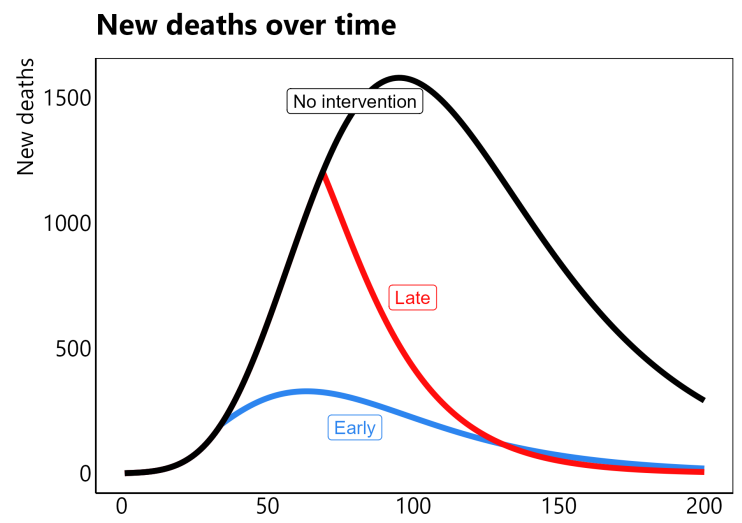

Total deaths versus new deaths

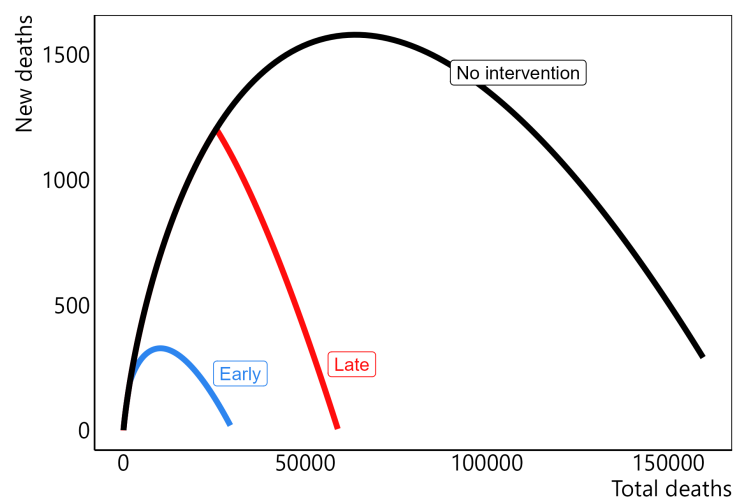

Source: Simulations

Figure 2.8. More stringency leads to fewer deaths

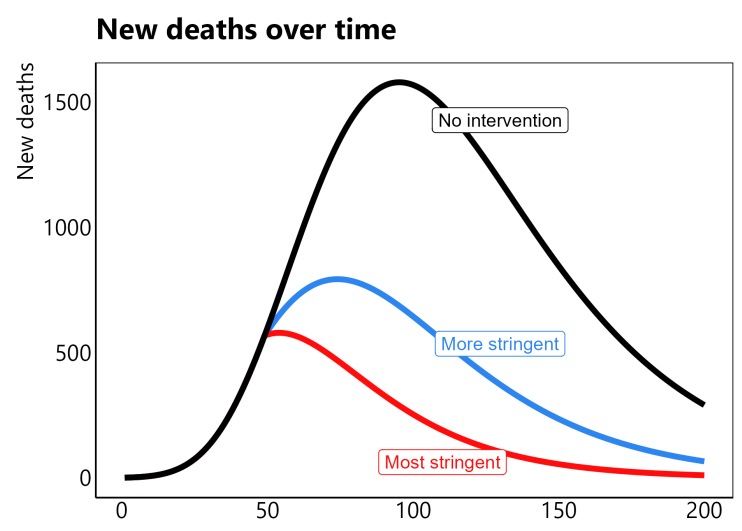

Total deaths versus new deaths

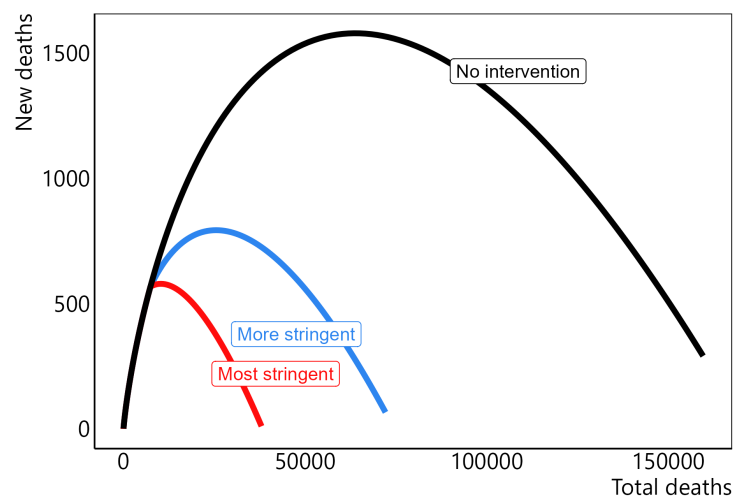

Source: Simulations 


\section{The Dynamics of Covid-19 Epidemics: Some Empirics}

We will focus in this section on the role of stringency, mobility and temperature on the dynamics of Covid-19 pandemics. We will show four things

- Stringency, mobility and temperature matter. For a given level of the still susceptible population, the higher the (lagged) stringency indicator, or the lower (lagged) mobility, the lower the growth rate of new deaths. (Lagged) temperature also matters: the higher the temperature, the lower the growth rate of new deaths.

- Timing matters. In a given wave, late lockdowns tend to lead to a higher number of deaths than early lockdowns.

- There is a large random component. Many countries or regions suddenly saw an explosion while other areas did not, even though was no obvious difference in policies or behavior.

\subsection{Higher Stringency, Lower Mobility and Higher Temperatures are Associated with a Lower Growth Rate of New Deaths}

To show that higher stringency and lower mobility are associated with a lower growth rate of new deaths, we will regress equations (19) and (20), which we repeat here for convenience:

$$
\begin{gathered}
\Delta \log \Delta d_{t}=\alpha-\beta \log \left(\frac{d_{t-1}}{N_{t-1}}\right)-\gamma s_{t-1}-\delta t_{t-1} \\
\Delta \log \Delta d_{t}=\alpha-\beta \log \left(\frac{d_{t-1}}{N_{t-1}}\right)-\gamma m_{t-1}-\delta t_{t-1}
\end{gathered}
$$

We use biweekly observations. Given the time lag between infection, incubation and deaths, it seems reasonable to assume that that new deaths in the current fortnight were infected in the previous fortnight. Assuming that there is a contemporaneous relation between stringency or mobility and new infections, there should be a one fortnight lag between stringency and mobility and the growth rate of new deaths. ${ }^{13}$ As the death toll in recent months is increasingly affected by vaccinations, we end the regressions at end February 2021.

Table 1 shows the result for all countries. ${ }^{14}$ The coefficients of lagged deaths per million and temperature have the expected sign and are highly significant. Column 1 shows the pooled estimates; column 4 the fixed effect estimates. We next confirm that the higher the stringency in the previous fortnight, the lower the growth rate of new deaths. The

\footnotetext{
${ }^{13}$ Using a lag between stringency and new deaths also mitigates endogeneity concerns. The contemporaneous correlation between stringency and daily deaths is positive: higher stringency is associated with more deaths. Of course, this is not a causal relationship but reflects the reaction of policies to high deaths.

${ }^{14}$ Analysis of the data was done in $\mathrm{R}$ using the stargazer package (v5.2.2; Hlavac (2018)).
} 
coefficients have the expected sign and are highly significant whether we use pooled regression (column 2) or fixed effects (column 5). However, the size of the coefficients is higher using fixed effects. We also confirm that the higher the mobility decline in the previous fortnight, the lower the growth rate of new deaths. The coefficients are highly significant whether we use pooled regression (column 3) or fixed effects (column 6), but the size of the coefficients is higher using fixed effects. Both stringency and mobility add significant explanatory power. The $R^{2}$ of the fixed effect equation that only includes lagged deaths and lagged temperature is 0.22 ; adding mobility increases this to $0.31 .^{15}$

Table 2 shows the same set of regressions for US states. The United States is the only country for which stringency indicators exist at the sub-national level - in this case states. They also show that higher stringency, a larger decline of mobility, and higher temperatures are associated with a lower growth rate of new deaths.

Table 3 shows the regressions for Mexican states. For Mexico, we do not have stringency indicators at the state level, and the regressions therefore only use mobility.

Table 1: All Countries: Regressions of $\Delta \log$ New Deaths

\begin{tabular}{|c|c|c|c|c|c|c|}
\hline & \multicolumn{6}{|c|}{ Dependent variable: } \\
\hline & \multicolumn{6}{|c|}{$\Delta \log$ new deaths per milion } \\
\hline & \multicolumn{3}{|c|}{ Pooled } & \multicolumn{3}{|c|}{ Fixed Effects } \\
\hline & $(1)$ & $(2)$ & $(3)$ & $(4)$ & $(5)$ & $(6)$ \\
\hline Stringency $(\mathrm{t}-1)$ & & $\begin{array}{c}-0.002^{* * *} \\
(0.0003)\end{array}$ & & & $\begin{array}{c}-0.006^{* * *} \\
(0.0004)\end{array}$ & \\
\hline Mobility decline (t-1) & & & $\begin{array}{c}-0.001^{* *} \\
(0.0004)\end{array}$ & & & $\begin{array}{c}-0.007^{* * *} \\
(0.001)\end{array}$ \\
\hline log deaths per million $(t-1)$ & $\begin{array}{c}-0.121^{* * *} \\
(0.006)\end{array}$ & $\begin{array}{c}-0.117^{* * *} \\
(0.006)\end{array}$ & $\begin{array}{c}-0.128^{* * *} \\
(0.007)\end{array}$ & $\begin{array}{c}-0.228^{* * *} \\
(0.008)\end{array}$ & $\begin{array}{c}-0.237^{* * *} \\
(0.008)\end{array}$ & $\begin{array}{c}-0.258^{* * *} \\
(0.008)\end{array}$ \\
\hline Temperature (t-1) & $\begin{array}{c}-0.005^{* * *} \\
(0.001)\end{array}$ & $\begin{array}{c}-0.004^{* * *} \\
(0.001)\end{array}$ & $\begin{array}{c}-0.005^{* * *} \\
(0.001)\end{array}$ & $\begin{array}{c}-0.006^{* * *} \\
(0.001)\end{array}$ & $\begin{array}{c}-0.006^{* * *} \\
(0.001)\end{array}$ & $\begin{array}{c}-0.011^{* * *} \\
(0.001)\end{array}$ \\
\hline Constant & $\begin{array}{c}0.343^{* * *} \\
(0.019)\end{array}$ & $\begin{array}{c}0.485^{* * *} \\
(0.027)\end{array}$ & $\begin{array}{c}0.387^{* * *} \\
(0.021)\end{array}$ & & & \\
\hline Observations & 3,026 & 3,024 & 2,388 & 3,026 & 3,024 & 2,388 \\
\hline $\mathrm{R}^{2}$ & 0.109 & 0.126 & 0.136 & 0.220 & 0.285 & 0.305 \\
\hline Adjusted $\mathrm{R}^{2}$ & 0.109 & 0.125 & 0.134 & 0.176 & 0.245 & 0.267 \\
\hline
\end{tabular}

\footnotetext{
${ }^{15}$ Chapter 2 of the IMF's October 2020 World Economic Outlook (International Monetary Fund (2020)) reaches similar results as we do here, suggesting lockdowns did impact the pace of the pandemics. Similar findings are shown in David and Pienknagura (2020), who in addition emphasize the heterogenous effect associated with the composition of the labor market.
} 
Table 2: US States: Regressions of $\Delta \log$ New Deaths per million

\begin{tabular}{|c|c|c|c|c|c|c|}
\hline & \multicolumn{6}{|c|}{ Dependent variable: } \\
\hline & \multicolumn{6}{|c|}{$\Delta$ log new deaths per million } \\
\hline & \multicolumn{3}{|c|}{ OLS } & \multicolumn{3}{|c|}{ Fixed Effects } \\
\hline & $(1)$ & $(2)$ & $(3)$ & $(4)$ & $(5)$ & $(6)$ \\
\hline Stringency $(\mathrm{t}-1)$ & & $\begin{array}{c}-0.007^{* * *} \\
(0.001)\end{array}$ & & & $\begin{array}{c}-0.012^{* * *} \\
(0.001)\end{array}$ & \\
\hline Mobility decline (t-1) & & & $\begin{array}{c}0.001 \\
(0.0004)\end{array}$ & & & $\begin{array}{c}-0.007^{* * *} \\
(0.001)\end{array}$ \\
\hline $\log$ deaths per million $(t-1)$ & $\begin{array}{c}-0.233^{* * *} \\
(0.010)\end{array}$ & $\begin{array}{c}-0.258^{* * *} \\
(0.010)\end{array}$ & $\begin{array}{c}-0.234^{* * *} \\
(0.010)\end{array}$ & $\begin{array}{c}-0.294^{* * *} \\
(0.011)\end{array}$ & $\begin{array}{c}-0.342^{* * *} \\
(0.010)\end{array}$ & $\begin{array}{c}-0.315^{* * *} \\
(0.011)\end{array}$ \\
\hline Temperature (t-1) & $\begin{array}{c}-0.004^{* * *} \\
(0.001)\end{array}$ & $\begin{array}{c}-0.003^{* * *} \\
(0.001)\end{array}$ & $\begin{array}{c}-0.003^{* * *} \\
(0.001)\end{array}$ & $\begin{array}{c}-0.007^{* * *} \\
(0.001)\end{array}$ & $\begin{array}{c}-0.006^{* * *} \\
(0.001)\end{array}$ & $\begin{array}{c}-0.016^{* * *} \\
(0.001)\end{array}$ \\
\hline Constant & $\begin{array}{c}0.672^{* * *} \\
(0.028)\end{array}$ & $\begin{array}{c}1.137^{* * *} \\
(0.049)\end{array}$ & $\begin{array}{c}0.660^{* * *} \\
(0.029)\end{array}$ & & & \\
\hline Observations & 1,263 & 1,165 & 1,204 & 1,263 & 1,165 & 1,204 \\
\hline $\mathrm{R}^{2}$ & 0.305 & 0.384 & 0.312 & 0.388 & 0.528 & 0.431 \\
\hline Adjusted $\mathrm{R}^{2}$ & 0.304 & 0.382 & 0.310 & 0.360 & 0.507 & 0.405 \\
\hline
\end{tabular}

Table 3: Mexican states: Regressions of Change in Log New Deaths

\begin{tabular}{|c|c|c|c|c|}
\hline & \multicolumn{4}{|c|}{ Dependent variable: } \\
\hline & \multicolumn{4}{|c|}{$\Delta \log$ new deaths per million } \\
\hline & \multicolumn{2}{|c|}{ Pooled } & \multicolumn{2}{|c|}{ Fixed Effects } \\
\hline & $(1)$ & $(2)$ & $(3)$ & $(4)$ \\
\hline Mobility decline (t-1) & & $\begin{array}{c}-0.006^{* * *} \\
(0.001)\end{array}$ & & $\begin{array}{c}-0.014^{* * *} \\
(0.001)\end{array}$ \\
\hline $\log$ deaths per million $(t-1)$ & $\begin{array}{c}-0.167^{* * *} \\
(0.011)\end{array}$ & $\begin{array}{c}-0.202^{* * *} \\
(0.012)\end{array}$ & $\begin{array}{c}-0.210^{* * *} \\
(0.013)\end{array}$ & $\begin{array}{c}-0.331^{* * *} \\
(0.016)\end{array}$ \\
\hline Temperature & $\begin{array}{c}-0.006^{* * *} \\
(0.001)\end{array}$ & $\begin{array}{c}-0.003^{* *} \\
(0.001)\end{array}$ & $\begin{array}{c}-0.013^{* * *} \\
(0.002)\end{array}$ & $\begin{array}{c}-0.012^{* * *} \\
(0.002)\end{array}$ \\
\hline Constant & $\begin{array}{c}0.614^{* * *} \\
(0.048)\end{array}$ & $\begin{array}{c}0.792^{* * *} \\
(0.056)\end{array}$ & & \\
\hline Observations & 677 & 633 & 677 & 633 \\
\hline $\mathrm{R}^{2}$ & 0.262 & 0.311 & 0.293 & 0.435 \\
\hline Adjusted $\mathrm{R}^{2}$ & 0.260 & 0.308 & 0.257 & 0.405 \\
\hline
\end{tabular}




\subsection{Later Lockdowns Lead to Higher Deaths}

The death toll of a pandemic will not only depend on how stringent a lockdown or other nonpharmaceutical interventions are, but also how timely. As we showed in section 2, a late lockdown will result in a far higher death toll than an early lockdown.

To show that late lockdowns increased the initial death toll we need to define the timing and the timeliness of a lockdown.

- In theory, the timing of a lockdown is the moment when $R_{0 t}$ falls sharply. In practice, $R_{0 t}$ is not a directly observable variable. As a proxy, we measure the timing of a lockdown as the moment at which mobility fell to a level of at least 40 percent below normal. Most countries saw a very sharp fall in mobility in March or April, and the precise threshold does not make much difference. ${ }^{16}$

- To determine the timeliness, we cannot simply look at calendar dates. A lockdown in mid-March in a country when there were already many infections was late, while a lockdown in late April in a country where there were few infections may have been early. We measure the timeliness of a lockdown by looking at how widespread the disease was at the time of the lockdown. If the number of daily new cases per million people is already high, the lockdown is late, while if the number of daily new cases is still low, it is early. As the number of new cases may be underestimated because of lack of testing, ${ }^{17}$ we look instead at the number of daily deaths two weeks after lockdown. Given the lags, this is a good proxy for the number of new cases at the time of lockdown. And because of the lag, the number of daily deaths two weeks after lockdown is not yet affected by the lockdown itself.

We look at all countries in the world which had a lockdown in the Spring of 2020. We compare the timeliness (defined as daily number of deaths per million two weeks after the start of the lockdown) with the total number of deaths as of end May. We take end May as the cut-off point, as later deaths were often the result of second waves.

Early lockdowns were associated with lower total deaths (Figure 3.1). In Western Europe, Belgium locked down very late, while Germany locked down very early. By late May, Belgium had the highest death toll in Western Europe, and Germany the lowest.

\footnotetext{
${ }^{16}$ An alternative would be to use the Oxford stringency indicator, and define the timing of the lockdown as the moment at which the indicators exceeded a certain treshold.

${ }^{17}$ This was a widespread problem in the Spring of 2020.
} 
Figure 3.1. Daily Deaths Two weeks after Lockdown and Total Deaths on May 1

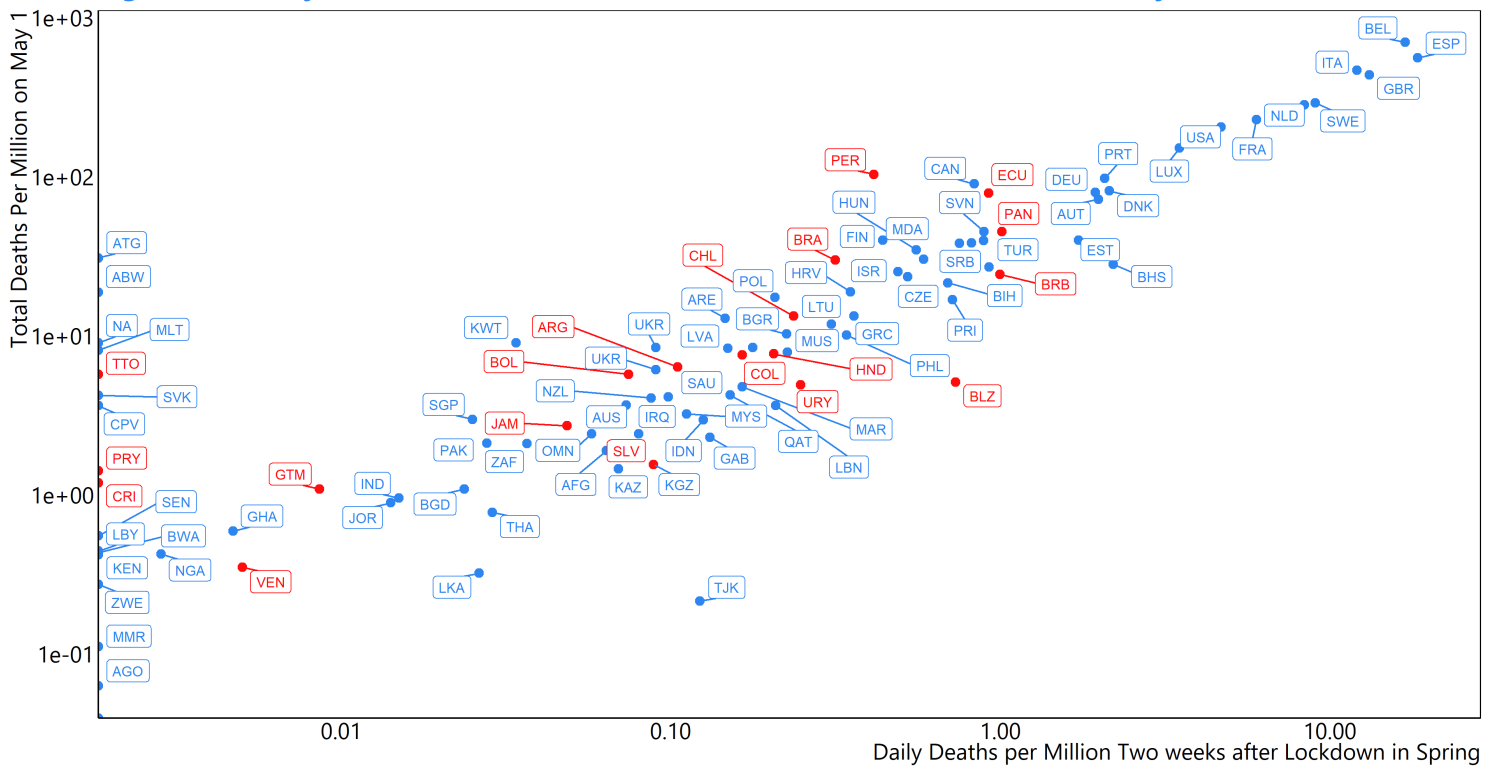

Source: Google Covid-19 hub and IMF staff calculations.

Figure 3.2. All Countries: Total Deaths vs New Deaths, March-December

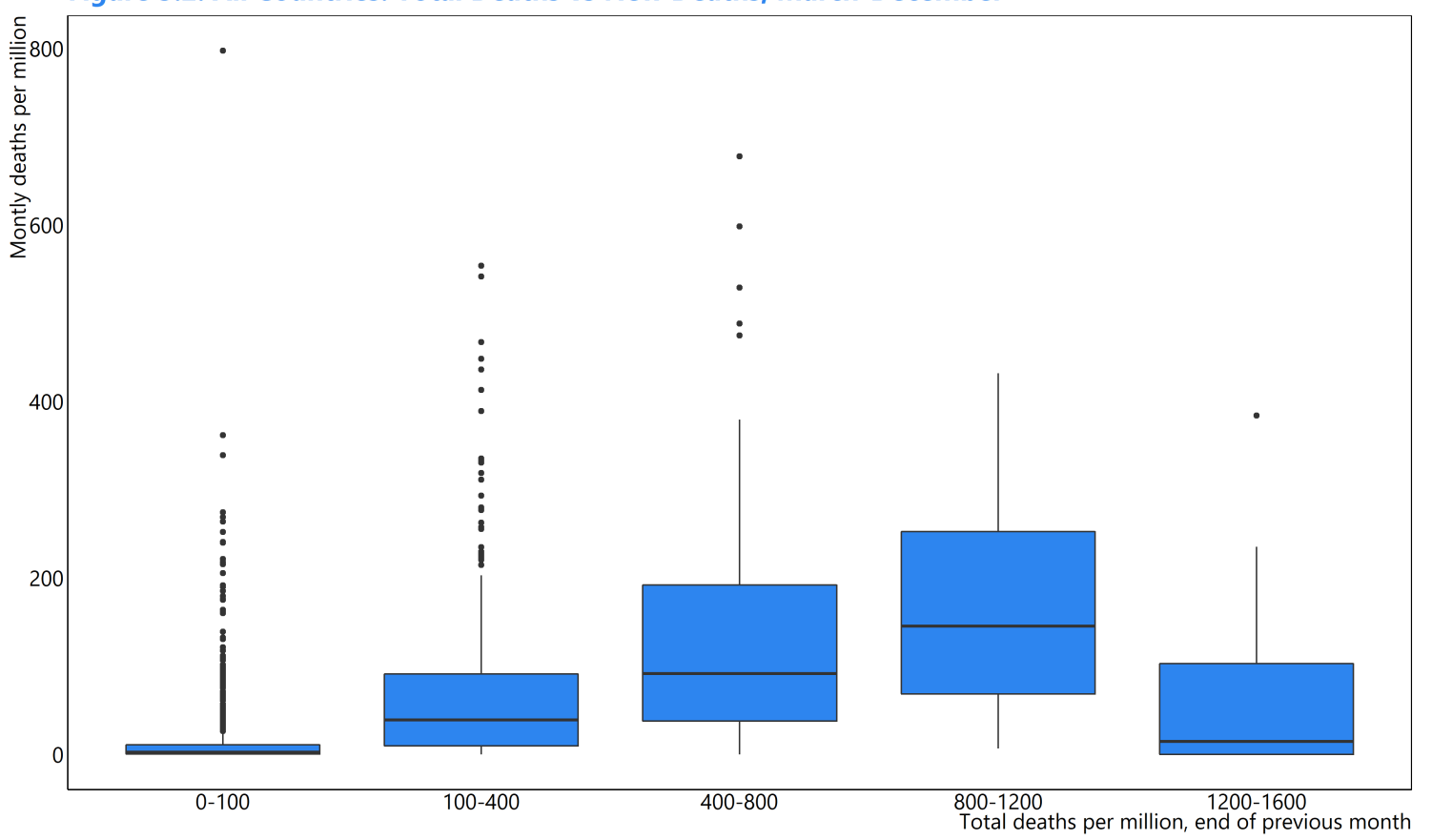

The $y$-axis shows monthly deaths per million for various countries. For example, deaths in Brazil in November is one observation. These observations are grouped by total deaths in the previous month. For example, all country-month observations for which total deaths in the preceding month was between 0 and 400 deaths per million are shown in the first group. The box represents the first quartile, median and third quartile. The lines extend to the highest and lowest observation, excluding outliers. The dots are outliers (an outlier is more than 1.5 times the height of the box away from the box.) 


\subsection{Randomness}

Monthly death tolls not only depend on stringency/mobility and total deaths; they also have a large random component. There have been many examples of countries and regions where there was no change in stringency or mobility and deaths suddenly exploded. Figure 3.2 compares total deaths in the preceding month with new deaths in the current month. The overall shape is in line with SEIR models (see Figure 2.2) - new deaths increase until total deaths have reached a certain level and then start to decline. But for quite a few countries with low deaths, there are sudden explosions.

Figure 3.3 looks at the monthly Covid death toll for all countries and compares this with stringency in the previous month. As the top chart shows, when stringency is low, the death toll in the subsequent month tends to be low. But, as bottom chart shows, in countries where death toll in given month is high, in more than half of the cases the stringency in previous month was low.

An example. The death toll in New York exploded in April. And stringency in March was low. But in all states stringency was low in March. And deaths only exploded in a few.

\subsection{Geographical Spread}

This randomness may be linked to geographical spread. In a standard SEIR model, there is only one nation-wide epidemic, and everyone in the still-susceptible population has the same risk of being infected. In practice, however, there is not one nation-wide epidemic but a series of regional epidemics. In April, Covid-19 was raging in New York City, but inhabitants of North Dakota were at low risk of getting infected.

If a pandemic is introduced in a new country, it is likely to first start in places that have many international linkages - which also tend to be densely populated. From there it will gradually spread to the rest of the country. That means in the first stages of an epidemic some parts of a country may be badly hit, while other parts still have very few cases. Over time, however, regional differences will diminish, as the disease spreads across the country.

This is clearly visible, for example, in the United States. In early June, you could drive from Mexico to Canada, and from the Pacific to the Atlantic, and only go through counties that had zero Covid-19 casualties (Figure 3.4). By late December, the disease had spread almost everywhere (Figure 3.5). 
Figure 3.3. Stringency, Monthly Deaths and Randomness

Stringency and Monthly Deaths

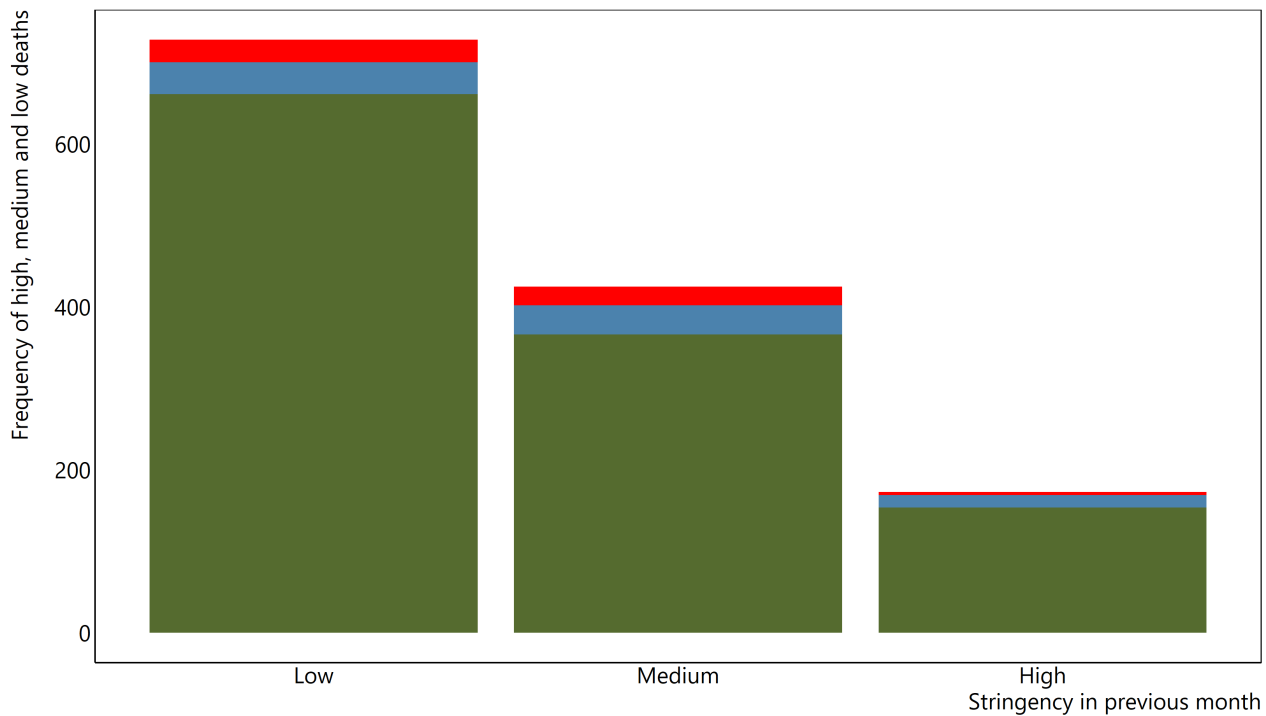

The $y$-axis shows the number of monthly observations for each country with low deaths (less

than 100 per million), medium deaths (100-200 per million) and high deaths (more than 200

per million). For example, deaths in Brazil in November (156 per million) is one observation

with medium deaths. These observations are grouped by stringency in the previous month

(low $=(0,60)$, medium $=(60,80)$, high $=(80,100))$. For example, all country-month observations for which

stringency in the preceding month was low are shown in the first group.

Monthly Deaths and Stringency in Previous Month

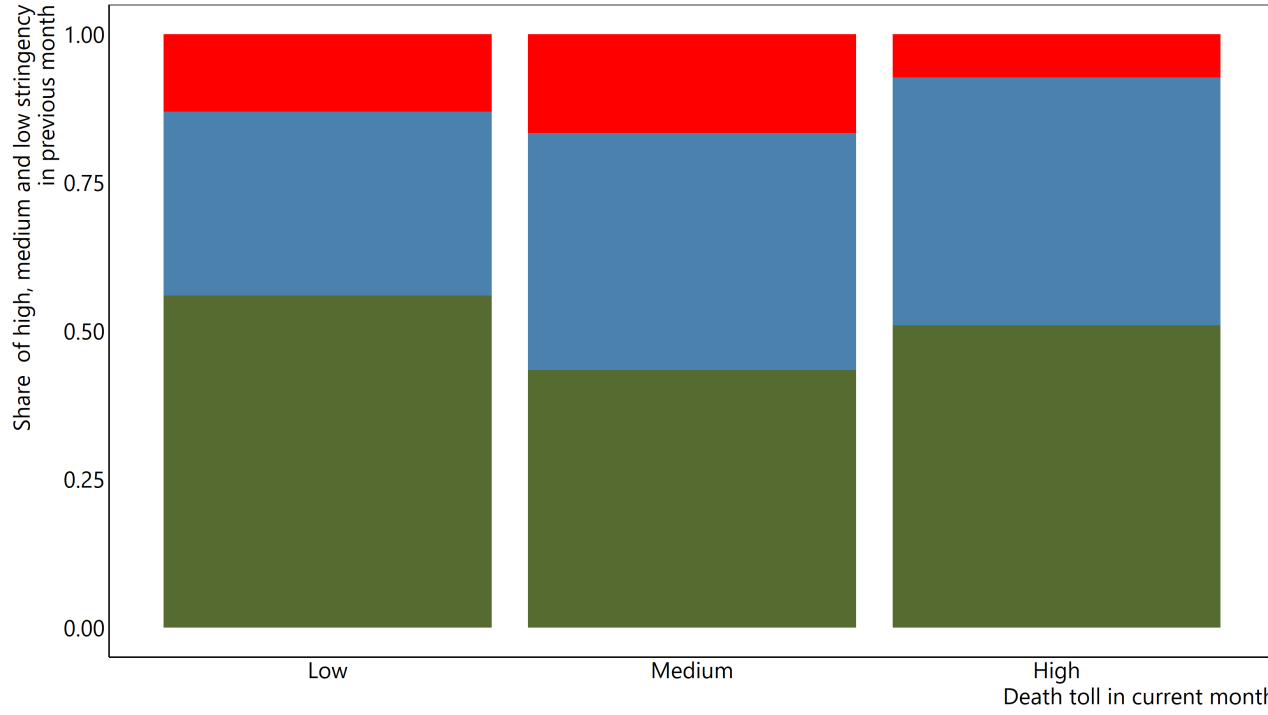

The $x$-axis groups all observations of monthly deaths for all countries into three groups: low

(less than 100 per million), medium (100-200 per million) or high (more than 200 per million). For

example, deaths in Brazil in November (156) is one observation with medium deaths. The $y$-axis shows the share of each group that had low $(0,60)$, medium $=(60,80)$, high $=(80,100)$ stringency in the previous month.

Source: Google Covid-19 hub 
Figure 3.4. US Counties: Covid-19 Deaths per million: Early June

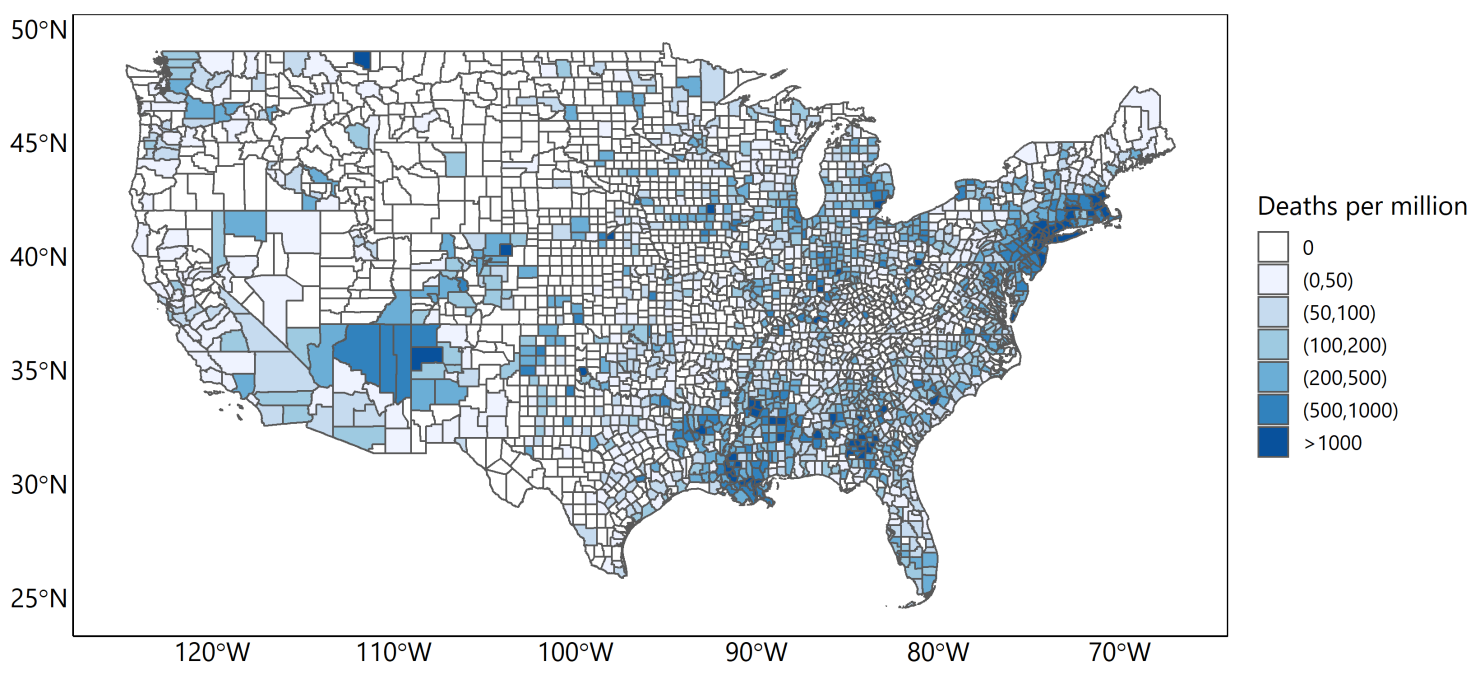

Figure 3.5. US Counties: Covid-19 Deaths per million: Late December

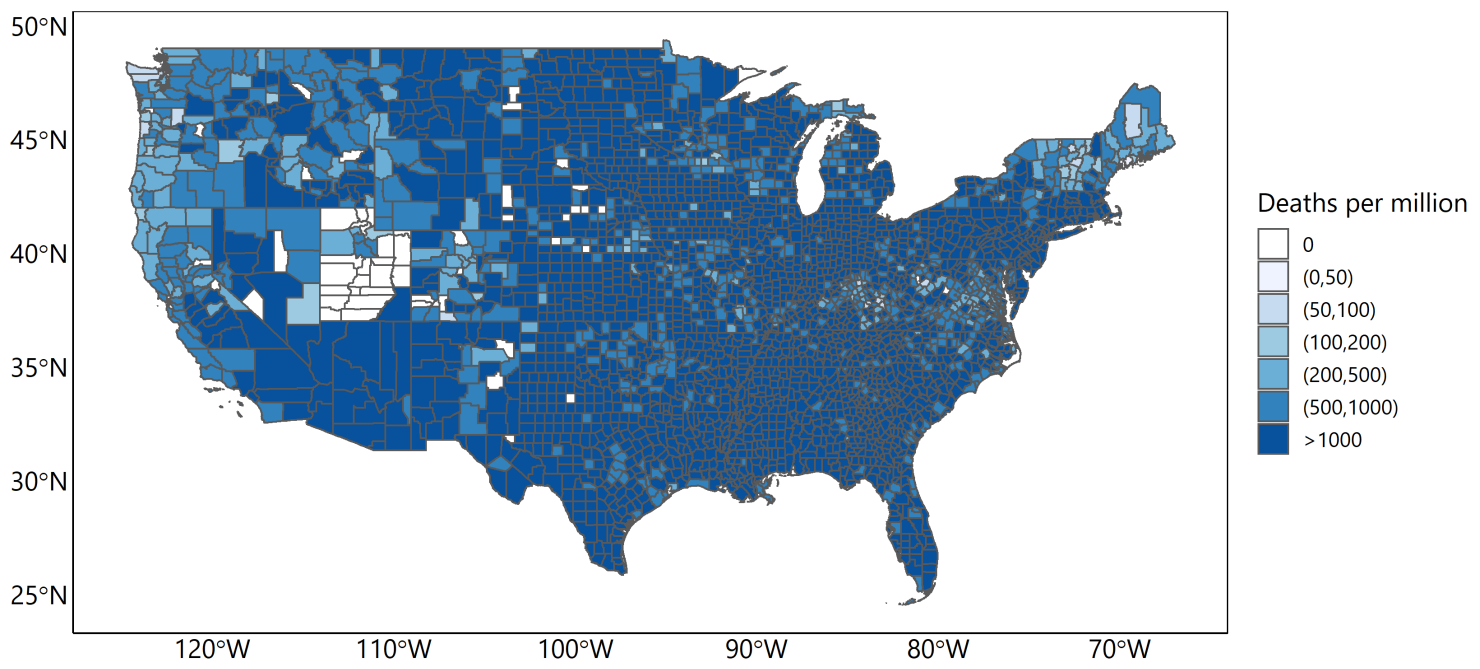




\section{Why did Lockdowns in Latin America not Stop the Pandemic?}

Latin America locked down early. In Colombia, the daily number of deaths two weeks after the lockdown - a proxy of the spread of the disease at the time of the lockdown - was still very low (Figure 4.1). In Spain, by contrast, the daily number of death was near 20 per million.

As a result, Latin America did not experience forest fires (Figure 4.2), which likely would had overwhelmed a poorly prepared health system, leading to even higher death numbers.

However, lockdowns in Latin America did not manage to stop the expansion of the epidemic. In Italy, the number of daily deaths had fallen to single digits by late July. But in Argentina, the number of daily deaths continued to rise, and peaked only in October.

Why did lockdowns not manage to stop the expansion of the epidemic? We will discuss three factors that may all have played a role:

- Early lockdowns require a sharper reduction of $R_{0 t}$

- Mobility rebounded as cases increased

- Lockdowns in Latin America were less effective

\subsection{Early Lockdowns Require a Sharper Reduction of $R_{0 t}$}

The higher the share of the still susceptible population, the lower $R_{0 t}$ needs to be to bring $R_{t}$ to below 1 . It follows from equation (9) that

$$
R_{t}<1 \rightarrow R_{0 t}<\frac{1}{\frac{S}{N}}
$$

When Latin America locked down, there had been very few cases, which implies that the share of the still susceptible population was high. In Europe, the epidemic was more widespread, which implies that the share of the still susceptible population was lower. To stop the epidemic, Latin America therefore needed to bring down $R_{0 t}$ down to a lower level than Europe.

In fact, R-effective fell more sharply in Peru than it did in France (Figure 4.3). But because it started at a higher level, it stayed above 1 . 
Figure 4.1. Colombia and Spain: Mobility and Daily Deaths per Million

Colombia

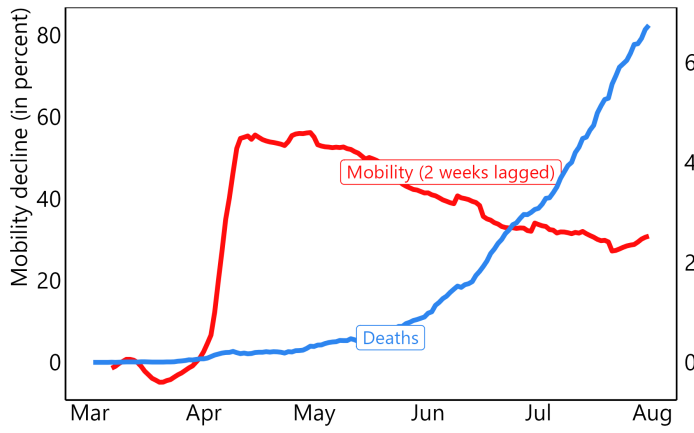

Spain

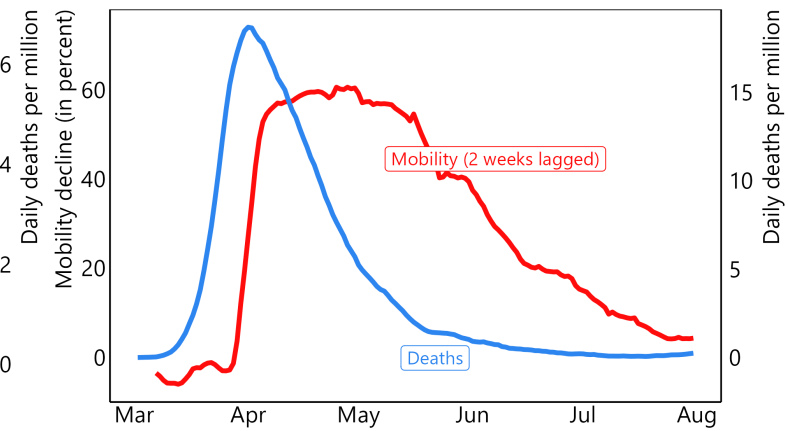

Source: Google Covid hub

Figure 4.2. South America and Western Europe: Covid-19 Deaths

New COVID-19 deaths

Per million, 7-day moving average

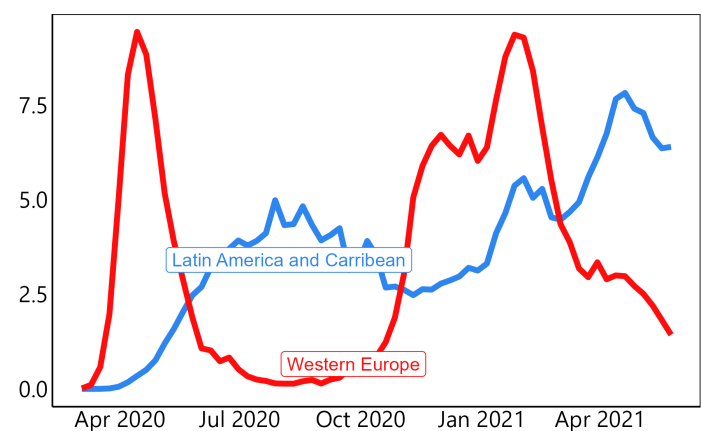

Total COVID-19 deaths

Per million

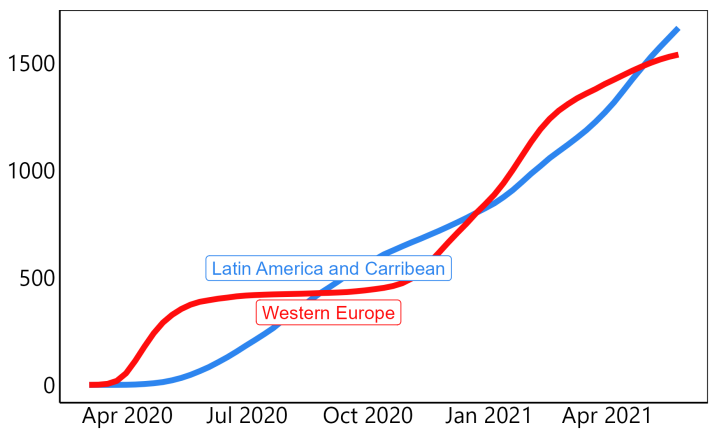

Source: John Hopkins

Figure 4.3. R-effective: Peru and France

$(R<1$ : pandemic in retreat, $R>1$ : pandemic expanding)

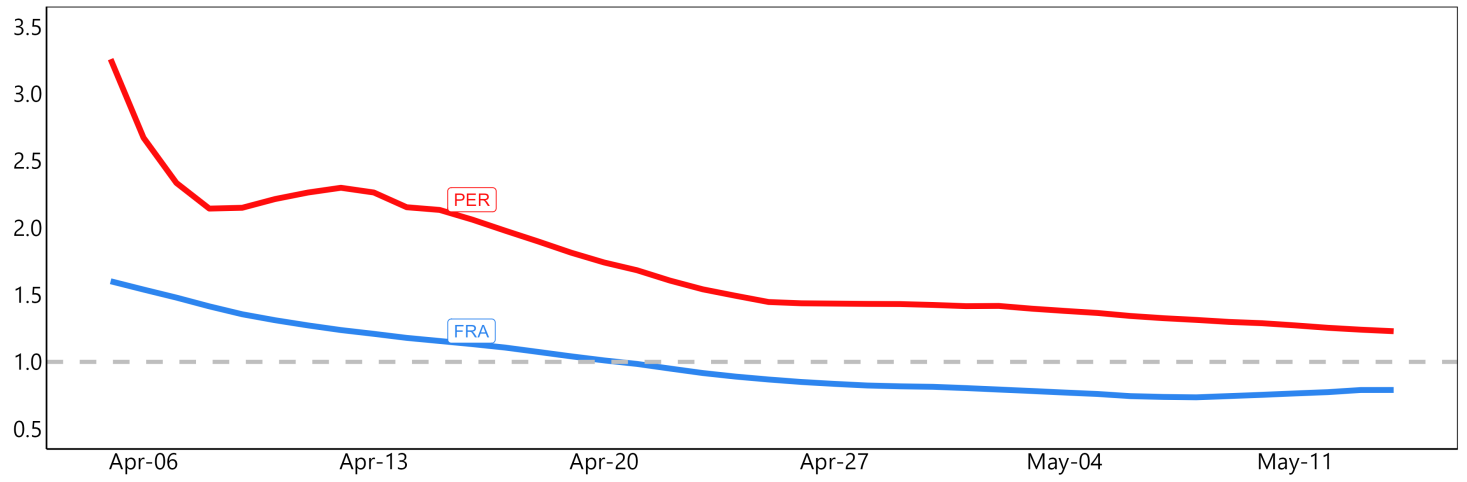

Google Covid-19 hub and IMF staff estimates 


\subsection{Mobility Rebounded as Cases Increased}

Another reason why the lockdowns did not stop the pandemic may have been "lockdown fatigue" and the necessity of low-income households to engage in economic activity. The result was an increase in mobility in Latin America from April onwards. This increase in mobility may have further contributed to the spreading of the disease. As Figure 4.4 illustrates, the rebound in mobility in Latin America occurred when the daily death toll was still rising. By contrast, the rebound in Europe occurred when daily deaths were in clear retreat (Figure 4.5).

Unlike in Europe, temperatures did not provide much support in the first six months in stopping the epidemic. In Italy, it warmed significantly during the Northern Hemisphere's Spring, which helped slow the growth of Covid (Figure 4.6). In Argentina, temperatures declined in the second quarter. In Mexico, temperatures increased, but by much less than in Italy.

We can use the regression results in section 3 to help explain why deaths in Argentina only started to decline in November (Figure 4.7). Why did they not start to decline in June? If we compare mid-November with mid-June, in mid-November lagged total deaths per million were 718 ; in mid-June it was 16 . Using the coefficients in column 6 of Table 1 , this difference would have reduced the growth rate by $\log 10(718 / 16) * 0.258=0.428$. The lagged temperature went from 10 to 22 , which would have reduced the growth rate by $12^{*} 0.011=0.132$. This was partly offset by the increase in mobility (the decline went from 53 to 36 percent); this should have increased the growth by $17^{*} 0.007=0.119$, Overall, we would expect that the growth rate in mid-November was 0.44 lower than in mid-June - close to the actual decline in the growth rate, which went from +0.305 to -0.102 . 
Figure 4.4. Latin America: Daily Deaths and Mobility

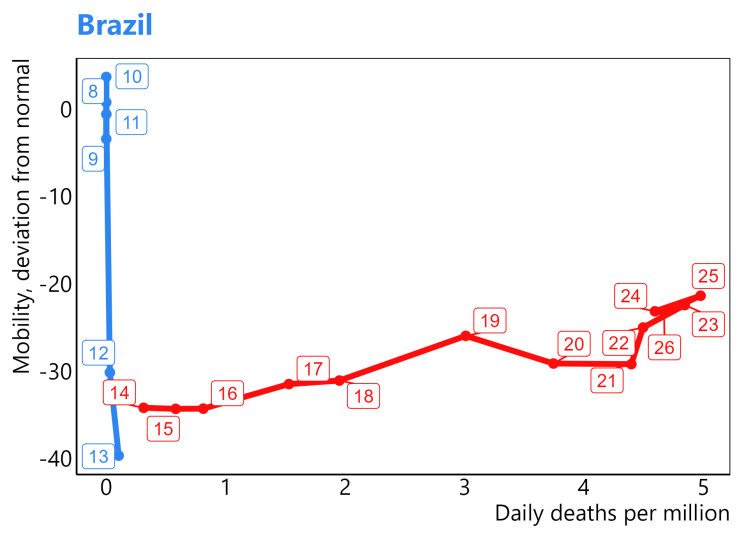

$$
\text { Colombia }
$$

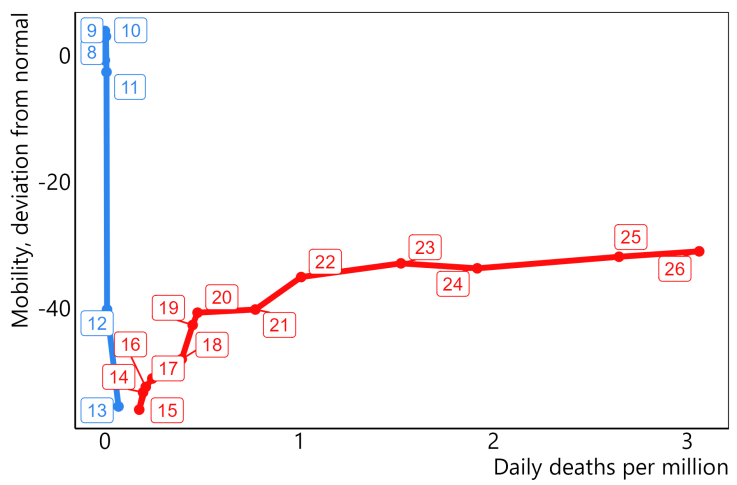

Numbers in labels are week numbers. Blue is week 8-13; red 14-26.

Source: Google Covid-19 hub

Figure 4.5. Western Europe: Daily Deaths and Mobility
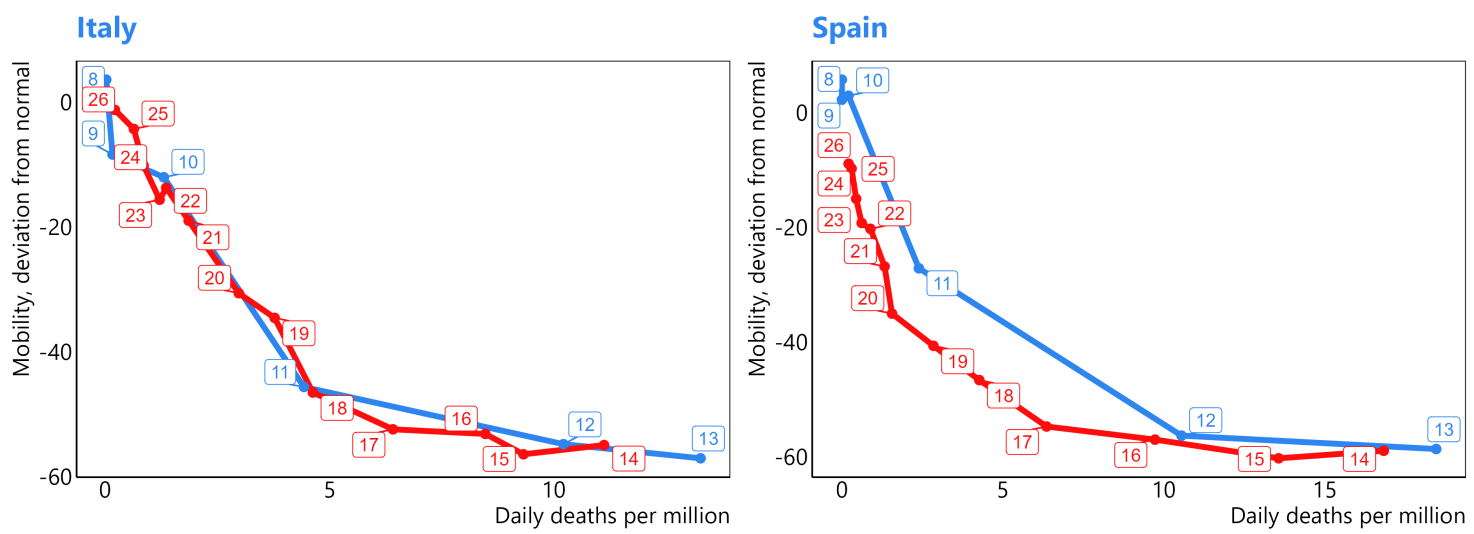

Numbers in labels are week numbers. Blue is week 8-13; red is week 14-26. Source: Google Covid-19 hub

Figure 4.6. Temperatures, 2020

\section{Italy and Argentina}

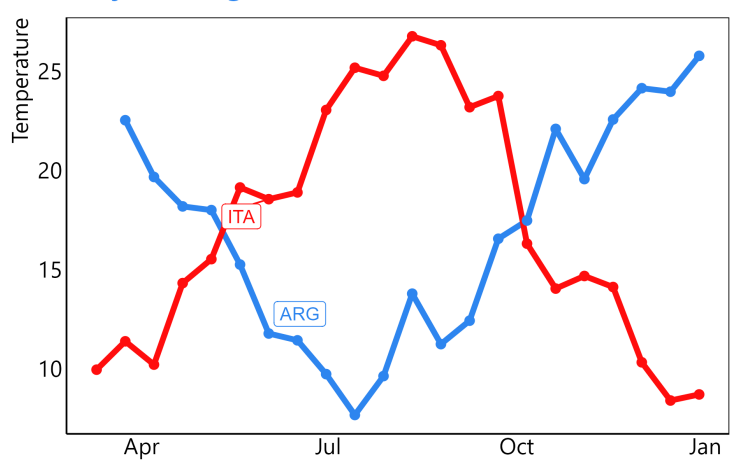

Italy and Mexico

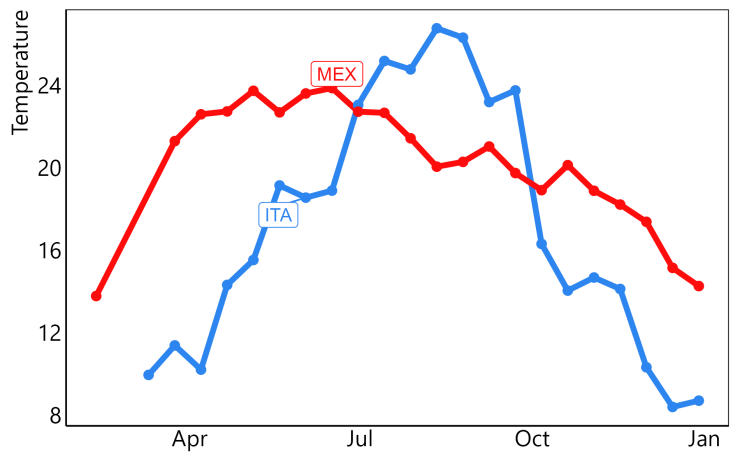

Each dot represents a two week period.

Source: Google Covid hub 
Figure 4.7. Argentina: Covid-19, 2020

Daily deaths per million
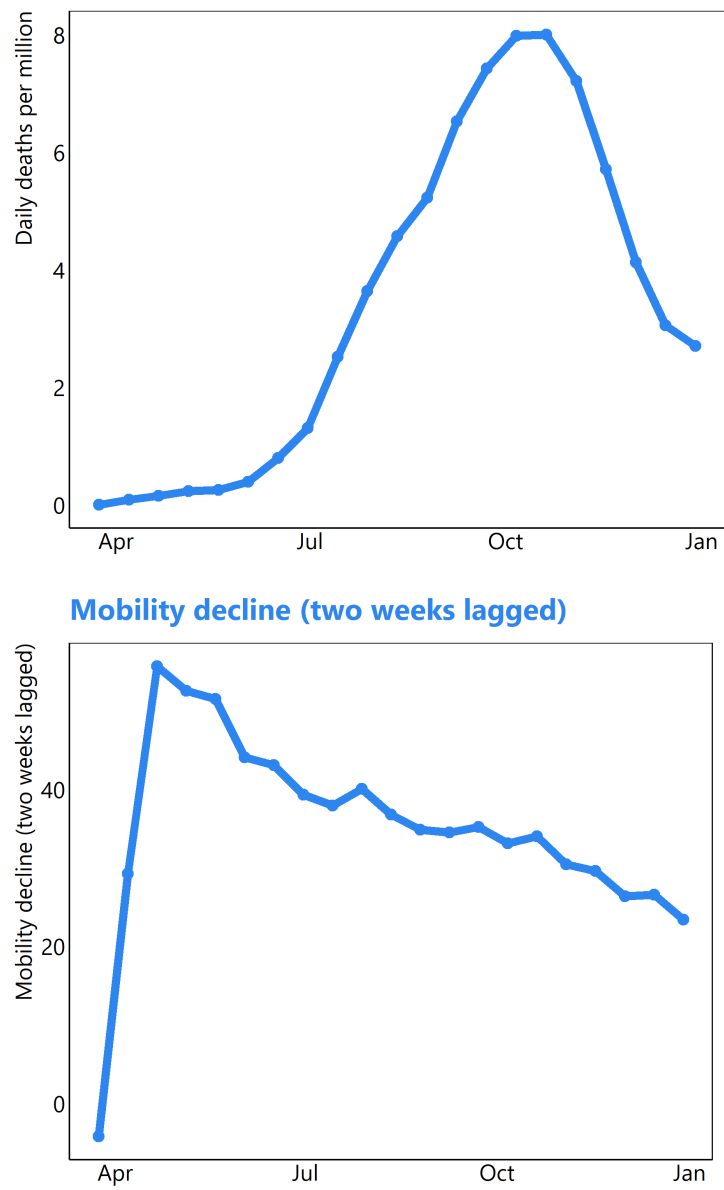

Growth Rates of New Deaths

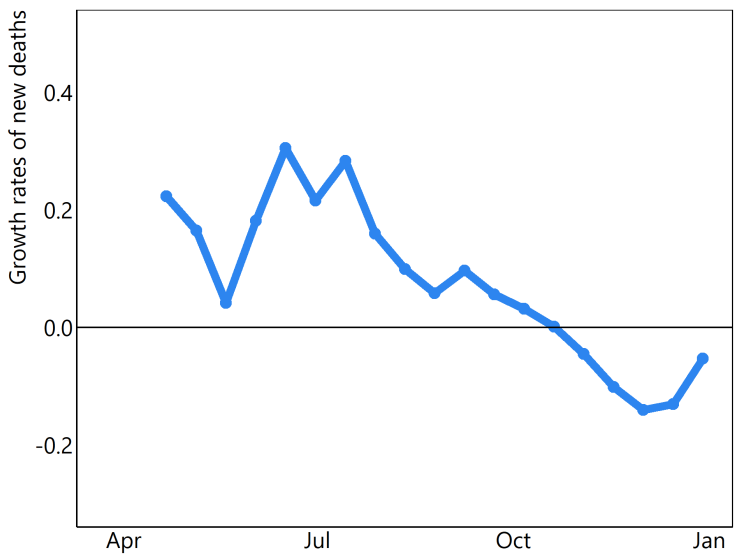

Deaths per million (two weeks lagged)

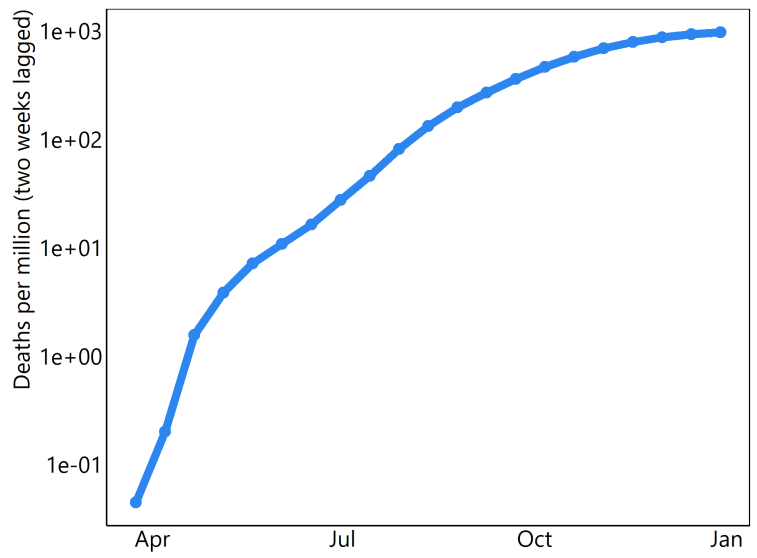

Temperature (two weeks lagged)

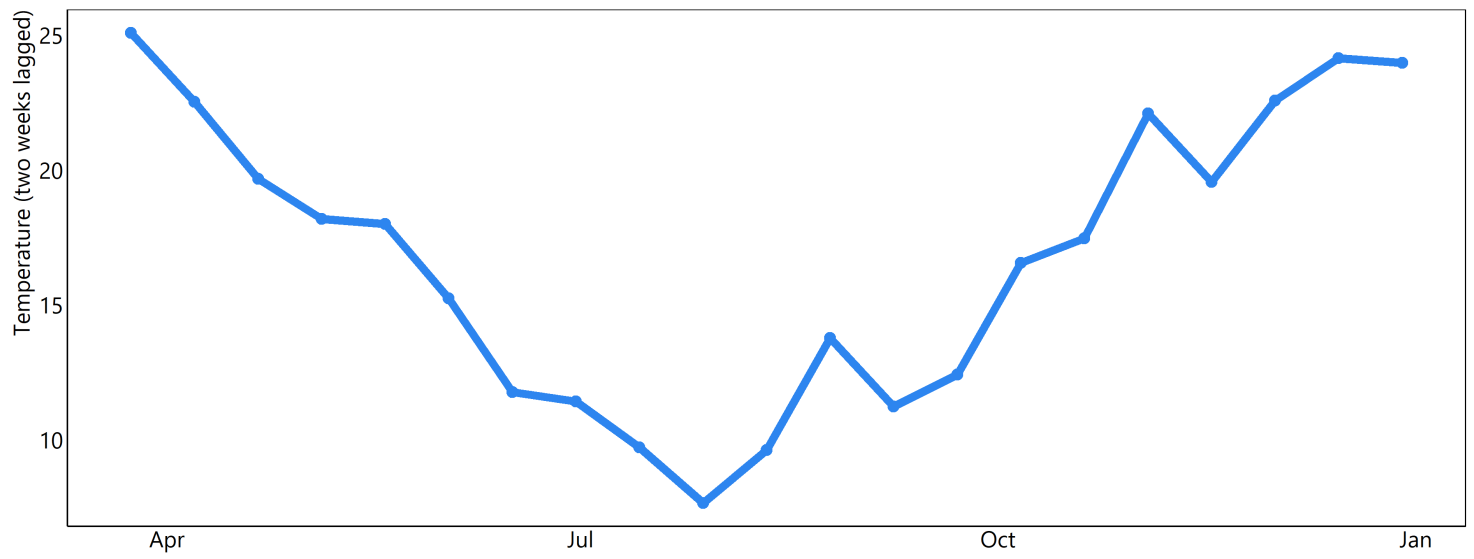

Each dot represents a two week period.

Source: Google Covid hub 


\subsection{Weak Institutional Capacity may Have Hampered the Effectiveness of Lockdowns}

The nature of work (informal) and living conditions (densely populated poor communities) as well as weak institutional capacity in Latin America may have hampered the effectiveness of lockdowns. Flattening the curve may be a challenge for countries with high degrees of economic informality and low government effectiveness - two features that are symptomatic of LAC region (Figures 4.8 and 4.9). ${ }^{18}$

Anecdotal evidence from Peru provides some indication of how these factors may have operated in practice and also points towards possible additional factors. In particular, crowded living conditions and agglomerations in food markets and banks may have contributed to the spread of the virus and diminished the effectiveness of the lockdowns. Limited financial inclusion and informal working conditions may have also contributed, as a nontrivial share of households needed to go to the banks in person to receive the government's cash transfers and also to do food purchases in cash in food markets.

\section{Regressions}

To show that government effectiveness matters, we add to the fixed effects regressions of Table 3 a variable that captures the interaction of stringency and government effectiveness (Table 4). ${ }^{19}$ The coefficient is highly significant, suggesting that in countries with lower government effectiveness, the same level of stringency will have less impact on the growth rate of new deaths. ${ }^{20}$

Our findings are similar if we use other, related, variables. In Table 5, we show that lower scores on the rule of law and higher informality (the share of employment in the informal sector) are associated with a lower impact of stringency. As government effectiveness is highly correlated with GDP per capita, we also tried GDP per capita itself, and the Human Development Index. These regressions yielded very similar results.

\footnotetext{
18 David and Pienknagura (2020) also find that countries where informality is commonplace, where a small share of jobs can be performed remotely, and where government effectiveness is low, experience smaller declines in COVID-19 cases after making containment measures more stringent. Other empirical work has identified that higher population density and weak health systems may also be a factor hampering the effectiveness of containment policies (Deb et al. (2020)).

${ }^{19}$ The government effectiveness indicator comes from the Worldwide Governance Indicators. See Kaufmann et al. (2010).

${ }^{20}$ Standard panel analysis is of course always subject to identification problems, meaning that jumping from a partial correlation to a claim of causality might be a strong leap of faith. Here, of particular concern are the coefficients of new deaths on stringency. Using lags attenuates the problem, but given the high serial correlation, does not solve it. Note however that the endogeneity in question - that is, more deaths causing lower higher stringency - carries a bias of positve sign: more deaths, higher stringency. This of course makes it hard to clearly identify a negative influence of stringency on deaths: it biases a supposedly negative effect towards zero. Now, we were able to find negative coefficients in spite of this bias. So the correct way to read our coefficients is that they represent a lower bound for the effect of stringency on deaths.
} 
Figure 4.8. Informality

(Percent)

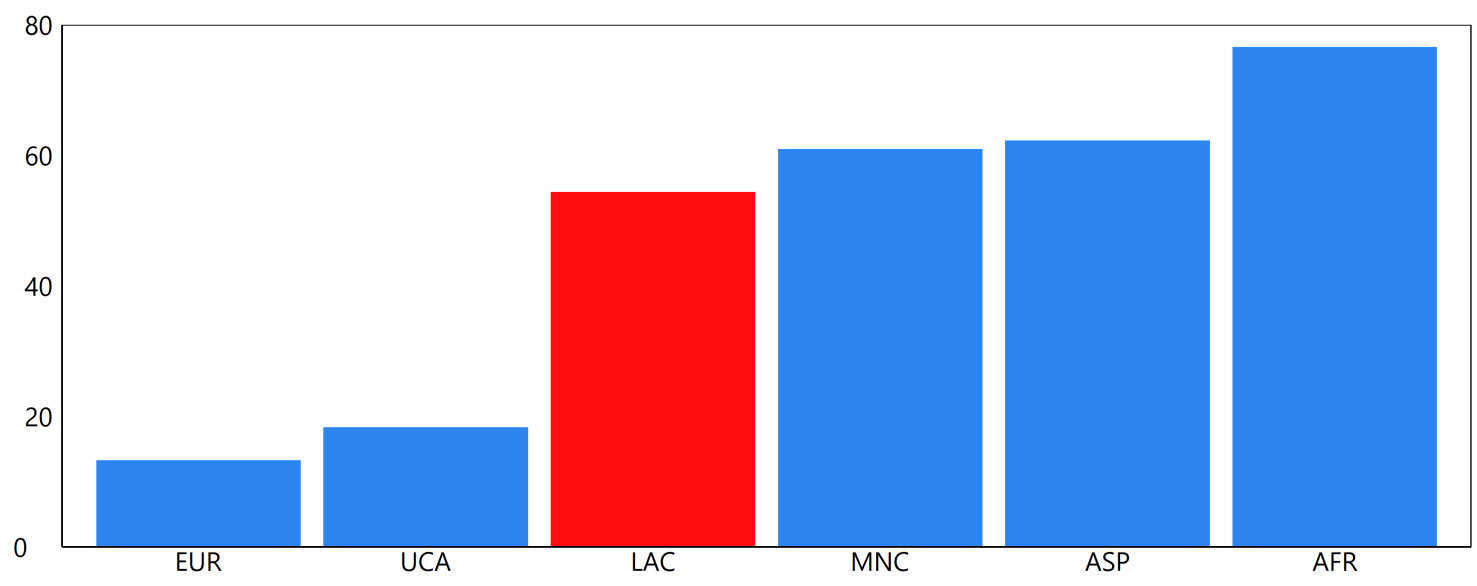

Source: ILO and IMF staff calculations.

ASP: Asia and Pacific. MNC: Middle East, North Africa, Central Asia.

UCA: United States and Canada.

Figure 4.9. Government effectiveness

(Higher is better, average by region)

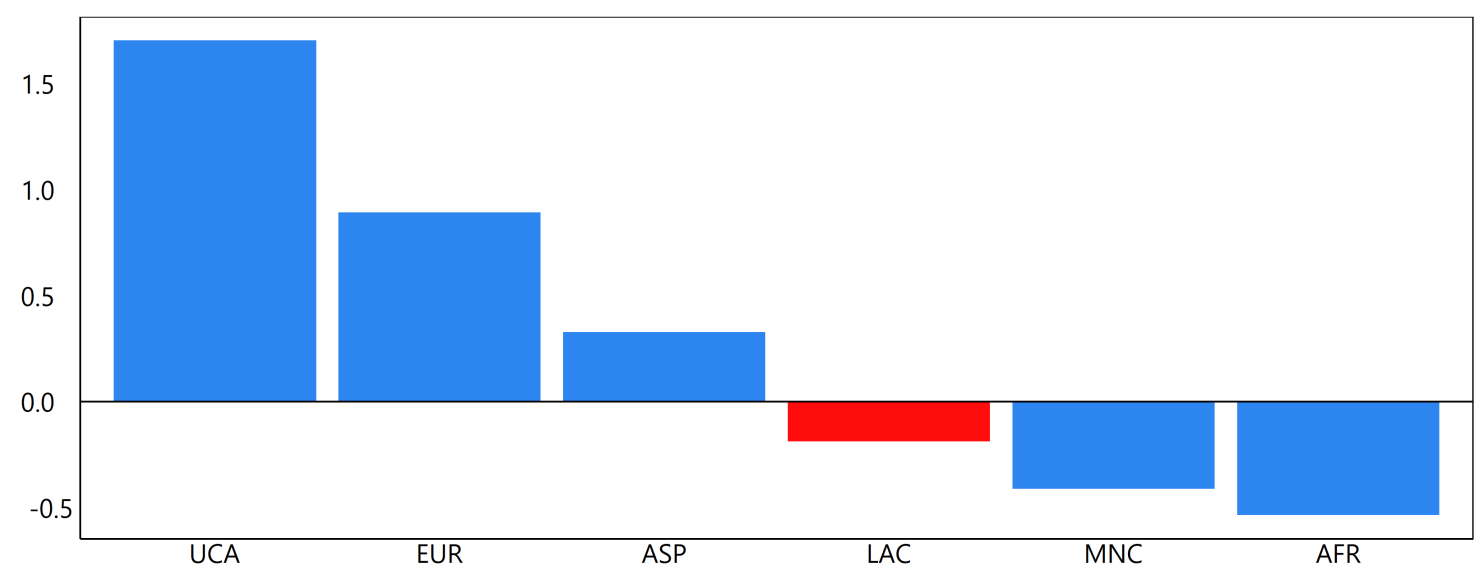

Source: Worldbank Worldwide Governance Indicators and IMF staff calculations. ASP: Asia and Pacific. MNC: Middle East, North Africa, Central Asia.

UCA: United States and Canada. 
Table 4: All Countries: Government Effectiveness and the Impact of Stringency on Covid-19

\begin{tabular}{|c|c|c|c|c|}
\hline & \multicolumn{4}{|c|}{ Dependent variable: } \\
\hline & \multicolumn{4}{|c|}{$\Delta \log$ new deaths per milion } \\
\hline & $(1)$ & $(2)$ & $(3)$ & $(4)$ \\
\hline Stringency $(t-1)$ & $\begin{array}{c}-0.009^{* * *} \\
(0.001)\end{array}$ & $\begin{array}{c}-0.008^{* * *} \\
(0.002)\end{array}$ & & \\
\hline Government effectiveness * Stringency $(\mathrm{t}-1)$ & & $\begin{array}{c}-0.002 \\
(0.002)\end{array}$ & & \\
\hline Mobility decline (t-1) & & & $\begin{array}{c}-0.006^{* * *} \\
(0.002)\end{array}$ & $\begin{array}{c}-0.006^{* *} \\
(0.003)\end{array}$ \\
\hline Government effectiveness * Mobility decline (t-1) & & & & $\begin{array}{l}-0.001 \\
(0.002)\end{array}$ \\
\hline log total deaths per million $(\mathrm{t}-1)$ & $\begin{array}{c}-0.410^{* * *} \\
(0.048)\end{array}$ & $\begin{array}{c}-0.393^{\text {*** }} \\
(0.050)\end{array}$ & $\begin{array}{c}-0.398^{* * *} \\
(0.053)\end{array}$ & $\begin{array}{c}-0.398^{* * *} \\
(0.053)\end{array}$ \\
\hline Temperature $(t-1)$ & $\begin{array}{c}-0.007^{* *} \\
(0.004)\end{array}$ & $\begin{array}{c}-0.008^{* *} \\
(0.004)\end{array}$ & $\begin{array}{c}-0.011^{* * *} \\
(0.004)\end{array}$ & $\begin{array}{c}-0.012^{* * *} \\
(0.004)\end{array}$ \\
\hline Observations & 636 & 636 & 582 & 582 \\
\hline $\mathrm{R}^{2}$ & 0.213 & 0.216 & 0.180 & 0.180 \\
\hline Adjusted $\mathrm{R}^{2}$ & 0.014 & 0.016 & -0.025 & -0.026 \\
\hline
\end{tabular}


Table 5: All Countries: Governance Related Variables and the Impact of Stringency on Covid

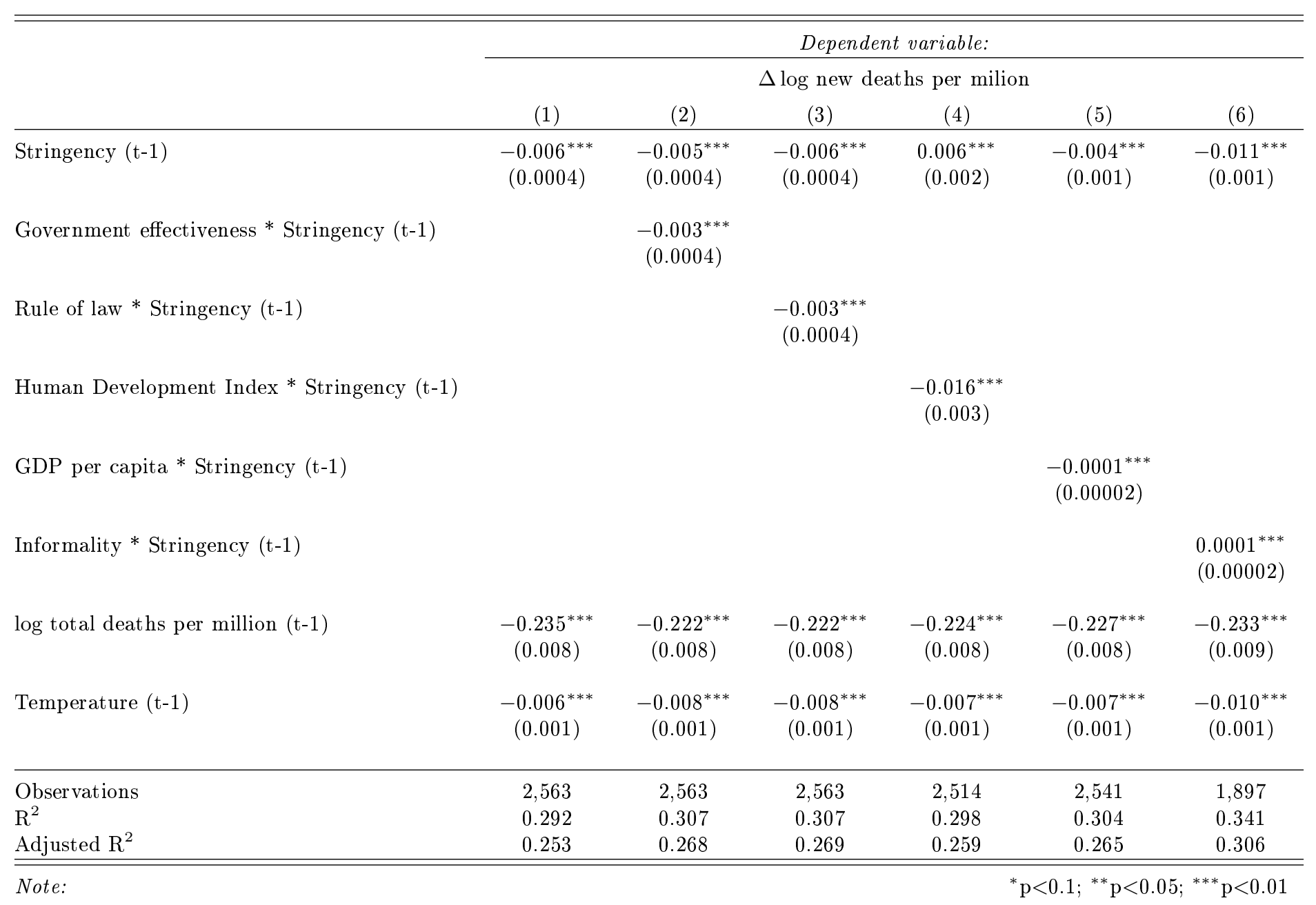




\section{Second Waves}

According to the model, two factors may play an important role in triggering second waves: increased mobility / lower stringency and lower temperatures.

- If mobility picks up / stringency is reduced, and the temperature does not change, the growth rate of new deaths will pick up again. If the mobility increase is sufficiently high, the growth rate will become positive, and a second wave may start. Figure 5.1 shows a simulation of the model in which after a while, stringency is gradually reduced. The result is a second wave.

- If the temperature drops, and mobility does not change, the growth rate of new deaths will pick up. If the temperature drop is sufficiently high, the growth rate will become positive, and a second wave may start.

\section{Figure 5.1. Second Waves}

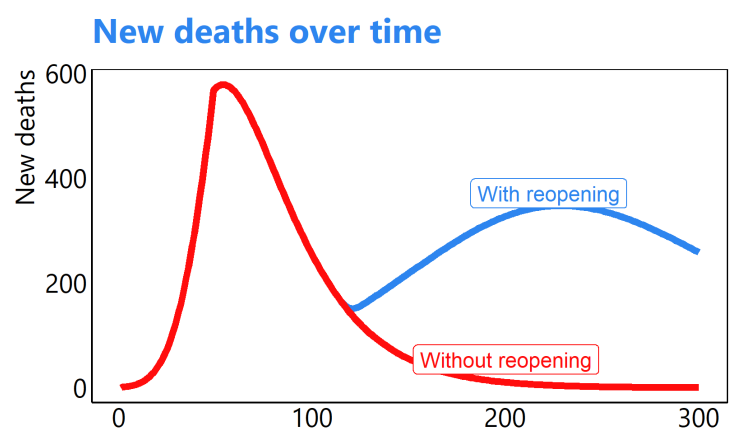

Total deaths versus new deaths

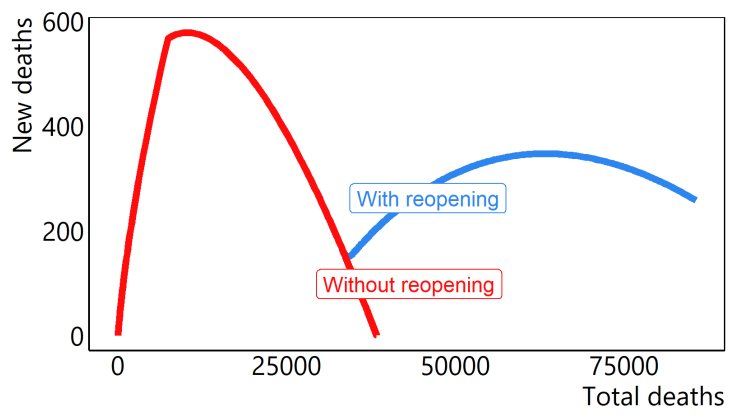

Source: Simulations

In many countries in the Northern Hemisphere, including in Italy, mobility picked up in the summer of 2020 (Figure 5.2), but daily deaths remained low. It is likely that the impact of increased mobility was offset by higher temperatures. In the fall, when temperatures dropped, this was no longer the case, and Covid deaths shot back up.

The increase in daily deaths in Mexico between October 2020 and January 2021 may also have been the result of the drop in temperature (Figure 5.3). When temperatures started to increase in February, the daily death toll started to decline again.

\section{New Variants}

Another factor that could trigger a second wave is the introduction of new, more contagious or more deadly variant. The P1 variant led to a very strong second wave in Manaus, Brazil in January 2021, even though the death toll stood already at two thousand per million (Figure 5.7). 
Figure 5.2. Italy: Covid-19
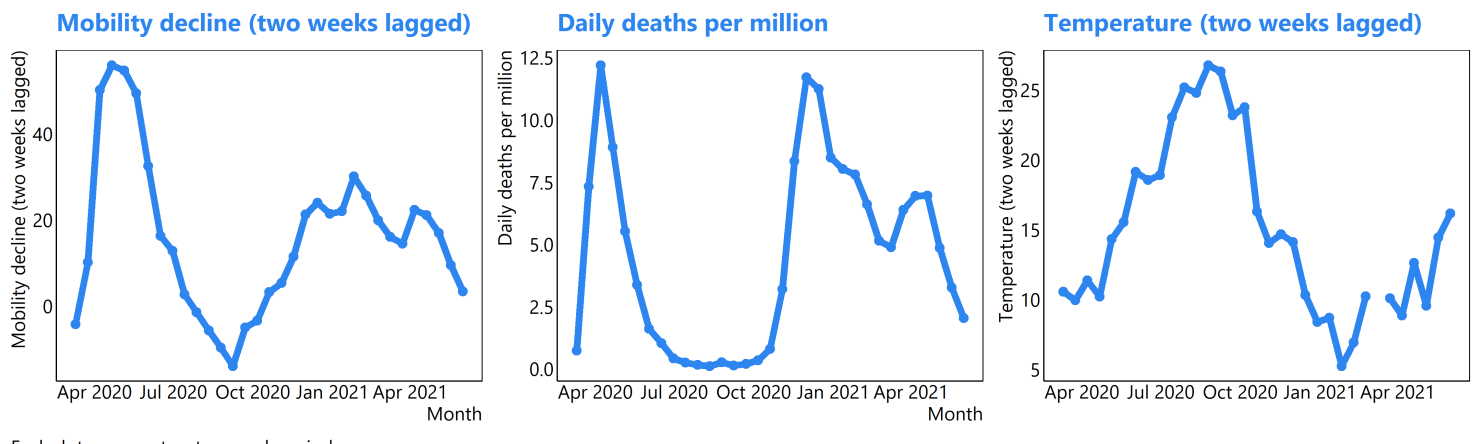

Each dot represents a two week period

Figure 5.3. Mexico: Covid-19

Mobility decline (two weeks lagged)
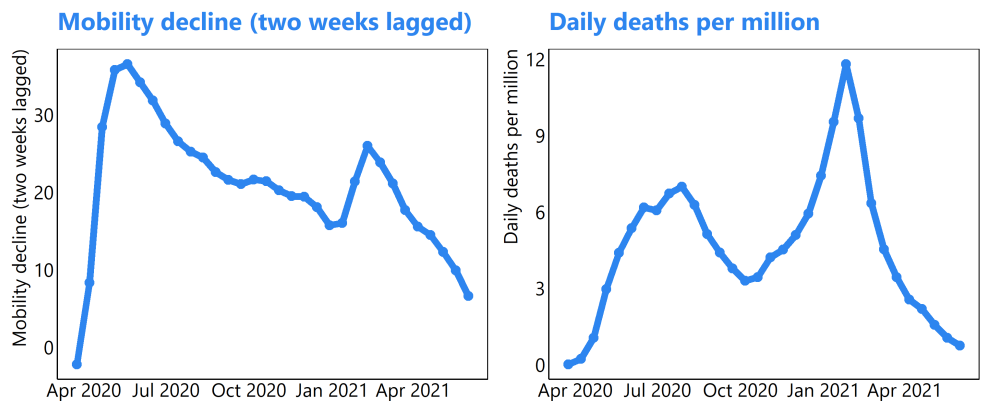

Temperature (two weeks lagged)

Fach dot represents a two week period.

Each dot represents a two we
Source: Google Covid hub

Figure 5.4. Manaus: Covid-19
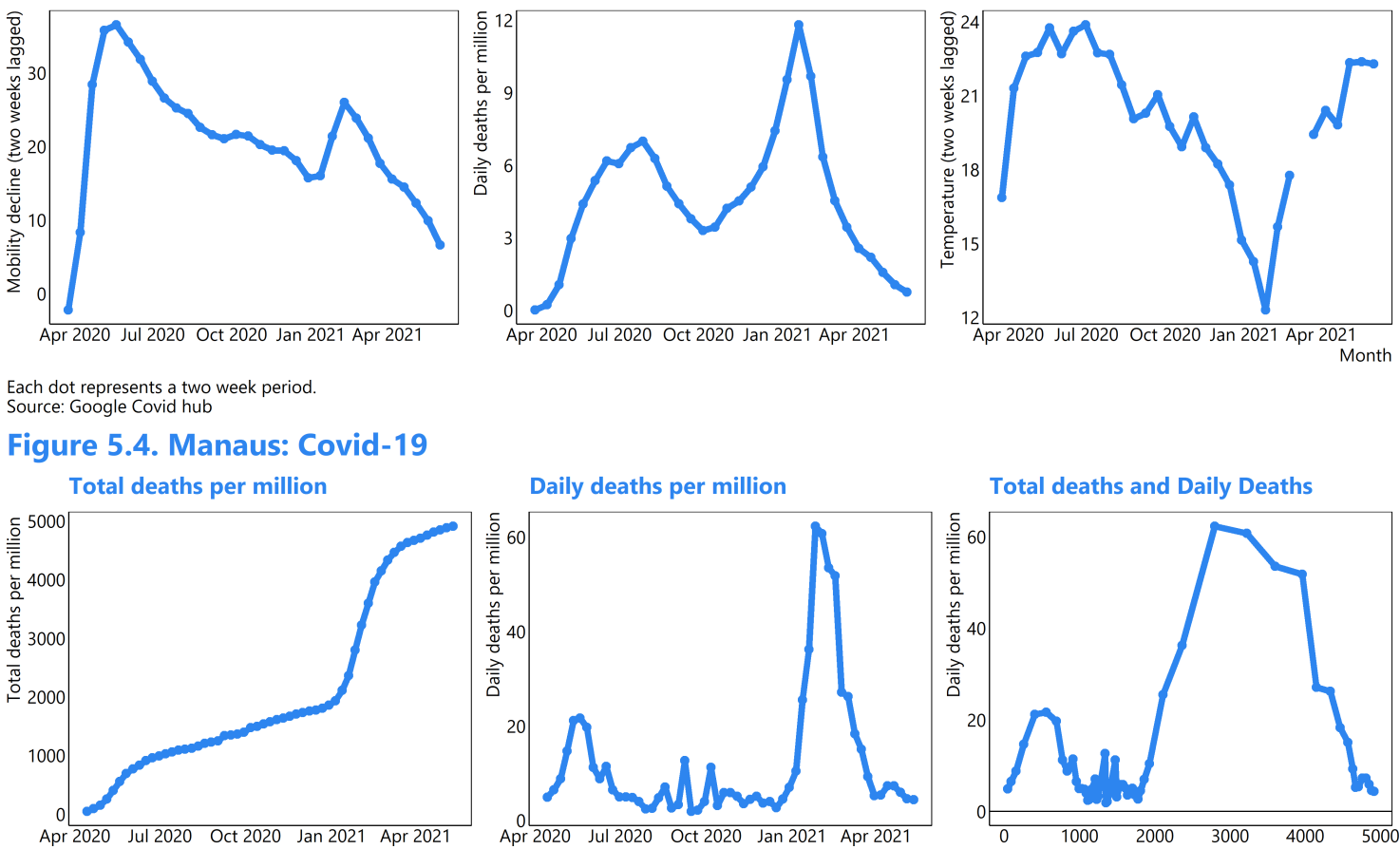

ach dot represents a week

Source: Google Covid hub 


\section{What Factors made Latin America Vulnerable?}

The dynamics of the covid related deaths were analyzed in section 4. Here we look at "structural determinants", that is country characteristics that go beyond the dynamics of the epidemic and that make countries more vulnerable. We identify five factors that help explain cross-country differences in deaths per million (Table 6): the percentage of the population that is overweight; the percentage of the population over 70; government effectiveness (higher effectiveness means fewer deaths for a given elderly population); hospital beds (more beds means fewer deaths for a given elderly population); and having a history of widespread BCG vaccination (against tuberculosis). ${ }^{21}$ The following messages arise from our analysis:

First, having an overweight population matters. If Mexico, where 61 percent of the population is overweight, would have had the same share of overweight people as Vietnam (14.7), Mexico would have $(61-14.7)^{*} 9.114=421$ deaths per million less at end February 2021 according to the fourth column of the table. ${ }^{22}$

Second, having an older population has a large impact on the number of deaths. For Italy, where government effectiveness is 0.50 and the number of hospital beds is 3.2 , a one percentage point higher share of the population over 70 is associated with (113.78$\left.25.903^{*} 0.5-3.362^{*} 3.2\right)=90.1$ per million more deaths. If the share of population over 70 in Italy had not been 16.2 percent but the same share as in Paraguay (3.8), Italy would have had $(16.2-3.8) * 90.1=1116$ fewer deaths per million.

Third, government effectiveness matters. In countries where government effectiveness is higher, the impact of having an older population on the number of deaths is lower. It could be that government effectiveness is a proxy for the quality of the health care system.

Fourth, hospital beds matter. In countries with more hospital beds, the impact of having an older population on the number of deaths is lower. If Italy would not have had 3.2 beds per thousand, but the same number as Germany ( 8 per thousand), the death toll according to the regressions would have been $(8-3.2)^{*} 16.2^{*} 3.362=261$ per million less. Note that the impact of hospital beds on deaths is less in countries where the share of the elderly population is lower.

Finally, having a history of widespread BCG vaccination matters. Countries without BCG vaccination have 442 deaths per million more than countries with vaccination.

Compared with Africa and Asia, South America has a much higher share of the popu-

\footnotetext{
${ }^{21}$ The inclusion of the BCG dummy is motivated by the known medical evidence that the Bacillus Calmette-Guérin has a general protective effect against a range of bacterial and viral diseases other than Tuberculosis. Rivas et al. (2021) tested more than 6,000 healthcare workers in the Cedars-Sinai Health System for evidence of antibodies to SARS-CoV-2 and crossed this with their vaccination histories. They found that workers who had received BCG vaccinations in the past (one third of the sample) were significantly less likely to test positive for SARS-CoV-2 antibodies or to report having had infections with coronavirus-associated symptoms over the prior six months than those who had not received BCG.

${ }^{22}$ As differences in new deaths in recent months are increasingly driven by differences in vaccination rates, we end the regressions at end February 2021.
} 
lation that is overweight (Figure 6.1). Compared with Europe, the share of the population over 70 is lower, but this is partly offset by lower government effectiveness and fewer hospital beds. We checked whether continent dummies were significant (column 5). The dummy for South America is significant only at the 10 percent level, and lower than the coefficient for Europe (which is significant at the 5 percent level). 
Table 6: Total deaths per million

\begin{tabular}{|c|c|c|c|c|c|}
\hline & \multicolumn{5}{|c|}{ Total deaths per million } \\
\hline & June & Oct & Dec & Feb & Feb \\
\hline & (1) & $(2)$ & (3) & (4) & (5) \\
\hline $\operatorname{Bcg}(y / n)$ & $\begin{array}{c}-259.102^{* * *} \\
(47.002)\end{array}$ & $\begin{array}{c}-357.832^{* * *} \\
(83.393)\end{array}$ & $\begin{array}{c}-400.052^{* * *} \\
(120.378)\end{array}$ & $\begin{array}{c}-442.657^{* * *} \\
(162.334)\end{array}$ & $\begin{array}{c}-463.518^{* * *} \\
(153.441)\end{array}$ \\
\hline Percent overweight & $\begin{array}{c}0.701 \\
(0.734)\end{array}$ & $\begin{array}{c}4.628^{* * * *} \\
(1.263)\end{array}$ & $\begin{array}{c}6.566^{* * *} \\
(1.800)\end{array}$ & $\begin{array}{c}9.114^{* * *} \\
(2.412)\end{array}$ & $\begin{array}{c}8.359^{* * *} \\
(2.549)\end{array}$ \\
\hline Percent over 70 & $\begin{array}{c}18.926^{* * *} \\
(5.340)\end{array}$ & $\begin{array}{c}25.959^{* * *} \\
(9.412)\end{array}$ & $\begin{array}{c}78.519^{* * *} \\
(13.495)\end{array}$ & $\begin{array}{c}113.780^{* * *} \\
(18.199)\end{array}$ & $\begin{array}{c}73.652^{* * *} \\
(22.548)\end{array}$ \\
\hline Government effectiveness * percent over 70 & $\begin{array}{l}-1.252 \\
(2.115)\end{array}$ & $\begin{array}{c}-9.850^{* * *} \\
(3.744)\end{array}$ & $\begin{array}{c}-22.057^{* * *} \\
(5.396)\end{array}$ & $\begin{array}{c}-25.903^{* * *} \\
(7.273)\end{array}$ & $\begin{array}{c}-17.853^{* *} \\
(7.116)\end{array}$ \\
\hline Hospital beds per thousand $*$ percent over 70 & $\begin{array}{c}-1.540^{* * *} \\
(0.500)\end{array}$ & $\begin{array}{c}-1.799^{* *} \\
(0.885)\end{array}$ & $\begin{array}{c}-2.344^{*} \\
(1.273)\end{array}$ & $\begin{array}{c}-3.362^{*} \\
(1.717)\end{array}$ & $\begin{array}{l}-2.718 \\
(1.677)\end{array}$ \\
\hline Asia & & & & & $\begin{array}{l}-48.259 \\
(90.962)\end{array}$ \\
\hline Europe & & & & & $\begin{array}{c}332.709^{* *} \\
(166.646)\end{array}$ \\
\hline North America & & & & & $\begin{array}{c}13.136 \\
(138.069)\end{array}$ \\
\hline Oceania & & & & & $\begin{array}{c}-697.045^{* *} \\
(288.831)\end{array}$ \\
\hline South America & & & & & $\begin{array}{l}240.811^{*} \\
(141.632)\end{array}$ \\
\hline Constant & $\begin{array}{c}208.0666^{* * *} \\
(59.668)\end{array}$ & $\begin{array}{l}221.686^{* *} \\
(104.297)\end{array}$ & $\begin{array}{c}66.488 \\
(149.692)\end{array}$ & $\begin{array}{l}-29.771 \\
(201.351)\end{array}$ & $\begin{array}{c}135.796 \\
(197.510)\end{array}$ \\
\hline$N$ & 126 & 129 & 131 & 132 & 132 \\
\hline $\mathrm{R}^{2}$ & 0.459 & 0.356 & 0.514 & 0.554 & 0.624 \\
\hline Adjusted $R^{2}$ & 0.437 & 0.330 & 0.495 & 0.536 & 0.593 \\
\hline
\end{tabular}


Figure 6.1. Deaths per million as of End February 2021
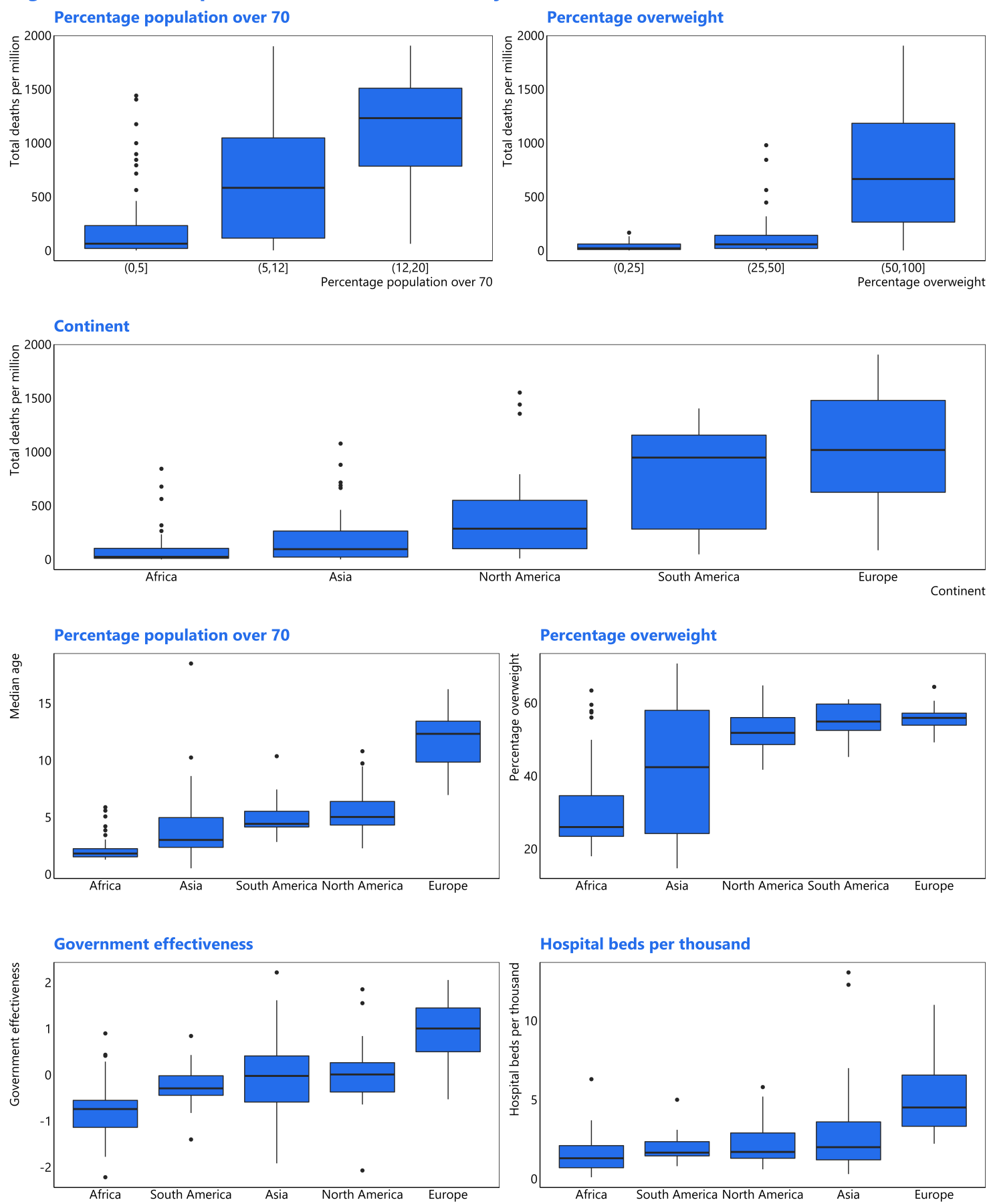


\section{Density and Temperature}

We next try to find the impact of temperature and density. These factors are hard to tease out using country-wide data. The average population density of the US is low, but deaths were very high in New York-where population density is very high.

We therefore used data at the municipality level for four Latin American countries for which information on population structure and density are available at this level of disagreggation. ${ }^{23}$ We regressed deaths per million as of end February 2021 on the share of population over 70 , the average temperature in the past year, the size of the population, and population density. We used both pooled regression and fixed effects regression - the later both using country fixed effects and states fixed effects.

All variables are highly significant. Both density and population matter, and their impact is important. According to column 3, a city of 1 million people has 362 deaths per million more than a city of 10 thousand people. Going from a population density of 1 thousand to 10 thousand people per square kilometer, raises the death toll by 152 per million. Temperature matters too: municipalities where the average annual temperate is above 20 degree celsius have 127 deaths per million less than those whether the temperature is less.

Table 7: Total deaths per million in municipalities in Argentina, Brazil, Mexico, and Peru

\begin{tabular}{|c|c|c|c|}
\hline & $\begin{array}{c}\text { Pooled } \\
(1) \\
\end{array}$ & $\begin{array}{l}\text { Total deaths per mill } \\
\text { Countries fixed effects } \\
(2)\end{array}$ & States fixed effects \\
\hline Percent population over 70 & $\begin{array}{c}18.263^{* * *} \\
(2.612)\end{array}$ & $\begin{array}{c}18.327^{* * *} \\
(2.692)\end{array}$ & $\begin{array}{c}23.680^{* * *} \\
(2.741)\end{array}$ \\
\hline Average temperature $>20(\mathrm{y} / \mathrm{n})$ & $\begin{array}{c}-110.208^{* * *} \\
(18.102)\end{array}$ & $\begin{array}{c}-89.767^{* * *} \\
(19.111)\end{array}$ & $\begin{array}{c}-127.326^{* * *} \\
(30.364)\end{array}$ \\
\hline Log10 Population & $\begin{array}{c}195.246^{* * *} \\
(16.315)\end{array}$ & $\begin{array}{c}235.735^{* * *} \\
(17.377)\end{array}$ & $\begin{array}{c}181.483^{* * *} \\
(18.089)\end{array}$ \\
\hline $\log 10$ Density & $\begin{array}{c}102.365^{* * *} \\
(11.693)\end{array}$ & $\begin{array}{c}91.035^{* * *} \\
(11.976)\end{array}$ & $\begin{array}{c}152.139^{* * *} \\
(13.519)\end{array}$ \\
\hline Constant & $\begin{array}{c}-326.455^{* * *} \\
(69.267)\end{array}$ & & \\
\hline$N$ & 8,732 & 8,732 & 8,732 \\
\hline $\mathrm{R}^{2}$ & 0.052 & 0.055 & 0.052 \\
\hline Adjusted $\mathrm{R}^{2}$ & 0.051 & 0.055 & 0.041 \\
\hline
\end{tabular}

\footnotetext{
${ }^{23}$ Argentina, Brazil, Canada, Mexico, Peru.
} 


\section{The Impact of Lockdowns and Fear on Economic Activity and Mobility}

We raise the question what impact the Covid epidemic had on economic activity in Latin America. To what extent was the drop in activity the result of stringency (i.e., policies) and what was the role of fear (i.e., behavior changes that were not the result of policies, and would have occurred even in the absence of government intervention)? We will proxy fear by the number of deaths. ${ }^{24}$

\subsection{The Impact of Covid-19 on Economic Growth}

We first investigate whether growth in countries with higher stringency and more deaths fell further short relative to pre-Covid forecasts than growth in countries with less stringency and fewer deaths. We would expect higher stringency to be associated with growth shortfalls, as higher stringency in 2020 was associated with sharper drops in mobility (Figure 7.1, left panel). The link between total deaths per million and the mobility decline is much weaker (Figure 7.1, right panel).

Figure 7.1. Stringency and Death Toll versus Mobility in 2020, Europe and Americas

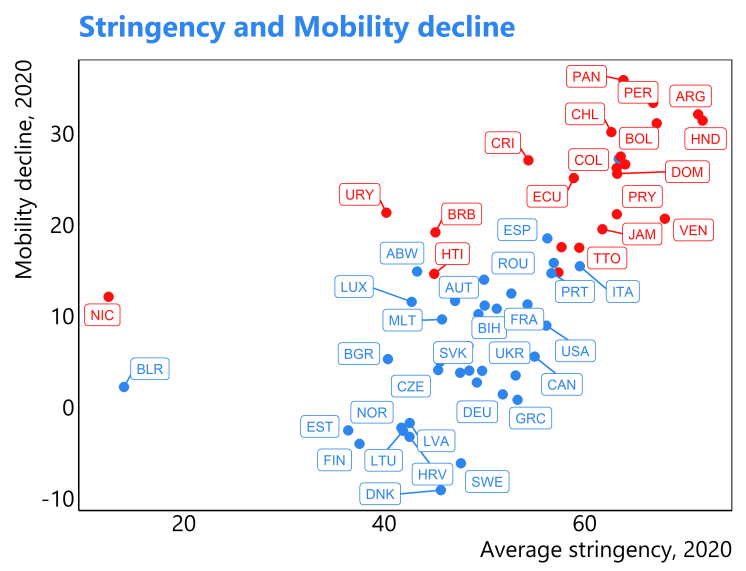

Deaths per million and Mobility Decline

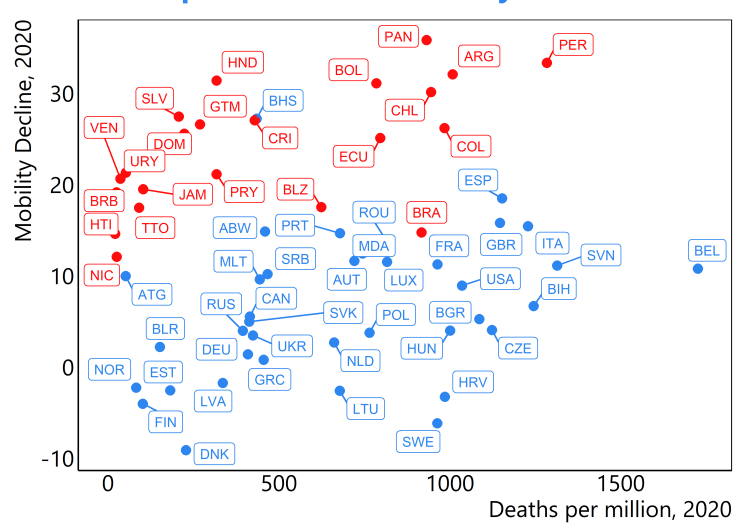

Latin America is red, Europe, US and Canada are blue.

As pre-Covid forecast we take the 2020 forecast in the IMF's October 2019 World Economic Outlook database. We compare this with the estimate in the April 2021 WEO database - which at the time of this writing was the latest available estimate.

\footnotetext{
${ }^{24} \mathrm{~A}$ similar type of analysis is carried out in Chapter 2 of the IMF's October 2020 World Economic Outlook (International Monetary Fund (2020)), showing that both stringency and "voluntary" distancing were important factors behind the economic slump. What the WEO calls "voluntary distancing" we dub a bit more grimly as "fear effect" here. And instead of using cases, which were poorly measured at the beginning of the pandemics, we use deaths per million.
} 
We regress the forecast error on the tourism export share, deaths per million and average stringency (Table 8). We show regression results for all countries ${ }^{25}$ (column 1), all countries excluding countries with a high tourism export share ${ }^{26}$ (column 2), all countries in Europe and the Americas (column 3) and all countries in Europe and the Americas excluding high tourism export share countries (column 4)).

The regressions suggest that both stringency and deaths toll mattered. However, the quantitative importance of stringency was higher. Take Chile, which had 945 deaths per million in 2020, and an average stringency index of 63 . According to the coefficients in column 4 , the contribution of stringency to the forecast error was 7.2 percentage points and the contribution of the death toll was 1.9 percentage point. ${ }^{27}$

Table 8: WEO Forecast error of 2020 GDP growth

\begin{tabular}{|c|c|c|c|c|}
\hline & $\begin{array}{l}\text { All } \\
(1)\end{array}$ & $\begin{array}{l}\text { All excl. high tourism } \\
\text { (2) }\end{array}$ & $\begin{array}{l}\text { Growth forecast error } \\
\text { Europe and Americas } \\
(3)\end{array}$ & $\begin{array}{l}\text { Europe and America excl. high tourism } \\
\qquad(4)\end{array}$ \\
\hline Tourism export share & $\begin{array}{c}-0.158^{* * *} \\
(0.028)\end{array}$ & $\begin{array}{c}-0.383^{* * *} \\
(0.089)\end{array}$ & $\begin{array}{c}-0.124^{* * *} \\
(0.032)\end{array}$ & $\begin{array}{c}-0.261^{* * *} \\
(0.089)\end{array}$ \\
\hline Stringency & $\begin{array}{l}-0.055 \\
(0.038)\end{array}$ & $\begin{array}{c}-0.121^{* * *} \\
(0.032)\end{array}$ & $\begin{array}{c}-0.136^{* * *} \\
(0.039)\end{array}$ & $\begin{array}{c}-0.115^{* * *} \\
(0.028)\end{array}$ \\
\hline Deaths per million & $\begin{array}{c}-0.002^{* *} \\
(0.001)\end{array}$ & $\begin{array}{l}-0.001 \\
(0.001)\end{array}$ & $\begin{array}{c}-0.002^{* *} \\
(0.001)\end{array}$ & $\begin{array}{c}-0.002^{* *} \\
(0.001)\end{array}$ \\
\hline Constant & $\begin{array}{l}-2.429 \\
(1.994)\end{array}$ & $\begin{array}{c}2.107 \\
(1.755)\end{array}$ & $\begin{array}{l}2.008 \\
(2.053)\end{array}$ & $\begin{array}{c}1.560 \\
(1.480)\end{array}$ \\
\hline$N$ & 82 & 58 & 42 & 34 \\
\hline $\mathrm{R}^{2}$ & 0.329 & 0.438 & 0.511 & 0.591 \\
\hline Adjusted $\mathrm{R}^{2}$ & 0.303 & 0.407 & 0.472 & 0.550 \\
\hline
\end{tabular}

Notes:

*** Significant at the 1 percent level

${ }^{* *}$ Significant at the 5 percent level.

* Significant at the 10 percent level.

\footnotetext{
${ }^{25}$ We have excluded large oil exporters and a few outliers (Libya, Lebanon, Macao (which had a growth shortfall of 50 percent) and Guyana (an outlier, with a growth shortfall of 65 percent).

${ }^{26}$ We define high tourism share countries as countries where the share of tourism in total exports exceeds 15 percent. We exclude these countries as they were hit hard by Covid, but not necessarily by Covid in their own country.

${ }^{27}$ The forecast error predicted by the model (9.1 percent) was close to the actual forecast error (8.9 percent).
} 


\section{LAC Panel Regressions}

Next, we look at monthly activity in 2020 in 16 Latin American countries. Figure 7.2 suggests that the decline in activity in the Spring was principally the result of the increase in stringency and that the increase in deaths played less of a role.

The chart also suggests that the impact of stringency declined over time. Indeed by the end of the year, year-on-year activity growth was almost back to zero, even though stringency levels were still well above pre-Covid levels. The charts suggest that this was because the impact of stringency on mobility declined over time.

Regressions of activity on stringency and monthly deaths (Table 9) confirm that stringency was the most important, and that its impact declined over time. ${ }^{28}$ The $R^{2}$ of the equation that includes stringency (column 1) is much higher than the equation that includes monthly deaths, which is not statistically significant (column 3). If we add the interaction of a month index and stringency (column 2), the coefficient is highly significant and positive, suggesting that the impact of stringency declined over time. If we add the interaction of a month index and monthly deaths (column 4), the coefficient is also positive and statistically significant, but it is far too large - after month 9 the total impact of deaths on mobility flips sign and becomes positive. If we add monthly deaths to an equation that includes stringency, the coefficient is not significant (column 5). If we also add the interaction of a month index and monthly deaths, the coefficient is again too large (column 6).

In short, in Latin America, both stringency and daily deaths affected economic activity, but the impact of the former was quantitatively more important. The stringent lockdowns in the second quarter of 2020 led to a sharp downturn in Latin America. Thereafter stringency was eased and the impact of stringency on activity declined, leading to a recovery in the second half of 2020. But for the year as a whole, the impact was significant.

\footnotetext{
${ }^{28}$ Goldstein et al. (2020) also finds that the impact of lockdowns declines over time. Yeyati and Sartorio (2020) document a generalized and increasing non-compliance of lockdowns over time, which is significantly higher in emerging and developing economies.
} 
Figure 7.2. Latin America: Stringency, Deaths and Economic Activity in 2020

Stringency and Activity
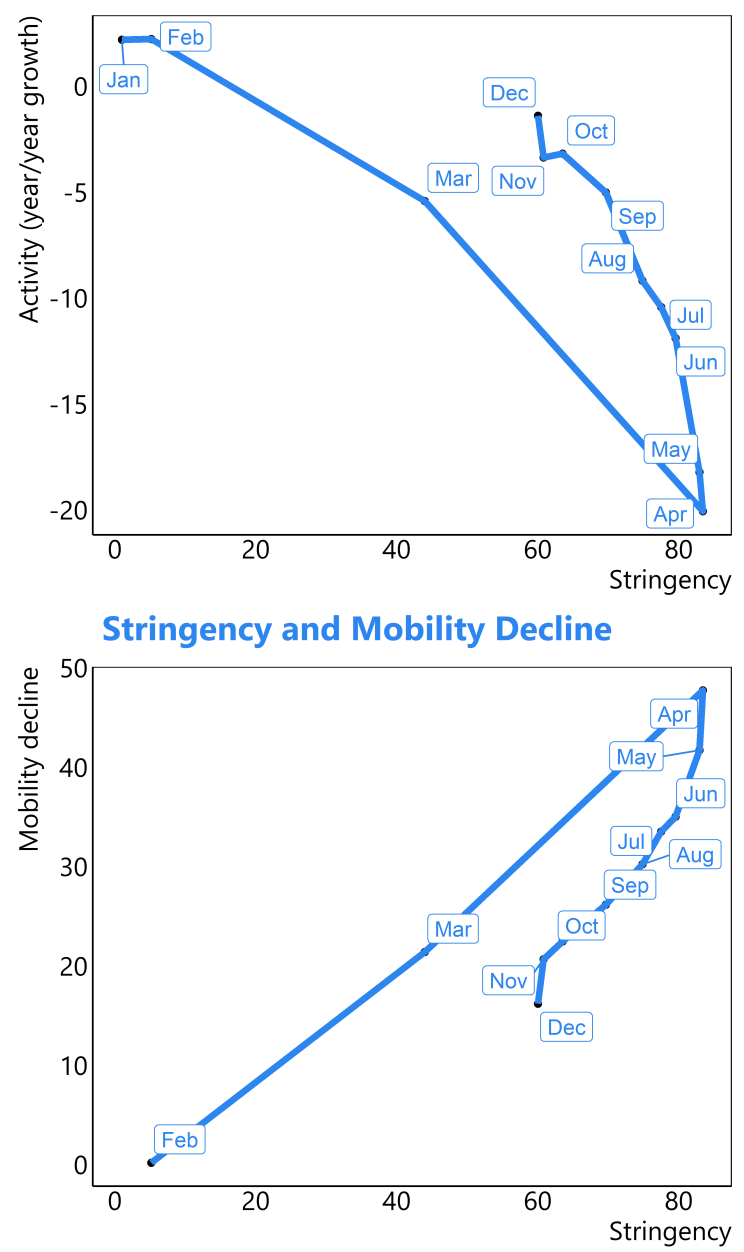

Monthly deaths and Activity

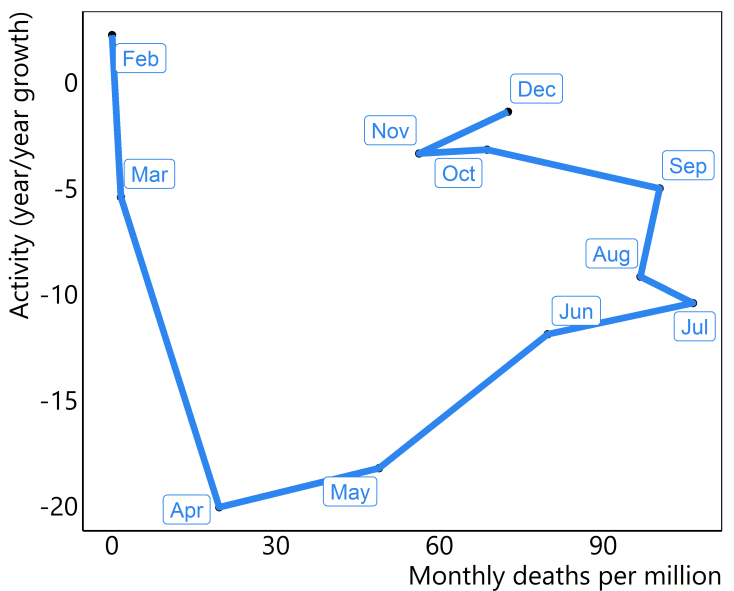

Mobility Decline and Activity

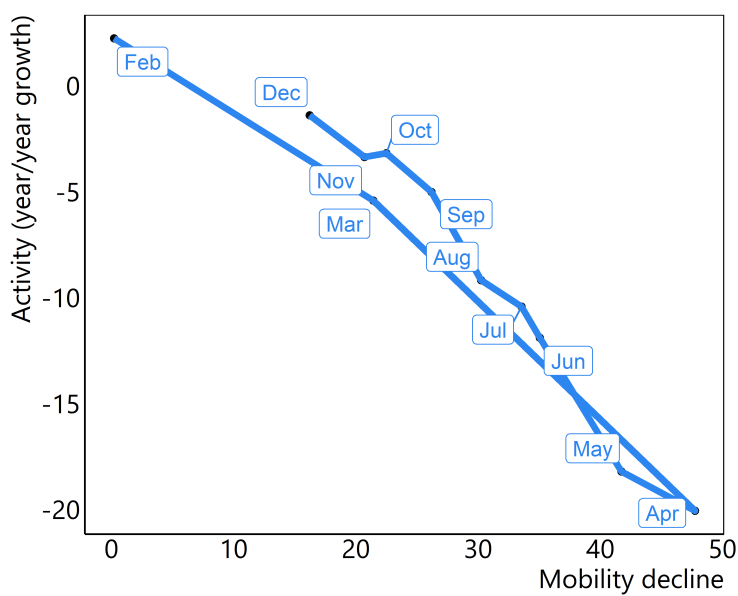

Unweighted average of 16 Latin American countries.

Source: Haver, Google Covid Hub 
Table 9: Latin American Countries: Regressions of activity on stringency and monthly deaths, 2020.

\begin{tabular}{|c|c|c|c|c|c|c|}
\hline & \multicolumn{6}{|c|}{ Dependent variable: } \\
\hline & \multicolumn{6}{|c|}{ Year-on-year growth of activity } \\
\hline & (1) & $(2)$ & $(3)$ & $(4)$ & $(5)$ & (6) \\
\hline Stringency $(\mathrm{t})$ & $\begin{array}{c}-0.217^{* * *} \\
(0.020)\end{array}$ & $\begin{array}{c}-0.371^{* * *} \\
(0.018)\end{array}$ & & & $\begin{array}{c}-0.369^{* * *} \\
(0.018)\end{array}$ & $\begin{array}{c}-0.340^{* * *} \\
(0.022)\end{array}$ \\
\hline $\mathrm{t} *$ Stringency $(\mathrm{t})$ & & $\begin{array}{c}0.024^{* * *} \\
(0.002)\end{array}$ & & & $\begin{array}{c}0.025^{* * *} \\
(0.002)\end{array}$ & $\begin{array}{c}0.021^{* * *} \\
(0.003)\end{array}$ \\
\hline Monthly deaths per million ( $\mathrm{t}$ ) & & & $\begin{array}{l}-0.014 \\
(0.011)\end{array}$ & $\begin{array}{c}-0.207^{* * *} \\
(0.025)\end{array}$ & $\begin{array}{l}-0.009 \\
(0.007)\end{array}$ & $\begin{array}{c}-0.048^{* *} \\
(0.019)\end{array}$ \\
\hline $\mathrm{t}^{*}$ Monthly deaths per million $(\mathrm{t})$ & & & & $\begin{array}{c}0.024^{* * *} \\
(0.003)\end{array}$ & & $\begin{array}{c}0.005^{* *} \\
(0.002)\end{array}$ \\
\hline Observations & 175 & 175 & 175 & 175 & 175 & 175 \\
\hline $\mathrm{R}^{2}$ & 0.426 & 0.736 & 0.012 & 0.319 & 0.739 & 0.747 \\
\hline Adjusted $\mathrm{R}^{2}$ & 0.368 & 0.707 & -0.088 & 0.245 & 0.709 & 0.716 \\
\hline
\end{tabular}




\subsection{What Explains the Sharp Drop in Mobility in Latin America-Policies or Fear?}

One drawback of using economic activity indicators is that for most countries they are available at a low frequency (typically monthly) only, and with significant delays. Moreover, sub-national data are available only with much longer delays.

An alternative for using economic activity data is using mobility data. These are available at a daily frequency, with only a few weeks delay; they exist for subnational levels; and they are a good proxy for economic activity.

It is difficult to disentangle whether the sharp decline in mobility in Latin America was the result of the lockdown, or of behavior changes that would have occurred even in the absence of lockdowns. Did mobility drop because people were ordered to stay at home, or because they opted to stay home, as they were afraid to get infected?

In countries with stricter lockdowns, mobility declined more. However, that does not necessarily mean that the sharp mobility declines were the result of the lockdowns. It could well be that the same fear that led countries to impose strict lockdowns, also resulted in a sharp decline in mobility that would have occurred even in the absence of lockdowns.

Regression analysis of cross-country differences cannot settle this issue either. The death toll was very low when Latin America locked down, but fear must have been high-otherwise countries would not have locked down.

Regression analysis of mobility differences within countries can shed some light on the importance of the behavior factor. To mitigate endogeneity concerns, we perform the analysis on the data from two countries that introduced nation-wide lockdowns early on in the pandemic when the new cases and deaths were still low, namely, Peru and Argentina. We compare weekly mobility of regions within these countries over time and assume that the stringency index for each region was the same as the nation-wide stringency index. ${ }^{29}$

We are particularly interested in two questions. First, has mobility been lower in regions with higher daily deaths? Second, why did mobility pick up even though daily deaths tolls continued rising? Has the impact of stringency on mobility declined over time, or has the impact of daily deaths on mobility diminished? We test this through the interaction of a time index with the stringency index and the interaction of a time index with the daily death toll. In all regressions, we use region fixed-effects, so all possible omitted variables that are not time-varying are accounted for and do not have a bearing on the estimated coefficients.

\footnotetext{
${ }^{29}$ For Latin American countries, the stringency index is only available at the national level.
} 
Table 10: Region fixed effects regressions of weekly mobility data in regions, 2020.

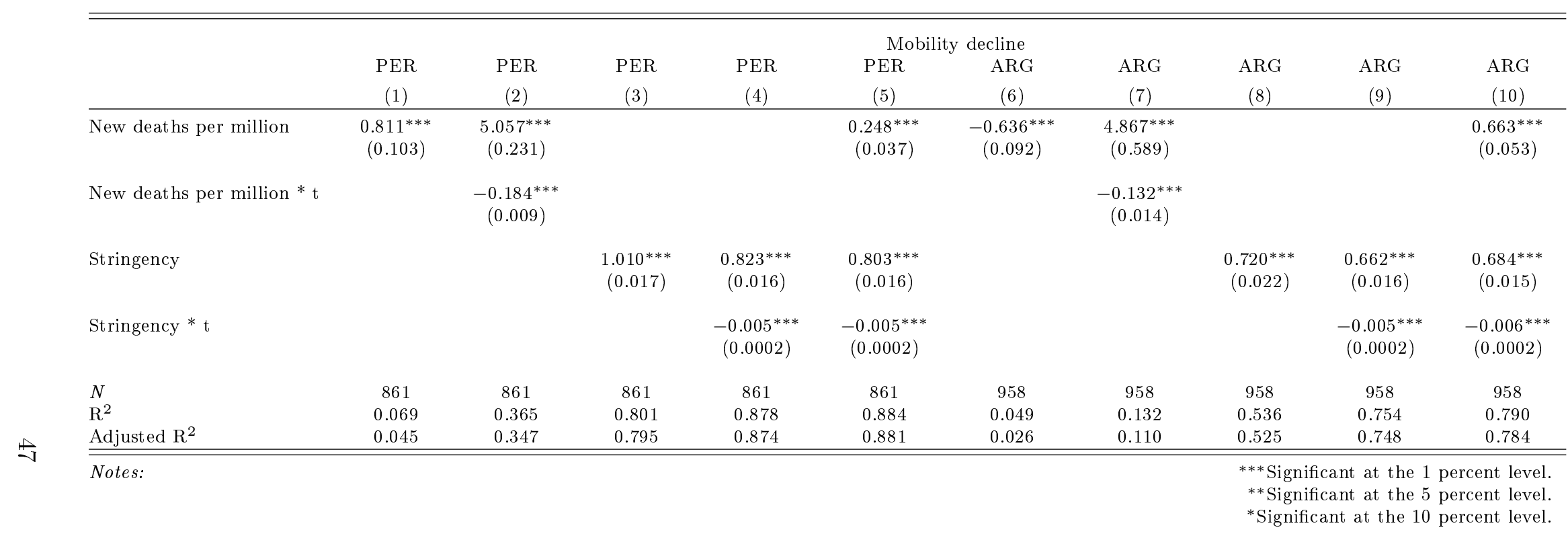


The results (Table 10) suggest that daily death tolls mattered, but they were quantitatively not as important as the impact of stringency.

- On its own, new deaths have little explanatory power. For Peru, the $R^{2}$ is low; and for Argentina the coefficient even has the wrong sign. ${ }^{30}$ Adding the interaction of a time index with daily deaths (column 2) increases the $R^{2}$. However, the coefficient of the interaction is so large that the total impact of new deaths on mobility switches sign after a while and more deaths are associated with higher mobility.

- On its own, stringency has a lot of explanatory power.The $R^{2}$ is high and the coefficients have the right sign. Adding the interaction of a time index with stringency increases the fit, and confirms that the impact of stringency on mobility declines over time, although the sign does not change.

- Adding new deaths to an equation that contains stringency slightly increases the fit, while the coefficient of new deaths has the right sign and is highly significant.

The contribution of new deaths to mobility can also be seen from a time fixed effect regression - in which we assess, how for a given time period, cross-region differences in mobility are determined by cross-region differences in mortality. As Figure 6.5 shows, there is some variation across regions in both mobility and new deaths. The time fixed effect regression essentially determines whether higher than average mortality in a given period is associated with lower than average mobility. As shown in Table 11, this is indeed the case.

Table 11: Time fixed effects regressions of weekly mobility data in regions, 2020

\begin{tabular}{lcc}
\hline \hline & \multicolumn{2}{c}{ Mobility decline } \\
& PER & ARG \\
& $(1)$ & $(2)$ \\
\hline New deaths per million & $0.482^{* * *}$ & $0.833^{* * *}$ \\
& $(0.045)$ & $(0.065)$ \\
$N$ & & \\
$\mathrm{R}^{2}$ & 861 & 1,332 \\
Adjusted $\mathrm{R}^{2}$ & 0.125 & 0.115 \\
\hline \hline \multirow{2}{*}{ Notes: } & 0.078 & 0.072 \\
& ${ }^{* * *}$ Significant at the 1 percent level. \\
& ** Significant at the 5 percent level. \\
& *Significant at the 10 percent level.
\end{tabular}

In summary, in Latin America the biggest impact on mobility came from stringency, but fear also played a role, and the impact of stringency on mobility declined over time.

\footnotetext{
${ }^{30} t$ is a time index for the week.
} 
Figure 7.3. Peru: Stringency, Deaths and Mobility in 2020

Daily deaths and Mobility decline

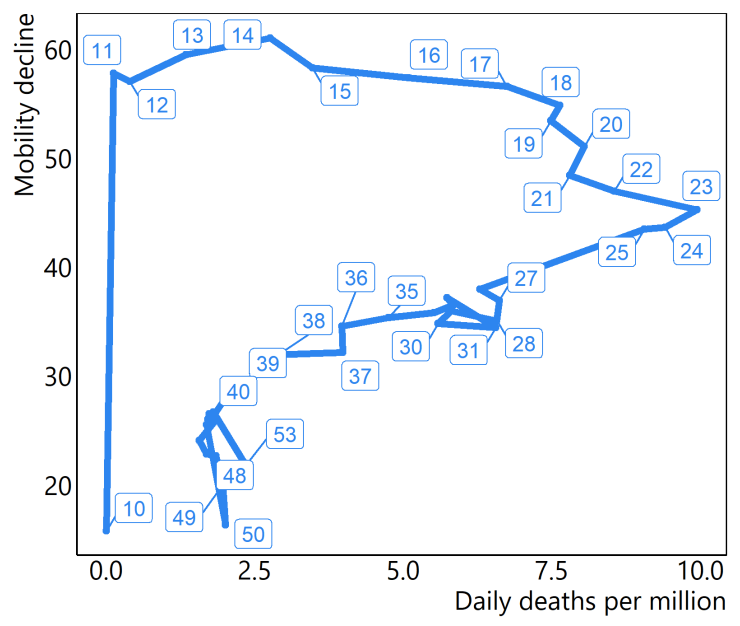

Stringency and Mobility decline

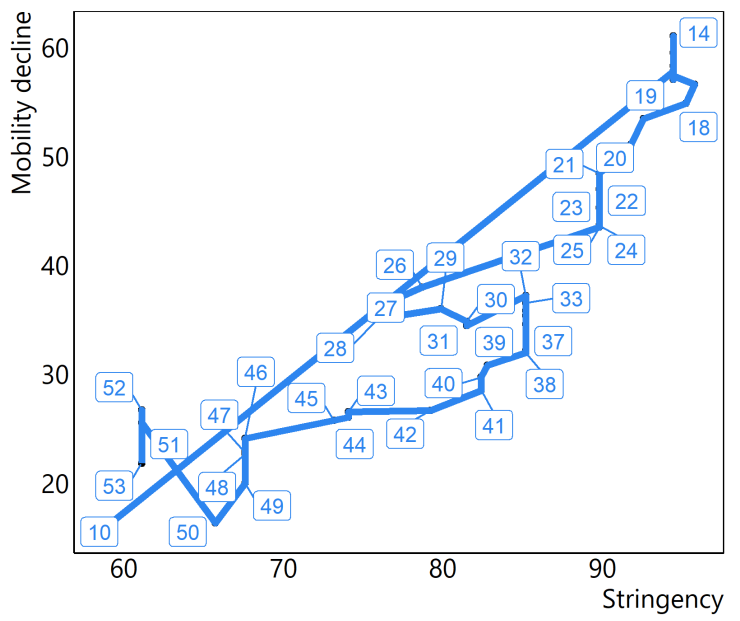

Numbers are week numbers.

Source: Google Covid Hub

Figure 7.4. Peruvian regions: Mobility Decline and Daily Deaths, 2020

Mobility decline

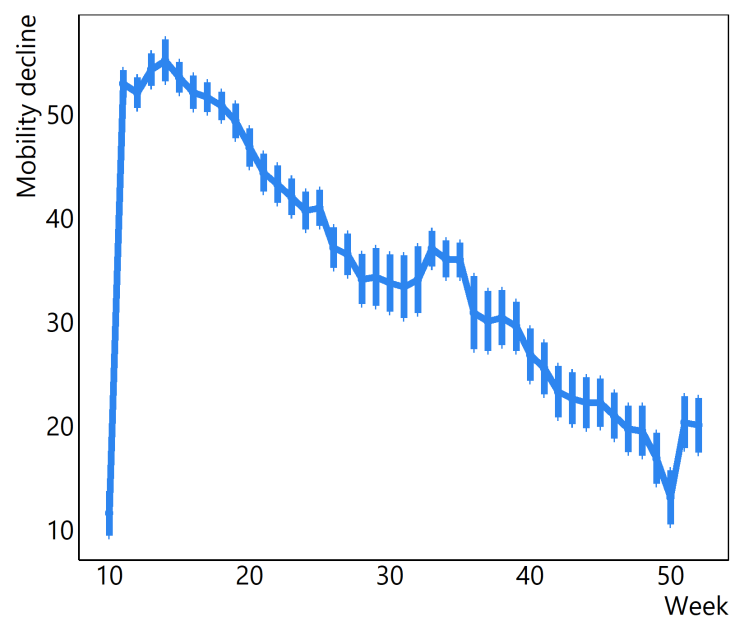

Deaths per million

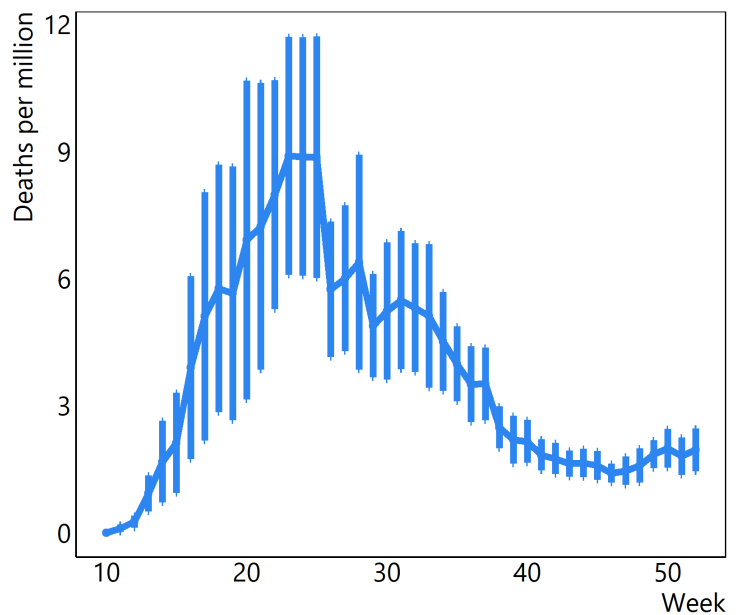

Unweighted average of 26 Peruvian regions. Error bars are 5th and 95th percentile.

Source: Google Covid Hub 


\section{The Future of the Pandemic in Latin America}

It is likely that the pandemic in Latin America will only end when herd immunity has been reached. Herd immunity happens when a virus cannot spread because it keeps encountering people who are protected against infection. Once a sufficient proportion of the population is no longer susceptible, any new outbreak peters out. Herd immunity can occur because people have had the disease, or because they have been vaccinated. Most estimates suggest that to acquire herd immunity, at least 70 percent of the population will need to be protected. ${ }^{31}$ Israel, where 59 percent of the population had been fully vaccinated as of May 12 , may have reached herd immunity. Daily new cases have dropped from 8300 in mid-January to 37 in mid-May.

Determining how close a country is to reaching herd immunity is not an easy exercise. One cannot simply add the official case count and the number of people that have been fully vaccinated, for two reasons.

- In many countries the official case count significantly underestimates the actual number of people that have been infected. In the United States, actual Covid-19 may be five times the official case count; ${ }^{32}$ and in many Latin American countries, the underestimation is likely to be more severe. ${ }^{33}$

- The group of people that has been vaccinated and the group that has had Covid-19 partly overlap.

In most countries in Latin America, it is likely that too few people have been vaccinated to reach herd immunity.

As of early-June, the rate of fully-vaccinated people in the five biggest countries in terms of population (Brazil, Mexico, Colombia, Argentina, Peru), ranged between 4 percent (Peru) and 11 percent (Brazil), compared with 41 percent in the US and 59 percent in Israel (Figure 8.1).

At the same time, new and more contagious variants are spreading. ${ }^{34}$ An example is the P1 virus in Brazil. Moreover, winter is approaching in the Southern Hemisphere, and

\footnotetext{
${ }^{31}$ See, for example, Fine et al. (2011).

32 A Columbia University study led by infectious disease specialist Jeffrey Shama suggested that at the end of January 2021 more than 120 million Americans had been infected; five times the official cases count (26.9 million), and just over a third of the population.

${ }^{33}$ In Mexico, according to official statistics, as of mid-May only 1.8 percent of the population of Mexico had been infected, compared with 11 percent in the United States. But the official Covid death-toll does not differ much (1797 per million in the US versus 1688 in Mexico). As the number of excess deaths in Mexico is more than two times the number of official deaths (See Annex A), it is likely that the number of actual cases per million in Mexico is well above that in the United States.

${ }^{34}$ More contagious variants also have a higher threshold for herd immunity. If every infected person infects 2 other persons, the epidemic will start to die out when more than half of the population has been infected. When every infected person infects 4 other persons, this only happens when 75 percent of the population has been infected.
} 
with lower temperatures infection rates may pick up. In Argentina, daily deaths are near pandemic-heights.

In the Spring of 2020, policies in Latin America focused on minimizing the spread of Covid-19. This was typically done through lockdowns, which had large economic costs. Moreover, lockdowns did not succeed in stopping the spread of Covid-19, which may have been because the share of the susceptible population was still too high.

Ignoring the disease is, however, no option either, as a very large percentage of the population may get infected, overwhelming the health system.

Budish (2020) has suggested that a better alternative for policy makers is to focus on maximizing social welfare subject to the restraint of keeping R-effective at or below 1 . To minimize the economic cost, he advocates not a blanket restriction of economic activity, but restrictions that focus on activities that have the lowest utility to risk ratio.,

The results in this paper suggest that boosting the economy while containing R-effective means walking a fine line in loosening stringency. The higher the number of people that has already been infected, the more stringency can be reduced. However, if stringency is reduced too much, and mobility picks up too much, R-effective will increase to above 1 . 
Figure 8.1. Percentage of population that is fully vaccinated (As of June 3)

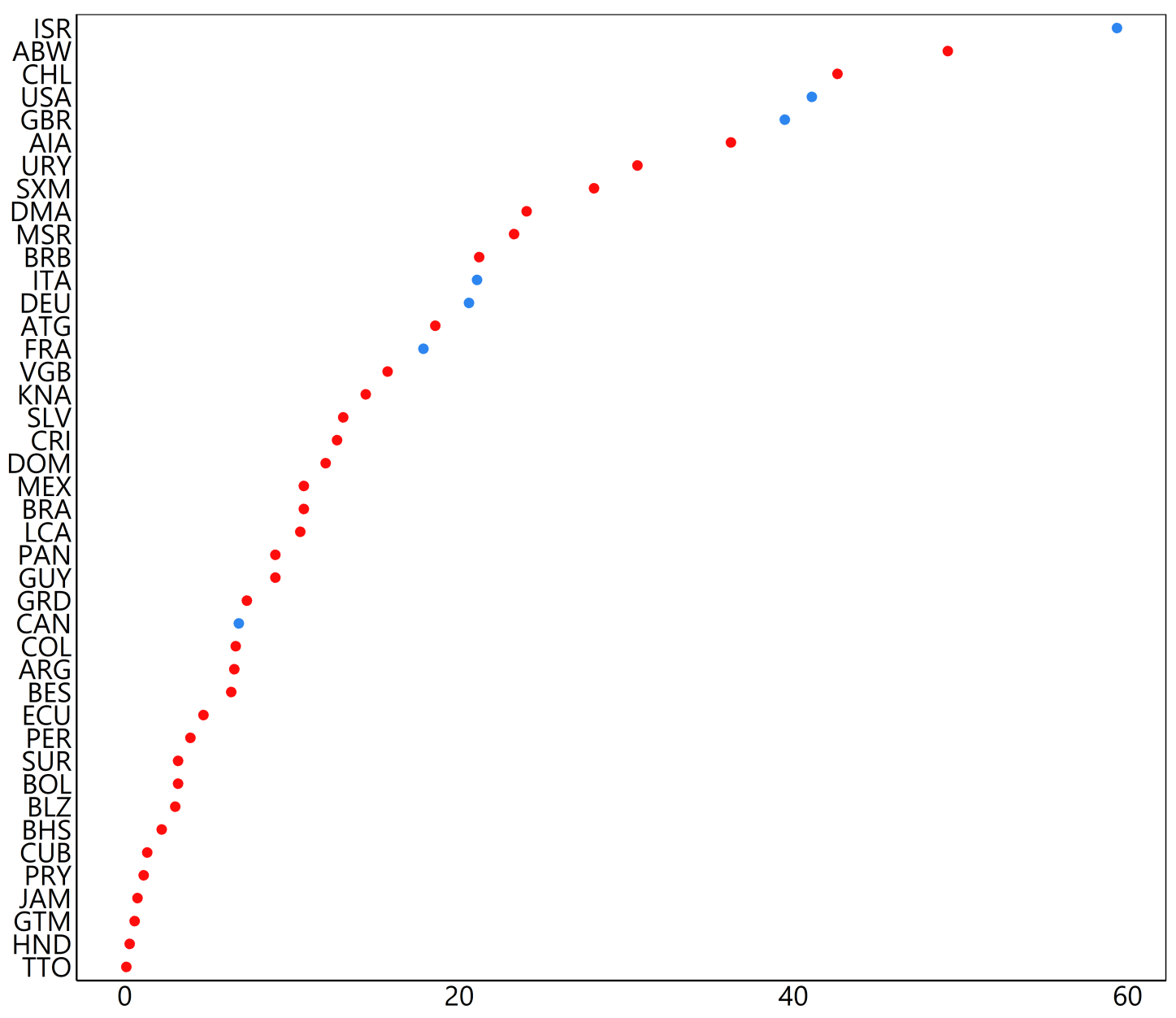

Source: Our World in Data. 


\section{Bibliography}

Atkeson, Andrew (2020), "What Will Be the Economic Impact of COVID-19 in the US? Rough Estimates of Disease Scenarios." Technical Report w26867, National Bureau of Economic Research, Cambridge, MA, URL http://www.nber.org/papers/w26867.pdf.

Bakker, Bas, Carlos Goncalves, Pedro Rodriguez, Mauricio Vargas, Dmitry Vasilyev, Carlo Pizzinelli, Vibha Nanda, and Alain Brousseau (2020), "COVID-19 in Latin America and the Caribbean A High Toll on Lives and Livelihoods." In IMF Regional economic outlook. Western Hemisphere : pandemic persistence clouds the recovery., International Monetary Fund, URL https://www.imf.org/en/Publications/REO/WH/Issues/2020/ 10/13/regional-economic-outlook-western-hemisphere.

Budish, Eric (2020), "Maximize Utility subject to R less to or equal to 1: A Simple Price-Theory Approach to Covid-19 Lockdown and Reopening Policy." Technical Report w28093, National Bureau of Economic Research, Cambridge, MA, URL http: //www.nber.org/papers/w28093.pdf.

David, Antonio C. and Samuel Pienknagura (2020), "On the effectiveness of containment measures in controlling the COVID-19 pandemic: the role of labour market characteristics and governance." Applied Economics Letters, 0, 1-7, URL https://doi.org/10.1080/ 13504851.2020 .1841082$.

Deb, Pragyan, Davide Furceri, Jonathan D. Ostry, and Nour Tawk (2020), "The Effect of Containment Measures on the COVID-19 Pandemic." CEPR Discussion Papers 15086, C.E.P.R. Discussion Papers, URL https://ideas.repec.org/p/cpr/ceprdp/ 15086.html.

Fine, P., K. Eames, and D. L. Heymann (2011), "Herd Immunity": A Rough Guide." Clinical Infectious Diseases, 52, 911-916, URL https://academic.oup.com/ cid/article-lookup/doi/10.1093/cid/cir007.

Goldstein, Patricio, Eduardo Levy Yeyati, and Luca Sartorio (2020), "Lockdown fatigue: The diminishing effects of quarantines on the spread of COVID-19." Department of Economics Working Papers wp_gob_2021_01, Universidad Torcuato Di Tella, URL https://ideas.repec.org/p/udt/wpecon/wp_gob_2021_01.html.

Google (2021), "COVID-19 Community Mobility Report." URL https://www.google.com/ covid19/mobility?hl=en.

Hale, Thomas, Noam Angrist, Rafael Goldszmidt, Beatriz Kira, Anna Petherick, Toby Phillips, Samuel Webster, Emily Cameron-Blake, Laura Hallas, Saptarshi Majumdar, and Helen Tatlow (2021), "A global panel database of pandemic policies (Oxford COVID-19 Government Response Tracker)." Nature Human Behaviour, URL http://www. nature. com/articles/s41562-021-01079-8. 
Hlavac, Marek (2018), stargazer: Well-Formatted Regression and Summary Statistics Tables. Central European Labour Studies Institute (CELSI), Bratislava, Slovakia, URL https://CRAN.R-project.org/package=stargazer.

International Monetary Fund (2020), "Dissecting the Economic Impact." In World Economic Outlook (October 2020), URL http://dx.doi.org/10.5089/9781513556055.081.

Kaufmann, Daniel, Aart Kraay, and Massimo Mastruzzi (2010), "The worldwide governance indicators : methodology and analytical issues." Policy Research Working Paper Series 5430, The World Bank, URL https://ideas.repec.org/p/wbk/wbrwps/5430.html.

Rivas, Magali Noval, Joseph E. Ebinger, Min Wu, Nancy Sun, Jonathan Braun, Kimia Sobhani, Jennifer E. Van Eyk, Susan Cheng, and Moshe Arditi (2021), "BCG vaccination history associates with decreased SARS-CoV-2 seroprevalence across a diverse cohort of health care workers." Journal of Clinical Investigation, 131, e145157, URL https: //www.jci.org/articles/view/145157.

Wang, Huwen, Zezhou Wang, Yinqiao Dong, Ruijie Chang, Chen Xu, Xiaoyue Yu, Shuxian Zhang, Lhakpa Tsamlag, Meili Shang, Jinyan Huang, Ying Wang, Gang Xu, Tian Shen, Xinxin Zhang, and Yong Cai (2020), "Phase-adjusted estimation of the number of Coronavirus Disease 2019 cases in Wuhan, China." Cell Discovery, 6, 10, URL http://www.nature.com/articles/s41421-020-0148-0.

Yeyati, Eduardo Levy and Luca Sartorio (2020), "Take me out: De facto limits on strict lockdowns in developing countries." Department of Economics Working Papers wp_gob_2020_08, Universidad Torcuato Di Tella, URL https://ideas.repec.org/p/ udt/wpecon/wp_gob_2020_08.html. 


\section{A Data Issues}

The number of Covid-19 cases and of Covid-19 deaths may be significantly underestimated in many Latin American countries. This underestimation is likely related to the limited testing capacity, which in LAC has been well below other regions. The lack of testing is evident in the positive cases to tests ratio. When there is limited testing, only sick people get tested, and the ratio of positive cases to tests is high. In Mexico, less than 1 percent of the population was tested in December 2020, and more than 40 percent of all tests came back positive (Figure A1). In the United States, 16 percent of the population was tested, and 12 percent of the tests came back positive. There has also been relatively little increase in testing over time in several Latin American countries, in contrast with the United States (Figure A2).

The lack of testing capacity may also have led to an underestimation in the number of deaths. In Mexico and Ecuador, the number of "excess" deaths-i.e., the number of deaths in the current year in excess of the average of the previous few years- has been much higher than the number of official deaths (Figure A3). According to excess deaths figures, Ecuador had an explosion in covid deaths in April; while official figures were much more subdued. In Peru, excess deaths used to be almost triple the number of official deaths, but in in early June 2021, after a scientific review of medical records ordered by the government, Peru revised its official death toll from 69,342 to 185,380 and now official covid deaths are similar to excess deaths.

The total number of deaths in a number of countries is significantly underestimated: in Mexico the number of excess deaths is 2.1 times the official number of deaths; in Ecuador 2.9. The problem is not unique to Latin America. In several countries in Central, Eastern and Southeastern Europe, excess deaths were also much higher than official deaths (Figure A4). 
Figure A.1. Covid-19 Testing and Test Positivity Rate, December 2020

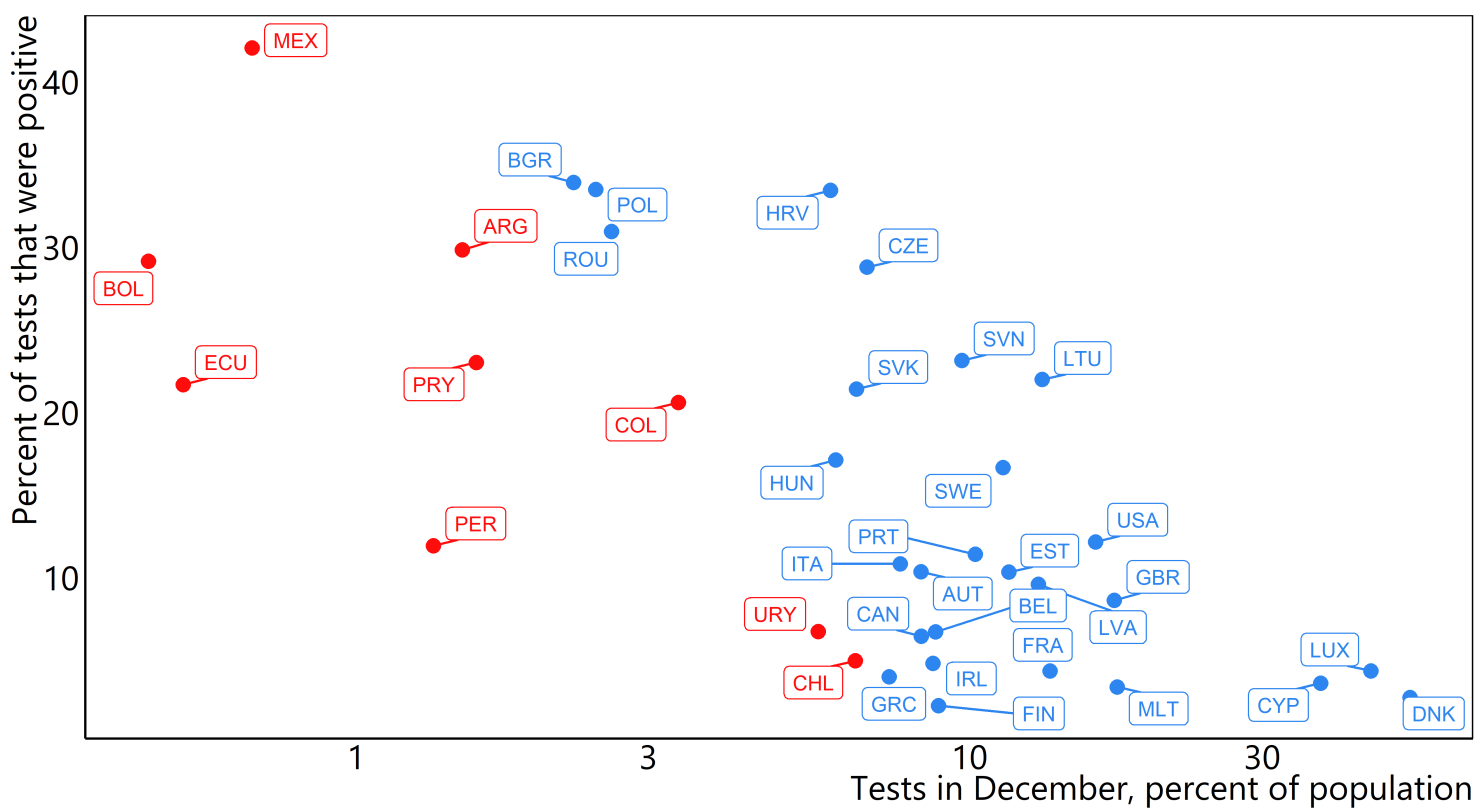

Source: Google Covid-19 hub and IMF staff calculations.

Figure A.2. Covid-19 Testing over Time

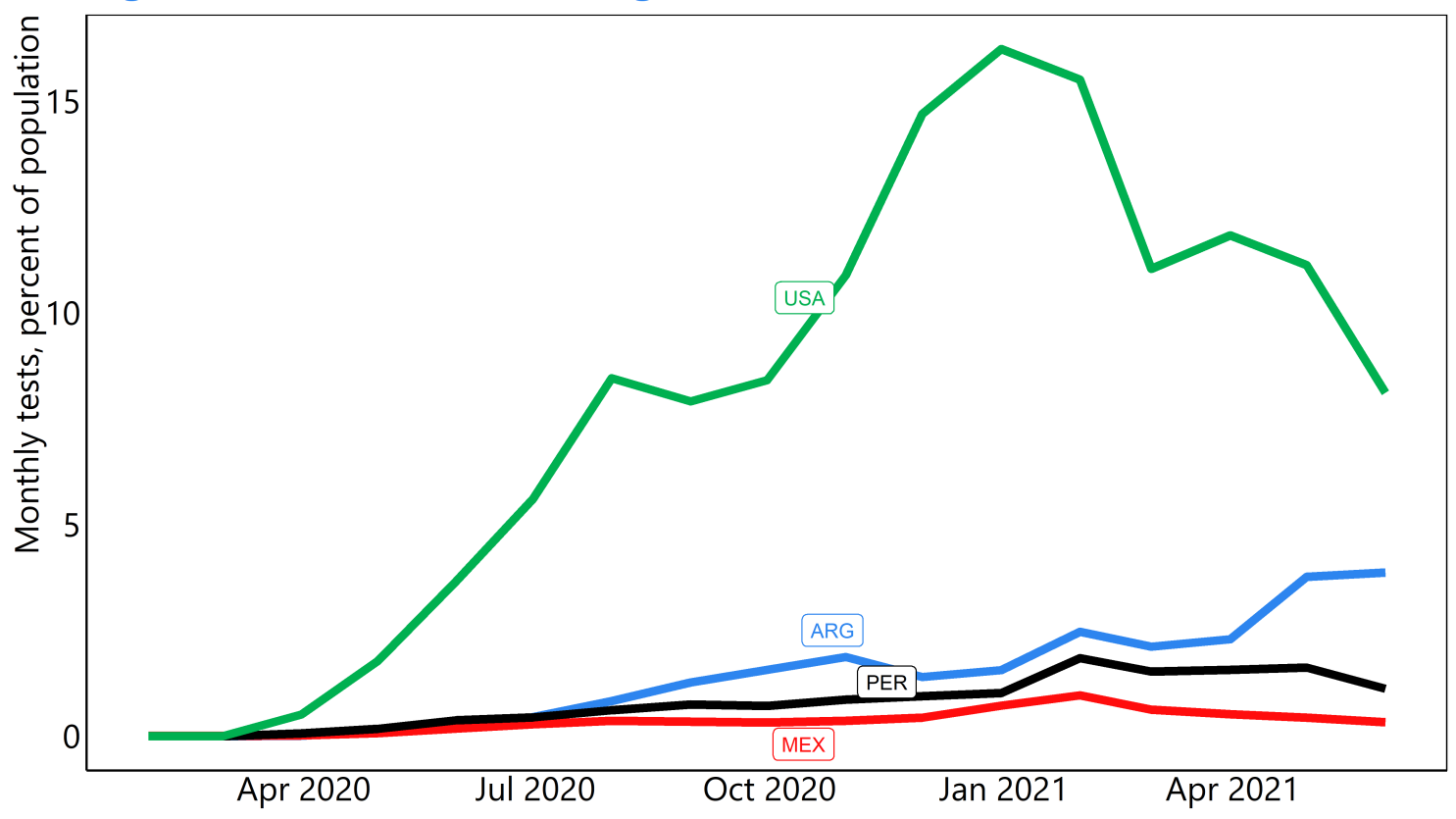

Source: Google Covid-19 hub. 
Figure A.3. Official Covid and excess Deaths over time

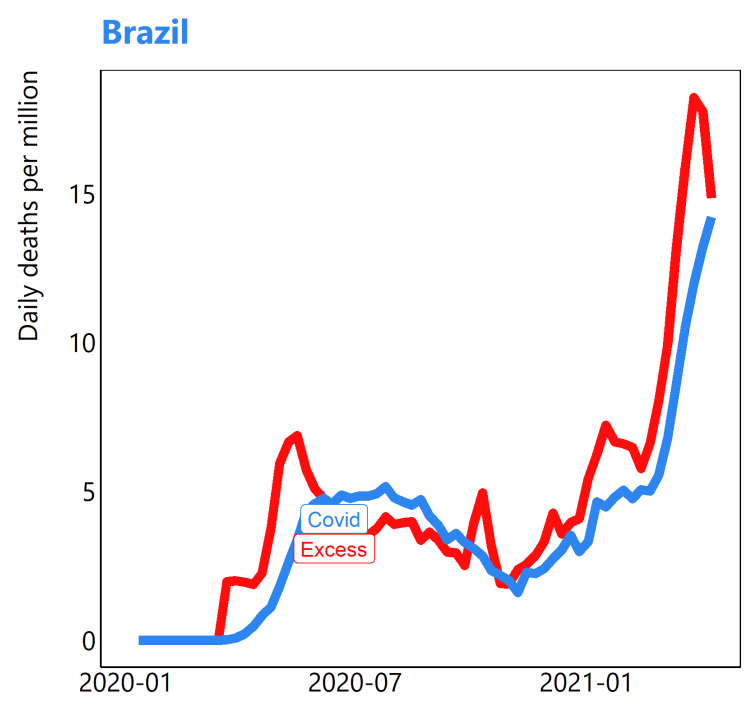

Mexico
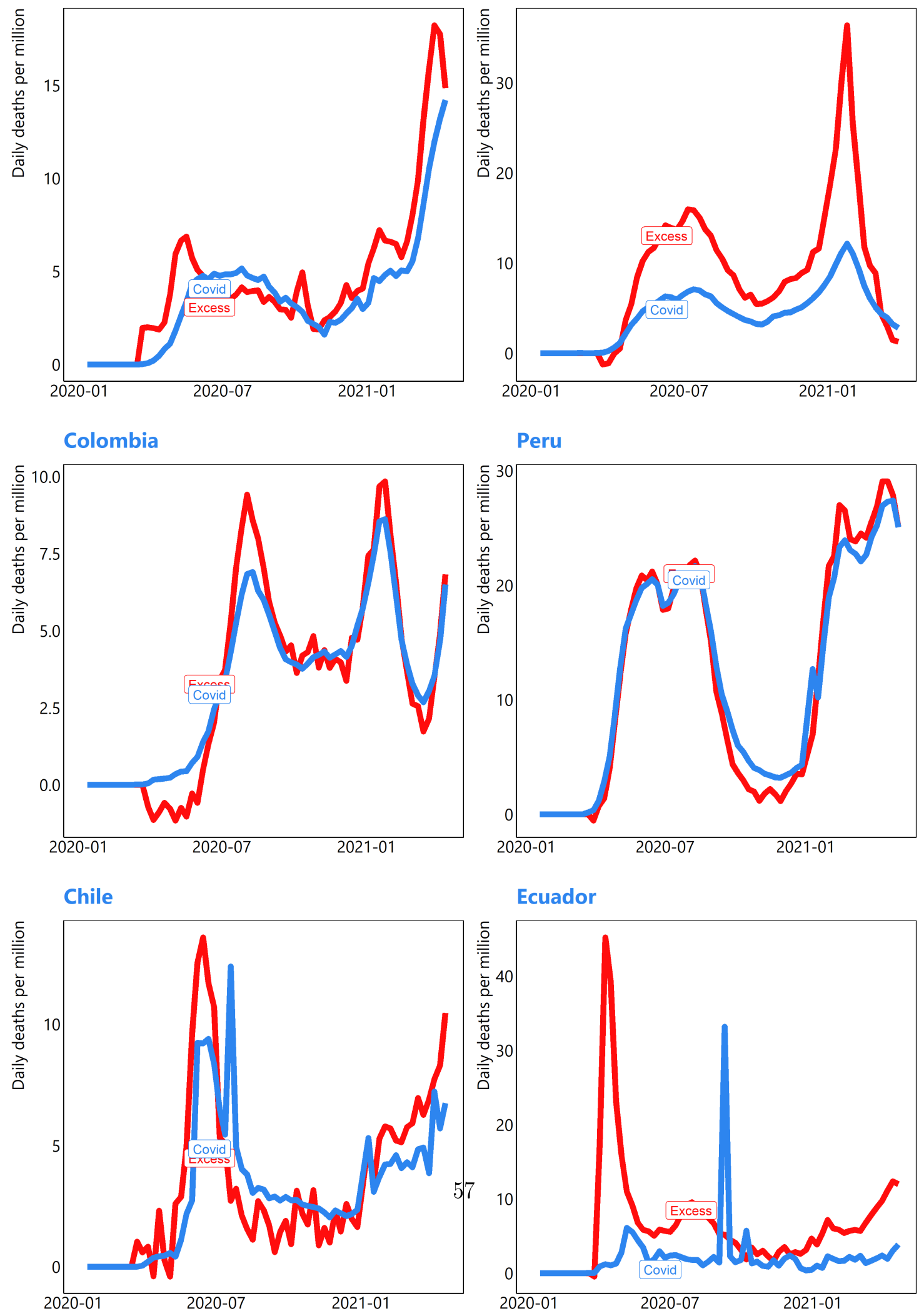

Source: Financial Times Excess Deaths Tracker)

CInternational Monetary Fund. Not for Redistribution 
Figure A4. Covid Deaths versus Excess Deaths, end-March 2021

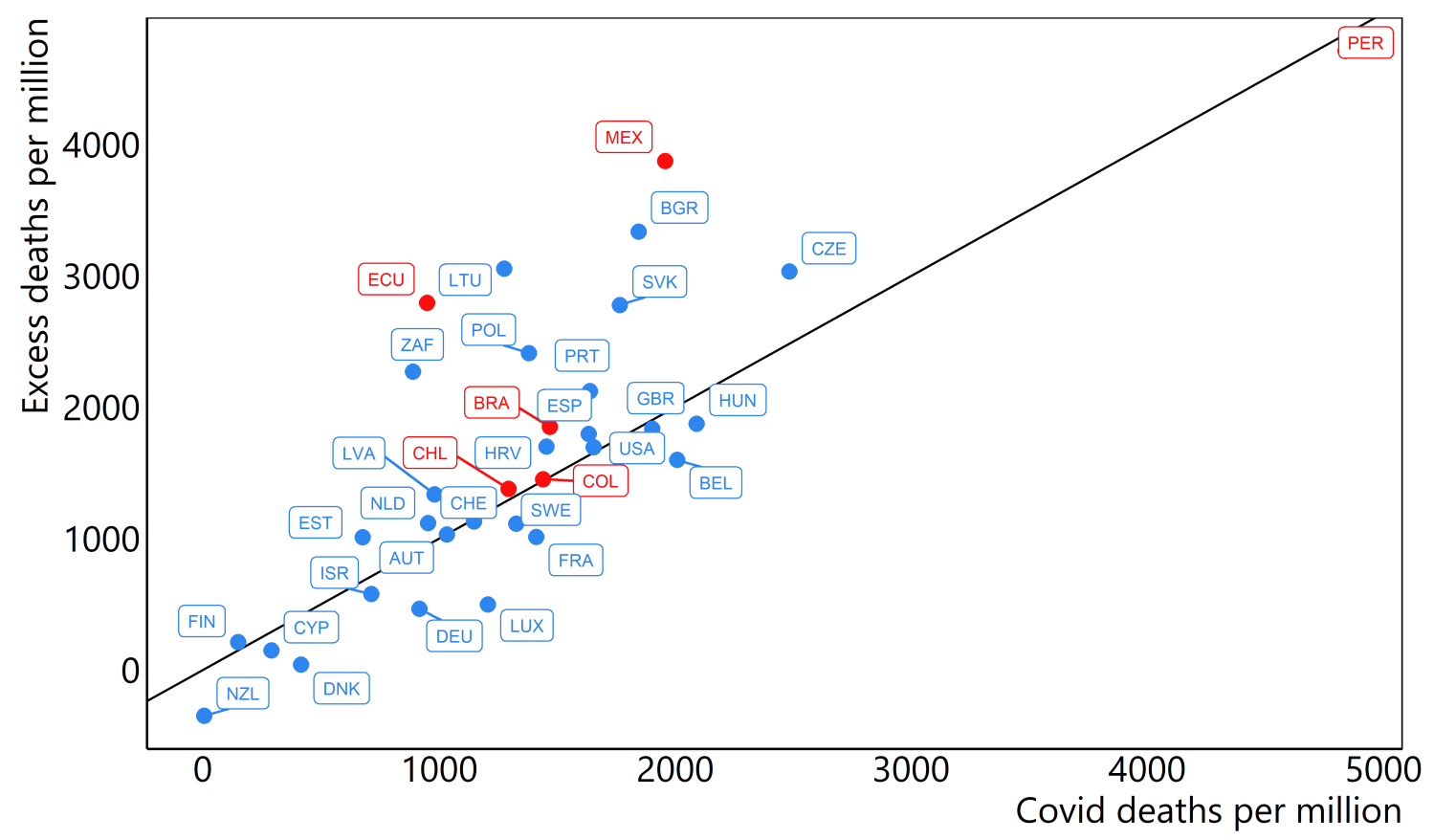

Source: Financial Times Excess Deaths Tracker; Google Covid-19 Hub. 


\section{B Covid in Individual Countries}

Table A1. Covid-19 in Latin America (Per million, as of June 4, 2021)

\begin{tabular}{|c|c|c|c|c|}
\hline & Total deaths & $\begin{array}{r}\text { New deaths } \\
(7 \text { day ma) }\end{array}$ & Total cases & $\begin{array}{l}\text { New cases } \\
\text { (7 day ma) }\end{array}$ \\
\hline Peru & 5,636 & 7.1 & 59,935 & 148 \\
\hline Brazil & 2,215 & 7.9 & 79,232 & 302 \\
\hline Colombia & 1,786 & 10.3 & 69,140 & 493 \\
\hline Argentina & 1,779 & 11.8 & 86,632 & 673 \\
\hline Mexico & 1,773 & 6.1 & 18,844 & 23 \\
\hline Chile & 1,553 & 5.7 & 73,830 & 373 \\
\hline Panama & 1,481 & 0.8 & 88,330 & 141 \\
\hline Paraguay & 1,347 & 14.4 & 51,620 & 401 \\
\hline Uruguay & 1,300 & 16.4 & 88,807 & 1,081 \\
\hline Bolivia & 1,276 & 6.4 & 32,850 & 231 \\
\hline Ecuador & 1,176 & 2.8 & 24,414 & 61 \\
\hline Belize & 817 & 0.4 & 32,345 & 25 \\
\hline Costa Rica & 815 & 5.4 & 64,384 & 389 \\
\hline Honduras & 652 & 2.5 & 24,336 & 66 \\
\hline Suriname & 566 & 12.2 & 27,290 & 415 \\
\hline Guyana & 512 & 4.2 & 22,197 & 133 \\
\hline Guatemala & 461 & 1.3 & 14,510 & 56 \\
\hline St. Lucia & 436 & 2.3 & 27,817 & 57 \\
\hline Trinidad \& Tobago & 397 & 10.0 & 18,436 & 325 \\
\hline El Salvador & 348 & 0.5 & 11,431 & 20 \\
\hline Dominican Republic & 336 & 0.3 & 27,509 & 120 \\
\hline Jamaica & 321 & 0.7 & 16,425 & 17 \\
\hline Barbados & 164 & 0.0 & 14,020 & 10 \\
\hline St. Vincent \& Grenadines & 108 & 0.0 & 18,612 & 66 \\
\hline Venezuela & 95 & 0.5 & 8,414 & 46 \\
\hline Nicaragua & 28 & 0.0 & 1,129 & 3 \\
\hline Haiti & 28 & 0.4 & 1,321 & 13 \\
\hline Grenada & 9 & 0.0 & 1,431 & 0 \\
\hline Dominica & 0 & 0.0 & 2,611 & 0 \\
\hline St. Kitts \& Nevis & 0 & 0.0 & 1,466 & 27 \\
\hline
\end{tabular}


C Data Sources

- Google Covid-19 Open-Data. https://github.com/GoogleCloudPlatform/covid19-open-data

Data downloaded from https://storage.googleapis.com/covid19-open-data/v2/main.csv.

- Google Community Mobility Reports.

https://www.google.com/covid19/mobility/

\section{- John Hopkins University CSSE COVID-19 Dataset} https://github.com/CSSEGISandData/COVID-19/tree/master/cSse_covid_19_data

- Our World in Data Covid-19 Data https://github.com/owid/covid-19-data/tree/master/public/data

- The Economist Covid-19 excess deaths tracker.

https://raw.githubusercontent.com/TheEconomist/covid-19-excess-deaths-tracker/

master/output-data/excess-deaths/all_weekly_excess_deaths.csv

- Financial Times Corona Virus Excess Mortality Data

https://raw.githubusercontent.com/Financial-Times/coronavirus-excess-mortality-data/ master/data/ft_excess_deaths.csv

- Worldwide Governance Indicators https://datacatalog.worldbank.org/dataset/worldwidegovernance-indicators

- ILO, Statistics on the Informal Economy https://ilostat.ilo.org/topics/informality/ Data downloaded from httpuuu7ghh https://www.ilo.org/ilostat-files/Documents/ EXcel/INDICATOR/EMP_NIFL_SEX_ECO_NB_A_EN.XIsX 